\title{
THE INTERGENERATIONAL TRANSMISSION OF HUMAN CAPITAL: EVIDENCE FROM THE GOLDEN AGE OF UPWARD MOBILITY
}

\author{
David Card \\ Ciprian Domnisoru \\ Lowell Taylor \\ Working Paper 25000 \\ http://www.nber.org/papers/w25000
NATIONAL BUREAU OF ECONOMIC RESEARCH
1050 Massachusetts Avenue
Cambridge, MA 02138
September 2018

We gratefully acknowledge support from Eunice Kennedy Shriver National Institute of Child Health and Human Development (R01 HD091134-01). The content is solely the responsibility of the authors and does not necessarily represent the views of the NICHHD, NIH, or the National Bureau of Economic Research. We are grateful also for support from the Russell Sage Foundation for research support. We also thank Alexandra Fahey, Alyse Fromson-Ho, Jared Grogan, Ingrid Haegle, Evan Rose, Dounia Saeme, and Ali Wessel for invaluable help in assembling school quality data.

NBER working papers are circulated for discussion and comment purposes. They have not been peerreviewed or been subject to the review by the NBER Board of Directors that accompanies official NBER publications.

(C) 2018 by David Card, Ciprian Domnisoru, and Lowell Taylor. All rights reserved. Short sections of text, not to exceed two paragraphs, may be quoted without explicit permission provided that full credit, including $\odot$ notice, is given to the source. 
The Intergenerational Transmission of Human Capital: Evidence from the Golden Age of Upward Mobility

David Card, Ciprian Domnisoru, and Lowell Taylor

NBER Working Paper No. 25000

September 2018

JEL No. I24

\section{ABSTRACT}

We use 1940 Census data to study the intergenerational transmission of human capital for children born in the 1920s and educated during an era of expanding but unequally distributed public school resources. Looking at the gains in educational attainment between parents and children, we document lower average mobility rates for blacks than whites, but wide variation across states and counties for both races. We show that schooling choices of white children were highly responsive to the quality of local schools, with bigger effects for the children of less-educated parents. We then narrow our focus to black families in the South, where state-wide minimum teacher salary laws created sharp differences in teacher wages between adjacent counties. These differences had large impacts on schooling attainment, suggesting an important causal role for school quality in mediating upward mobility

David Card

Department of Economics

549 Evans Hall, \#3880

University of California, Berkeley

Berkeley, CA 94720-3880

and NBER

card@econ.berkeley.edu

Ciprian Domnisoru

Department of Economics

University of California, Berkeley

Berkeley, CA 94702

ciprian.domnisoru@gmail.com
Lowell Taylor

Carnegie Mellon University

H. John Heinz III College

5000 Forbes Avenue

Pittsburgh, PA 15213

and NBER

1t20@andrew.cmu.edu

A data appendix is available at http://www.nber.org/data-appendix/w25000 


\section{Introduction}

Societies aspire to equality of opportunity - the goal that all children have the chance to achieve a prosperous life. An effective system of public education can play a key role in pursuit of this ideal. In the U.S. widespread access to public elementary schools opened a pathway to prosperity for many children by 1900. Even more remarkably, over the next 40 years the "high school movement" led to sustained public investments that enabled the U.S. to jump ahead of other nations in the share of students with a secondary education (Goldin and Katz, 2008). ${ }^{1}$ This era of increasing human capital investment set the stage for rising incomes and stable or even declining inequality in the decades following World War II, resulting in what Goldin (2001) has called America's "human-capital century."

Despite the large gains in average educational attainment in the early twentieth century, not all families benefited equally. Black students in the South were particularly disadvantaged by the low quality of segregated schools and limited access to high school. ${ }^{2}$ For instance, as late as 1938, South Carolina (a state in which nearly half of the student-aged population was black) had only 20 accredited high schools for blacks, compared to 306 for whites. ${ }^{3}$ White children in many rural areas also faced limited access to high-quality schooling.

We study the intergenerational links between parent and child schooling in this era of expanding, but unevenly distributed, educational opportunity. Specifically, we use 100\% population records from the 1940 Census to study education choices of young people (in the 14-18 age range) who were living with at least one parent. In 1940 the Census Bureau collected for the first time information on educational attainment for essentially the entire population, enabling us to study intergenerational links within millions of families. We combine these data with information on local schools, which, in the states with de jure segregation, was recorded by race. Importantly, in 1940 most young people completed their education before leaving home. By age 18 , for example, nearly $60 \%$ of white men had left school but almost $90 \%$ were living with their parents - only slightly below the fraction at age 5. This allows us to construct simple measures of educational attainment that capture upward mobility relative to parents, and to estimate censored regression models of desired education that flexibly condition on parental education.

The transmission of economic success between generations has engaged social scientists for over a century. ${ }^{4}$ Most recently, an important series of studies by Chetty et al. (2014a,

\footnotetext{
${ }^{1}$ The fraction of 14-17 year olds enrolled in high school rose from $10 \%$ in 1900 to over $70 \%$ in 1940 (US Department of Education,1993, Table 9).

${ }^{2}$ As we discuss below, black students outside the South were also often relegated to separate schools, as were some Chinese and Mexican American students.

${ }^{3}$ See South Carolina State Superintendent of Education (1938), pp. 98-103.

${ }^{4}$ Galton (1869) posed the issue as (largely) one of inherited ability. Prominent contributions circa 1970, focusing on the role of educational and other institutions, included Coleman et al. (1966), Blau and Duncan (1967) and Jencks et al. (1972). A large subsequent literature on intergenerational links in economic wellbeing has emerged, including studies in the U.S. and elsewhere (see reviews by Solon, 1999, and Black
} 
2014b) has shown that the rate of intergenerational mobility for children born in the early 1980s varies widely across areas of the U.S., and is correlated with measures of school quality and other local factors. ${ }^{5}$ Our work provides an historical counterpart to this work, albeit using education rather than income as the measure of socioeconomic status, while offering two new contributions to the literature:

First, we conduct our analyses separately by race. We show that average mobility rates at mid-century were substantially lower for black families than for whites or Asian Americans - a pattern that contributed to the persistence of lower education levels for African Americans for at least another generation. Nevertheless, in some parts of the country (specifically in the West) mobility rates for blacks were as high as those for whites.

Second, we go beyond a purely observational analysis of the factors associated with upward mobility by studying the effects of school quality on educational attainment of black children in the South. In the era of Jim Crow and political disenfranchisement, most school resource decisions were made by whites, with little input from local black families. ${ }^{6}$ To address remaining concerns over causality, we focus on the effects of state laws setting minimum salaries for teachers. Consistent with patterns noted by Jones (1928) and Bond (1934), salaries paid to black teachers were generally lower in Deep South states (Alabama, Louisiana, Georgia, Mississippi, and South Carolina) than in other segregated states; race-specific minimum teacher salary policies reinforced these inequalities. This sets the stage for a cross-border research design (Dube et al., 2010) that uses differences between contiguous counties to isolate the effects of teacher salaries while differencing out unobserved local factors.

At a conceptual level, our research builds on a theoretical literature originating with Becker and Tomes (1979 and 1986) and Loury (1981). Indeed, we frame our empirical analysis using a model in the spirit of these papers. We assume that parents face a tradeoff between current consumption and investment in their children's human capital. More prosperous parents choose higher levels of education for their children, bequeathing some of their socioeconomic advantage to the next generation. Using this model we argue that in the 1920s and 1930s a key factor mediating the strength of this intergenerational link was the quality of local schools. To the extent that higher quality schools yield higher returns per year of schooling, parents of a given family background status will invest more when their children have access to better schools. On the cost side, observed enrollment patterns suggest there was a discrete jump in the marginal cost of schooling between high

and Devereux, 2011).

${ }^{5}$ Previous U.S.-based work on the topic (e.g., Solon, 1992, and Mazumder, 2005) typically relied on relatively small samples, making it impossible to document differences in mobility rates at the local level.

${ }^{6}$ See Margo $(1985,1990)$ for detailed historical overviews and references to the literature on disenfranchisement and black schooling. While black families had little power over public school resources, there were some mechanisms for local input. For example, the Rosenwald school construction program (Donohue et al., 2002; Aaronson and Mazumder, 2011) required co-funding by local black organizations, which potentially created an endogenous local component of school quality. We are able to control for exposure to Rosenwald schools: like Carruthers and Wanamaker (2013) we find that by 1940 the impacts were small. 
school and college that induced many families to stop schooling at 12 th grade. $^{7}$ In this setting, increases in school quality will tend to have larger effects on children who would have otherwise stopped schooling prior to completing high school, reducing between-family differences in schooling attainment by "leveling up" the lower tail.

We begin our empirical analysis by documenting a strong positive gradient between parental education and the schooling outcomes of children in the 1940 Census. Among white females aged 16-18, for instance, those with better-educated parents - at least one parent graduating from high school-had a $95 \%$ probability of completing 9th grade, whereas those with poorly-educated parents - neither parent beyond a 4th grade education - had only a $40 \%$ probability. Similar patterns are present for white males and for black children of both genders.

We next document wide geographic variation in the relationship between parent and child education, and in the rate of upward mobility in human capital levels between generations. As a benchmark, we measure upward mobility using the 9th grade completion rate of children aged 16-18 whose parents have 5-8 years of school (i.e., roughly in the middle of the parental educational distribution). At the state level upward mobility rates are highly correlated with average pupil-teacher ratios and average teacher salaries. At the county level upward mobility rates for children born in the 1920s are also highly correlated with measures of upward mobility in income constructed by Chetty et al. (2014a) for children born in the early 1980s, underscoring the potential value of understanding the local determinants of upward mobility in the earlier time period, and suggesting considerable persistence in the local forces that shape upward mobility.

To focus more narrowly on the relationship between desired education and local school characteristics we use censored regression (Tobit) models of schooling attainment that control for other family characteristics (e.g., living on a farm, and having parents that were born in a different state). Specifically, we fit models separately by race/gender and parental education level, treating children who are not enrolled at the census date as having completed their schooling, and those who are enrolled as censored. We include unrestricted state dummies that measure the relative educational attainment of children in different states in a specific parental education group. In a second stage, we then relate the estimated state dummies to administrative measures of average school quality at the state level. This analysis points to two main conclusions. First, within narrowly-defined parental education groups, school quality metrics are strongly related to schooling attainment for children born in the 1920s. Second, these estimated effects are largest for children with the least educated parents and smallest for those with the most educated parents. Thus higher average school quality in a state contributed to a narrowing of human capital disparities between generations.

Finally, we turn to a detailed analysis of schooling attainment among black children in

\footnotetext{
${ }^{7}$ In 1939 only $9 \%$ of 19-24 year olds were enrolled in college (Snyder, 1993, Table 24), nearly half at private institutions.
} 
the segregated South, using county-level data on pupil teacher ratios and average teacher salaries. Our key focus is on the effects of average teacher salaries, which we show are strongly related to the average education of teachers in each county. ${ }^{8}$ Many Southern states set minimum wages for public school teachers, with rates that were generally lower for black teachers, particularly in the Deep South states. The minimum annual salary in 1940 in Georgia, for example, was $\$ 280$ for white teachers and $\$ 175$ for black teachers, while in neighboring Tennessee, the minimum was $\$ 320$ for both groups.

To isolate the effects of these salary differences while controlling for local economic opportunities, we construct contiguous county pairs on either side of the borders of Southern states, focusing on pairs for which average education levels of white adults were similar on each side. We then fit two sets of models: one using within-pair difference in estimated county effects from Tobit models for observed education of teenage children; the other using within-pair differences in upward mobility rates. OLS models show a strong partial correlation between both sets of outcomes and the within-pair difference in average teacher wages. Instrumental variables estimates using the difference in state minimum salaries to instrument the difference in average teacher wages are similar or slightly larger, as would be expected if black teacher wages in a border county are largely exogenous to unobserved determinants of the desired schooling of black children, but are measured with some error. Interestingly, the magnitudes of the estimated teacher wage effects from these models are close to those from our state-level models, suggesting that there may be relatively little endogeneity bias in those models.

The paper proceeds as follows. In section 2 we provide some historical context and a descriptive overview of the main patterns of intergenerational schooling outcomes that motivate our paper. We set up a theoretical framework in section 3, with the intention of imposing some order on our thought process as we head into the empirical inquiry. We report state-level empirical analyses in section 4, then our analysis of Southern border counties in section 5 . We summarize and discuss in section 6 .

\section{$2 \quad$ Historical Setting}

We study the intergenerational transmission of human capital during the first half the 20th century - a period during which average schooling was increasing by nearly one year per decade (see Goldin and Katz, 2008, Figure 1.4). Our focus is on educational outcomes for teenage children who were living with their parents in $1940 .{ }^{9}$ The two generations we study are thus parents, who were born from roughly 1880 through 1910, and their children, born in the 1920s.

Two broad features of the historical landscape make these generations especially at-

\footnotetext{
${ }^{8}$ See Margo (1990) for an earlier analysis emphasizing the importance of teacher salaries.

${ }^{9}$ We defer to Section 4 an analysis of the leaving-home process that leads to our choice of specific age ranges for sons and daughters.
} 
tractive for studying the forces that shape the intergenerational transmission of human capital.

The first is wide variability in human capital within the parent generation. This heterogeneity reflects, in part, the way the U.S. public school system evolved during the late 19th and early 20th centuries. Most Americans born between 1880 and 1910 had access to public elementary schools. Access to public high schools, however, was very much dependent on the time and place of their childhood. This variation was the legacy of the decentralized structure of public schooling. As Goldin and Katz (2008) document, local finance and control was a defining feature of American public education from its inception, and the timing of the emergence of publicly funded high school was dependent on many local factors. ${ }^{10}$

Racial segregation also contributed to the inequality of schooling in the parent's generation. Segregation was legally mandated throughout the South and in Arizona and Kansas, and was permitted in many other states at the discretion of local school boards (see Petersen, 1935; Wright, 1941; and Knox, 1954). ${ }^{11}$ Several states, including California, also allowed de jure segregation of Mexican Americans (Wollenberg, 1974) and Chinese Americans (Kuo, 1998). Educational opportunities afforded black, Hispanic, and Chinese Americans were thereby often limited as a matter of official policy.

All told, it is not surprising that we observe dramatic differences in educational attainment within the parent generation by birth cohort, region, and race. We report relevant statistics, calculated from 1940 Census data, in Appendix A Table A. (All appendices are available from the authors.) We find, for example, that among black men and women born in the South in 1880-89, only about $13 \%$ completed at least 8 grades of education, and only $9 \%$ reached grade 12 . Among whites born in the West in 1900-09, in contrast, close to $90 \%$ completed eighth grade, and over $40 \%$ completed high school.

A second feature of the historical landscape that is valuable for our research design is inequality in educational resources available at the local level to the children's generation. By the time these children were in school (in the late 1920s and 1930s) some states had adopted equalization and standardization policies, but local taxes remained the dominant form of school finance. ${ }^{12}$ And between states there were very large differences in resources

\footnotetext{
${ }^{10}$ See chapters 4-6 of Goldin and Katz (2008), which provide a detailed account of the provision of primary and secondary public education in the U.S. in the 19th and 20th centuries. As to the high school movement specifically, these scholars argue, "The high school movement was, above all, a grassroots movement. It sprung from the people and was not forced upon them by a top-down campaign" (p. 245).

${ }^{11}$ Peterson (1935) reports that in the early 1930s all 18 Southern states, the District of Columbia, Arizona and Kansas mandated racially segregated schools. Separate schools were explicitly allowed in Indiana, New York, and Wyoming; and no legal impediment existed to segregation at the local level in 13 other states.

${ }^{12}$ Nationwide, the average local share of school spending was $83 \%$ in 1930 and $68 \%$ in 1940 . See Bensen and O'Halloran (1987) for an overview of historical trends. Wallis (2000) provides a broad historical overview of fiscal centralization in the U.S., while Coen-Pirani and Wolley (2018) give an economic analysis of changes in fiscal centralization during the 1930s.
} 
devoted to primary and secondary education. ${ }^{13}$ As a broad generalization, schools outside the South were better financed than those in the Southern states. The problem was compounded for black students by lower levels of resources in the black schools, particularly in the Deep South. In contrast, most Asian Americans in the children's generation attended regular public schools in California, which were among the highest-quality in the country, and had been desegregated for some years.

\subsection{Geographic Patterns in Schooling and Upward Mobility}

\section{Schooling of Parents and Children}

With these generalizations in mind, we provide some initial descriptive evidence on the relationship between parent and child education in the series of panels in Figure 1. In constructing these figures we focus on children aged 16-18 who reside with at least one parent. ${ }^{14}$ For these children we construct a simple metric of educational attainment - the fraction who have completed at least ninth grade (whether still enrolled or not). The panels in Figure 1 graph this outcome as a function of "parental schooling" - a variable equal to the higher of the parents' education, when both parents are present, or the parent's education in single-parent families. In all panels except $\mathrm{F}$ and $\mathrm{G}$, and in all the subsequent analysis below, we focus exclusively on families with native-born parents.

Panel A shows that at every level of parental education, the share of children with at least nine grades of education is substantially higher for white children than for black children, and is higher for daughters than sons (of either race). Panels B and C document regional variation in schooling outcomes for whites. These graphs show that education levels are much lower in the South than in other regions, with a wider gap for children of poorly educated parents. Panels D and E compare the gradients in the Deep South and the other Southern states (sometimes called the Peripheral South) for daughters and sons of both races. ${ }^{15}$ Importantly, the educational outcomes for white children (conditional on parental education) are essentially the same in the two sets of states, whereas for black children, schooling outcomes are lower in the Deep South. This simple comparison points

\footnotetext{
${ }^{13}$ In this respect our work stands in contrast to the prominent stream of research on intergenerational mobility emerging from Nordic counties (made possible by linked administrative records in those countries), e.g., Black et al. (2005), Meghir and Palme (2005), Aakvik et al. (2010), Meghir et al. (2013), Meghir et al. (2014), Lundborg, Nilsson, and Rooth (2014), and Carneiro et al. (2015). In our setting - the U.S. in 1940 - we have far greater levels of racial and cultural diversity, and also greater geographic variation in educational resources available to children.

${ }^{14}$ Here we follow Goldin and Katz (1999), who evaluated the education of children aged 14-18 who lived with parents in the 1915 Iowa Census. Hilger (2017b) takes a similar approach though his focus is on educational outcomes among older children (aged 26-29) who co-reside with parents. (We refine our age limits in the models presented in section 4.)

${ }^{15}$ Margo (1986) concludes that completed schooling levels of black adults in the 1940 Census were overstated relative to whites, a pattern that serves to widen the racial gap in child educational attainment conditional on parental education. This issue is presumably less important for comparisons between black families, particularly within regions.
} 
to the potential importance of school quality, which was broadly similar for whites in the two sets of states but of lower quality for blacks in the Deep South (see Card and Krueger, 1992b).

Although our primary focus is on native-born families, for the sake of interest in Panels $\mathrm{F}$ and $\mathrm{G}$ we show parallel evidence for families with at least one immigrant parent. There is a common perception that immigrants move to the U.S. in hopes of improving prospects for their children. Evidence in Panel F is consistent with that idea: children of poorly-educated immigrants have much higher levels of educational attainment than their native-born counterparts. ${ }^{16}$ Like the children of native-born parents, children of immigrant parents had lower educational attainment in the South, suggesting that some common feature of the Southern education system may have been partly to blame for the disparities for both groups.

\section{Upward Mobility}

There are many ways of measuring upward mobility in educational attainment. Motivated by the patterns in Figure 1, we consider parents with 5-8 years of education - approximately in the middle of the parental education distribution - and calculate the fraction of their children who "move up the educational ladder" by completing at least nine years of education. Figure 2 shows large regional differences in this simple measure of upward mobility, and quantifies a disadvantage for black children, most prominently in the South. In contrast, in the West the black-white gap is negligible, though both blacks and whites have slightly lower upward mobility than Japanese American families. ${ }^{17}$

Panels A and B of Figure 3 show upward mobility rates by state for white daughters and sons, respectively, and reveal striking geographic variation in mobility. Among sons, for example, upward mobility is lowest in Tennessee and Kentucky ( 0.35 and 0.37 respectively) and highest in California (0.82) and Utah (0.85). Panels C and D report comparable statewide mobility rates for black daughters and sons. ${ }^{18}$ Upward mobility was generally much lower for blacks than whites, particularly in the Deep South, with rates for black sons of only 0.09 in Mississippi, and 0.15 in South Carolina and Georgia. In contrast, black sons' upward mobility rates were quite high in Nebraska (0.79), California (0.83), and Minnesota (0.83). The near equality of upward mobility rates for white and black children in California suggests that lower average black mobility rates in other states may have been driven more by ecological factors than by inherent differences in the value of education among black

\footnotetext{
${ }^{16}$ Using data measured in the 1970 Census for children of roughly the same cohort, Card, DiNardo and Estes (2000) show that the conditional education gap between children of immigrants and children with U.S. born parents is present even in adulthood.

${ }^{17}$ See Hilger (2017a) for an interesting analysis of upward mobility among Asian American families focusing on California.

${ }^{18}$ We give results only for states for which we have a sample of at least 50 child-parent pairs among families in which parental education is $5-8$ grades.
} 
families. ${ }^{19}$

Given the large sample sizes available in the 1940 Census, we can also estimate upward mobility rates at much finer levels of geography. Panel A of Figure 4 presents county-level estimates for a pooled sample of black and white families, using different colors for counties with upward mobility rates in different deciles of the national distribution. For sake of comparison, Panel B shows a similar map using measures of intergenerational mobility in income for the cohort of children born 1980-83 constructed by Chetty et al. (2014a), again distinguishing counties by their deciles in the overall distribution of mobility rates. ${ }^{20}$ The similarities in the geography of upward mobility between these two cohorts are striking: the correlation across counties between the two mobility rates is 0.45 , suggesting a high degree of persistence in local factors affecting intergenerational mobility rates in the U.S., though the rate of upward mobility appears to have fallen in California.

These maps show that average upward mobility rates for children born in the early 1920s and early 1980s are both lower in the South. Panels C and D show that when we measure mobility rates separately by race in 1940, the rates for both race groups are lower in the South and higher in the Northeast and West. Indeed, the correlation across counties between the upward mobility rates of whites and blacks is 0.53 , so there is clearly a strong common component of geographic variation in mobility rates for both races.

\subsection{An Initial Look at Upward Mobility and School Quality}

As a final descriptive exercise we correlate state-level upward mobility rates with measures of school quality. We use two simple measures of school quality - the pupil-teacher ratio and average annual teacher wages - originally assembled by Card and Krueger (1992a, 1992b). ${ }^{21}$ Average pupil-teacher ratios range from just under 20 (in the Dakotas) to 36 (in Kentucky), while average teacher salaries range from $\$ 600$ per year (in Arkansas) to $\$ 2400$ per year (in New York). ${ }^{22}$

Panels A and B of Figure 5 show that upward mobility rates of white daughters and sons are correlated with each of the quality measures in the expected direction. Panels $\mathrm{C}$ and D repeat this exercise for black daughters and sons, using data on school quality for the segregated black schools in the 18 Southern states with de jure segregation. ${ }^{23}$ We note

\footnotetext{
${ }^{19}$ The relatively high upward mobility rates among black families outside the South may in part be the result of high upward mobility more generally among geographically mobile parents. If so this complicates interpretation of our comparisons. In our models below we therefore control for parental geographic mobility.

${ }^{20}$ These maps use a measure by Chetty et al. that gives the predicted income percentile (at age 26) for children born to parents at the 25 th percentile of the income distribution.

${ }^{21}$ Histograms showing the distributions of these measures across the 48 mainland states and the District of Columbia, but excluding schools for black students in segregated states, are shown in Appendix Figure A1. Card and Krueger also assembled data on average term lengths but in their analysis and our own analysis this variable adds little once the other two measures are included so we focus only on the two main measures.

${ }^{22}$ For reference, the CPI has risen by a factor of about 17 from 1940 to today, while average wages of non-supervisory workers in manufacturing have risen by a factor of approximately 38 .

${ }^{23}$ Kansas and Arizona also operated separate schools for black students but we have have been unable to
} 
that the horizontal scales differ for black and white students, reflecting the large variation in school quality for black students across the 18 states (e.g., the pupil/teacher ratio ranges from 25 to 50). All panels reveal striking correlations between the two measures of quality and the upward mobility rates.

Motivated by this descriptive evidence, we take a digression to develop a more fully specified conceptual framework that will guide our inquiry.

\section{A Benchmark Model}

Our goal is to build a simple model to study plausible links between the intergenerational transmission of human capital and the quality of schooling available to families. We work with a variant of the household model of Becker and Tomes $(1979,1986)$ and Loury $(1981)$, in which the utility of a parent-child family depends on current consumption and the future consumption of the child.

We assume that parents choose a level of schooling $E$ for their child, given their own resources and the potential earnings of the child. Parents have income $y_{0}$ per period, which is assumed to remain constant over time, and pay out-of-pocket $\operatorname{costs} c(t)$ for the $t^{\text {th }}$ period of schooling, which includes tuition and living costs for post-secondary education. ${ }^{24}$ For simplicity we assume the child's earnings 0 while in school and $y_{1}(E)$ per period after completing $E$ years of school. We assume that children live with parents until age $L>E$, after which point they are on their own. Ignoring (for the moment) any borrowing or lending, parents maximize

$$
U(E)=\int_{0}^{E} u\left(y_{0}-c(t)\right) e^{-r t} d t+\int_{E}^{L} u\left(y_{0}+y_{1}(E)\right) e^{-r t} d t+\int_{L}^{\infty} \theta v\left(y_{1}(E)\right) e^{-r t} d t
$$

where $u$ maps parental income to parental utility in period $t, v$ maps the child's income to the child's utility in period $t, \theta \geq 0$ is an altruism factor reflecting the value of the child's utility to the parent, and $r$ is a discount factor.

The marginal value of an additional unit of child's education is

$$
U^{\prime}(E)=e^{-r E}\left[\frac{y_{1}^{\prime}(E)}{r} \lambda_{1}-\left(y_{1}(E)+c(E)\right) \lambda_{0}\right]
$$

where

$$
\lambda_{1}=u^{\prime}\left(y_{0}+y_{1}(E)\right)\left(1-e^{-r(L-E)}\right)+\theta v^{\prime}\left(y_{1}(E)\right) e^{-r(L-E)},
$$

find race-specific data on school quality for these states.

${ }^{24}$ For students in areas with no local high school the out-of-pocket costs of secondary school may also include living and travel costs. 
and

$$
\begin{aligned}
\lambda_{0} & =\frac{u\left(y_{0}+y_{1}(E)\right)-u\left(y_{0}-c(E)\right)}{y_{1}(E)+c(E)} \\
& =u^{\prime}\left(\widetilde{y}_{0}\right) \text { for } \widetilde{y}_{0} \in\left[y_{0}-c(E), y_{0}+y_{1}(E)\right] .
\end{aligned}
$$

The first term on the right hand side of equation $(2), e^{-r E} \frac{y_{1}^{\prime}(E)}{r} \lambda_{1}$, is the marginal benefit of an additional unit of education, which yields a flow of income $y_{1}^{\prime}(E)$ per year starting in period $E$ and is valued using the marginal utility $\lambda_{1} \cdot{ }^{25}$ The second term, $e^{-r E}\left(y_{1}(E)+\right.$ $c(E)) \lambda_{0}$, represents the marginal cost of schooling, which includes an opportunity cost $y_{1}(E)$ and a direct cost $c(E)$, both of which are incurred in period $E$ and are valued using the marginal utility $\lambda_{0}$.

We note that if a parent simply maximizes the sum of parental and child income (as would be the case with access to perfect credit markets) then $\lambda_{0}=\lambda_{1}=1$. Otherwise, for families that cannot easily borrow against their children's future income, or that are less than perfectly altruistic, the marginal utility of $\$ 1$ paid as a lump sum at the end of schooling will be higher than the marginal utility of $\$ 1$ paid as a perpetuity to the parent and the child, implying that $\lambda_{0}>\lambda_{1}$.

Ignoring any discontinuities in schooling, an optimal choice for $E$ sets $U^{\prime}(E)=0$, leading to the condition

$$
\frac{y_{1}^{\prime}(E)}{y_{1}(E)}=r \frac{\lambda_{0}}{\lambda_{1}}[1+d(E)]
$$

where $d(E)=c(E) / y_{1}(E)$ is the ratio of the direct cost of the $E^{\text {th }}$ year of schooling to the opportunity cost. The left hand side of (3) is the proportional return to an additional unit of schooling, while the right hand side is the annuitized proportional cost, adjusted for any disparity between $\lambda_{0}$ and $\lambda_{1}$. In the case where parents maximize the sum of parental and child income and there are no direct costs of schooling, the right hand side of (3) is just $r$, yielding the well-known condition for optimal schooling derived by Mincer (1958). More generally, $r \frac{\lambda_{0}}{\lambda_{1}}$ represents an "adjusted discount rate" for the family, reflecting credit constraints and/or imperfect altruism. Assuming that better educated parents have lower values of $r \frac{\lambda_{0}}{\lambda_{1}}$, and that the proportional return to schooling is decreasing, the model implies that better educated parents will invest in more child education, providing an intergenerational linkage as in Becker and Tomes (1986) and Mulligan (1999).

\subsection{Mapping the Model to the Empirical Analysis}

The implications of this model depend on how the proportional returns to the $E^{\text {th }}$ year of schooling, $\operatorname{MR}(E) \equiv \frac{y_{1}^{\prime}(E)}{y_{1}(E)}$, and the proportional marginal costs of schooling, $\operatorname{MC}(E) \equiv$

\footnotetext{
${ }^{25}$ Note that $\lambda_{1}$ is a weighted average of $u^{\prime}\left(y_{0}+y_{1}(E)\right)$ and $\theta v^{\prime}\left(y_{1}(E)\right)$, where the weights depend on the fraction of the child's life outside the parental home after completion of education.
} 
$r \frac{\lambda_{0}}{\lambda_{1}}[1+d(E)]$, vary across families. Consider a simple linearized model that focuses on the effects of two key observable factors: the average quality of local public schooling, $Q$, and the level of parental education, $P$. Specifically, suppose that

$$
\operatorname{MR}(E)=\gamma_{0}+\gamma_{E} E+\gamma_{Q} Q+\gamma_{P} P+\phi
$$

where $\phi$ is an unobserved component in the return to schooling, while

$$
\mathrm{MC}(E)=\delta_{0}+\delta_{E} E+\delta_{Q} Q+\delta_{P} P+\xi
$$

where $\xi$ is an unobserved component of marginal cost. We assume that $\gamma_{E} \leq 0$, (i.e., the marginal return to additional years of schooling is non-increasing), that $\delta_{E} \geq 0$ (i.e., the marginal cost is non-decreasing), and that $\delta_{E}-\gamma_{E}>0$. In addition, we assume that $\gamma_{Q}>0$ (so higher quality schooling increases the return to additional schooling) and that $\delta_{Q} \leq 0$ (i.e., higher quality public schools, if anything, lower the marginal cost of schooling). Finally, we assume that children of better educated parents have the same or higher marginal returns to schooling, i.e., $\gamma_{P} \geq 0$, but strictly lower marginal costs of schooling $\left(\delta_{P}<0\right)$. Equations (4) and (5) imply a linear model of optimal schooling:

$$
E=\beta_{0}+\beta_{Q} Q+\beta_{P} P+\eta,
$$

with $\beta_{Q}=\frac{\gamma_{Q}-\delta_{Q}}{\delta_{E}-\gamma_{E}} \geq 0, \beta_{P}=\frac{\gamma_{P}-\delta_{P}}{\delta_{E}-\gamma_{E}}>0$, and $\eta=\frac{\phi-\xi}{\delta_{E}-\gamma_{E}} \cdot{ }^{26}$ This very simple model implies that for a given quality of local schools, children's schooling is linearly increasing in parent's schooling, and that better quality schools lead to a parallel shift in the mapping from parent's education to child's education. Thus, higher quality schooling raises schooling levels but does not differentially affect children from more- or less-educated families.

It also implies that the unobserved component of optimal schooling reflects a combination of the unobserved components of $M R$ and $M C$, which could in principle be correlated with $Q$ (or $P$ ). This is the main threat to a causal interpretation of the observed relationship between schooling choices and observed quality measures, motivating our cross-border analysis in Section 5 .

A more nuanced set of predictions arise if the marginal cost of schooling rises discontinuously at the end of high school. This case is illustrated in Figure 6, where we consider the optimal schooling choices for two children who face the same marginal returns to schooling but different marginal costs because of different family backgrounds. The MC schedule for the child with lower-educated parents (shown in blue) is relatively high, reflecting the high cost of additional investment for the family (i.e., a higher value of $r \frac{\lambda_{0}}{\lambda_{1}}$ ) whereas the schedule for the child with higher-educated parents (shown in red) is relatively low. Both schedules, however, discontinuously jump up for post-secondary schooling levels $(E>12)$, reflecting

\footnotetext{
${ }^{26}$ More generally, interpreting the coefficients of equations (4) and (5) as derivatives of $M R$ and $M C$ taken around an optimal choice for $E, \beta_{Q}$ and $\beta_{P}$ can be interpreted as the derivatives of the optimal schooling choice with respect to $Q$ and $P$.
} 
the additional direct costs of college. In this setting, children of families with $P$ in some range (say $P_{1} \leq P \leq P_{2}$ ) all stop schooling at the end of high school; only the most highly educated parents send their children to college. Higher school quality, which shifts up the MR schedule in Figure 6, leads to rising education for children of lower-educated parents (from $E^{*}$ to $E^{* *}$ in the example shown), but will not necessarily change the education choices for families that previously selected $E=12$.

We suspect that the intuition in Figure 6 is highly relevant for many families in the 1930s. Data on 25 year olds from the 1940 Census, for example, shows a striking mass point in the distribution of education at exactly high school completion, representing $28 \%$ of young adults in this cohort. Less than a third of those who completed high school had any college education. This suggests that most families faced a substantial jump in costs of education beyond the completion of high school. In our empirical analysis we therefore fit models for schooling attainment of children separately by parental education group, allowing for the possibility that the effect of school quality differs by the level of parental education.

Another factor that could contribute to differences in the effect of average school quality across parental education groups is the systematic sorting of better-educated families to higher-spending school districts. To illustrate, let $Q_{s}$ represent the average quality of schooling in a given state $s$, and let $Q_{s k}$ represent the average quality in the $k^{\text {th }}$ school district of that state, where a given family with parental education $P$ actually lives. The incentives for higher-educated parents to seek out the better-quality districts are arguably higher in states with lower average quality. Thus, we expect that

$$
E\left[Q_{s k} \mid Q_{s}, P\right]=\tau_{Q} Q_{s}+\tau_{P} P+\tau_{Q P} Q_{s} P
$$

with $\tau_{Q P}<0$, implying that the actual level of school quality experienced by bettereducated families varies less across states than that experienced by poorly educated families. Combining this with equation (6) leads to a model for the child's education that includes a negatively-signed interaction between average school quality and parental education.

\section{Empirical Analysis of Parental-Child Links in Education}

\subsection{Children in 1940 U.S. Census}

We noted that in 1940 most children completed schooling prior to leaving home. Consider the bar graphs in Figure 7: here, the blue bars represent the proportion of individuals at each age between 5 and 20 that we can identify as living with a parent, ${ }^{27}$ and the dark

\footnotetext{
${ }^{27}$ Young children not living with a parent often instead were residing with a grandparent or other relative, but some also lived in a household with unrelated adults. At older ages, especially at age 18 and older, individuals not living with a parent more typically were in households of their own.
} 
red bars represent the proportion of children who live with a parent and are enrolled in school. Focusing, for the moment, on white males (Panel B), we see that the proportion living with a parent is stable at around $90 \%$ until age 17, then declines slightly to $87 \%$ at age 18 before falling off more quickly at ages 19 and 20. School enrollment rates of white sons who live with a parent are relatively stable between ages 8 and 14, but fall steadily after age 14; by age 18 less than $40 \%$ are in school. ${ }^{28}$ Relative to sons, white daughters (Panel A) begin leaving home a little earlier, presumably reflecting the gender gap in age at marriage, though their enrollment rates conditional on living with a parent are similar. The patterns for black daughters and sons, in Panels $\mathrm{C}$ and $\mathrm{D}$, show a similar stability in the fraction of boys living with their parents until age 18, and of girls until age 16, though on average black children have about 10 percentage points lower rates of parental cohabitation, and also begin to leave school at earlier ages.

Table 1 presents a quantitative summary of the same information, focusing on children aged 14-18. Our reading of the data in Figure 6 and Table 1 is that for boys, there is little threat of selection bias in conditioning on living with one or both parents up to age 18. For girls, similar reasoning applies to samples up to age 16. Since we want to study attainment of at least 9th grade, in our analysis below we therefore focus on samples of sons aged 14-18 and daughters aged 14-16.

\subsection{Measures of School Quality}

We use two main measures of the quality of local public schools - the pupil-teacher ratio, and average annual wages of teachers. A concern with interpreting the teacher wage as a quality metric is that it reflects differences in the cost of living, rather than in the real wage paid to teachers. To address this, we used the full count 1940 Census data to extract information on wage earners with at least one year of post-secondary schooling who were working in occupations other than teaching. We then fit simple earnings equations for these non-teachers that include controls for education, race, gender, and experience, as well as dummy variables for each state. We then use the estimated state dummies to deflate observed teacher salaries. ${ }^{29}$ This adjustment effectively assumes that in the absence of other factors, teacher wages would have varied across states proportionally to non-teacher

\footnotetext{
${ }^{28}$ There are a number of possible explanations for the $<100 \%$ enrollment rate of younger children, including children with disabilities, children being home-schooled, children on break from school (though this is likely to be small because the 1940 Census was taken in April), and miscoding.

${ }^{29}$ To be slightly more precise, we begin with a data set of all white workers aged $22-65$ who (i) had at least one year of college education, (ii) reported earnings in the 1940 Census, and (iii) had an occupation not "teachers, n.e.c." (category 18). This gives a sample of 3.24 million observations - $26.8 \%$ female, average age 36.1, mean years of education 14.9, mean annual earnings $\$ 1703$ (standard deviation 1179) and mean log earnings 7.18 (standard deviation 0.78). We then fit a regression model for log earnings, including a dummy variable for female, dummies for each category of education, a cubic in potential years of experience, and unrestricted state dummies, with New York state as the omitted state. Denote the estimated fixed effect for state $s$ as $\hat{\delta}_{s}$. These provide estimates of the deviation in mean wages for a representative worker, relative to earnings in New York (in 1939). Our adjustment factor for each state is then $\exp \left(\hat{\delta}_{s}\right)$.
} 
wages. Panel A of Figure 8 shows that mean adjusted and unadjusted wages are highly correlated. In our models in the next section we use the adjusted wage data, but we have also estimated all models using the unadjusted series, and find very similar coefficients.

Panel B of Figure 8 provides some evidence that higher teacher wages were associated with a higher quality pool of teachers. We calculate the fraction of teachers in the 1940 Census with a college degree in each state, and plot this variable against the mean state teacher wage (taken from the administrative data). In general, states with higher wages also have better educated teachers.

Finally, in Panel $\mathrm{C}$ we plot the relationship between median earnings of teachers in a state and the median earnings of non-teachers (again restricting attention to those who attended at least one year of college). In most states, teachers earned less than nonteachers, but there are notable exceptions, including California, New York, and the District of Columbia. The graph also shows that there is large variation in teacher wages among states with similar non-teacher wages, suggesting that there was substantial variation in the willingness of communities with similar average incomes to pay for better-qualified teachers.

\subsection{Modeling the Effects of School Quality on Education Choices-White Families}

The reasoning illustrated in Figure 6 and the availability of very large sample sizes from the 1940 Census (in white families, 2.15 million daughters aged 14-16 and 3.67 million sons aged 14-18) leads us to consider empirical models in which the relationship between a child's educational outcomes and the quality of local schools varies by parental education. We begin by dividing households into four parental education groups: $0-4,5-8,9-12$, and more than 12 years of education. We then fit statistical models separately for sons and daughters in each group.

We use a two step procedure. First, we estimate a model of educational attainment for children in parental education group $g$ :

$$
E_{i g}^{*}=A_{i g} \alpha_{A g}+C_{i g} \alpha_{C g}+\alpha_{s(i) g}+u_{i g}
$$

where $A_{i g}$ is a set of age dummies for the $i^{t h}$ child in parent education group $g ; C_{i g}$ are additional family-level control variables, ${ }^{30} \alpha_{s g}$ are state dummies for education group $g$, and $s(i)$ is the state of residence of family $i$. We estimate this model as a Tobit (i.e., censored regression model), treating children who are not enrolled at the Census date as having completed their schooling, $E_{i g}^{*}=E_{i g}$, and those who are enrolled as being censored,

\footnotetext{
${ }^{30}$ These controls are an indicator for only mother present, an indicator for only father present, an indicator for both parents born in a different state, an indicator for one parent born in a different state, an indicator for urban area, an indicator for living on a farm, indicators for parents' age (in 5 year intervals), and single-year indicators for parental education.
} 
$E_{i g}^{*} \geq E_{i g}$. We adopt a normalization that sets the (weighted) sum of the state dummies to zero for each $g$.

We note that since the oldest children in our samples are 16 (for females) or 18 (for males), the censoring rates are fairly high for children in the highest parental education groups. In Appendix Table B1 we report the mean, median, and modal education levels observed for each parental education and gender group, as well as the fraction of children in each group who are still enrolled (and are therefore treated as censored). The censoring rate is $85 \%$ for males whose best-educated parent has 12 years of education and $89 \%$ for those whose best-educated parent has $>12$ years. For females the corresponding rates are $94 \%$ and $96 \%$. These high rates mean that our models have limited power to discern the desired schooling of children in the highest parental education groups. Nevertheless, we can still measure differences across states in the attainment of at least one year of high school for all of our parental education groups.

In a second stage, we then estimate models that relate the estimated state dummies to our two state-level school quality measures: $P T_{s}$, the average pupil-teacher ratio in state $s$, and $W_{s}$, the average level of teacher salaries (adjusted for state-level differences in average pay as described above). Specifically, we estimate three versions of the following specification:

$$
\hat{\alpha}_{s g}=\pi_{0 g}+P T_{s} \pi_{P T g}+W_{s} \pi_{W g}+\xi_{s g}
$$

In the first variant ("model 1") we include only the pupil-teacher ratio. In the second ("model 2") we include only the teacher wage. In the third ("model 3") we include both measures of local school quality. We estimate these models by weighted least squares, weighting the data for state $s$ by the inverse sampling variance of the estimated state dummy for group $g .{ }^{31}$

Table 2 presents parameter estimates. We observe several interesting features. First, school quality is strongly related to schooling attainment for most parental education groups, with effects that are largest for children with the least educated parents and smallest for those with the most educated parents. The general pattern suggests that higher school quality contributes to a closing of between-family gaps in human capital. ${ }^{32}$

A second interesting feature is that the estimated effects of the individual school quality measures are only slightly attenuated when we fit a model that includes both (model 3),

\footnotetext{
${ }^{31}$ If our first stage model was linear and there were no other control variables this weighting would lead to second stage estimates that are numerically identical to those from a one-step procedure in which we included the school quality measures directly in the first stage model (Hanushek, 1974).

${ }^{32}$ To investigate further, we broke down our parental education bins even further, forming 11 parental education groups $g$, and then repeated our exercise, again for daughters and sons separately. We find that the "school quality effects" $\left(\pi_{P T g}\right.$ and $\left.\pi_{W g}\right)$ for our 11 parental education groups $g$ decline in importance, almost monotonically, as parental education increases. See Appendix Tables B3 and B4. We also provide parameter estimates for the other control variables for a subset of the Tobit first-stage models in Appendix Table B2. Finally, Table B5 reports unweighted estimates, which are preferred by some analysts, and which are very similar.
} 
reflecting the limited correlation between $P T$ and $W$ across states $(\rho \approx 0.2)$.

A third feature is that the estimated effects of school quality are only slightly larger (10-20\%) for sons than daughters. Given the lower maximum age for daughters (16 vs. 18), this is reassuring, and suggests that the higher fraction of censoring for daughters does not substantially attenuate the effects of school quality.

A final feature we notice from Table 2 is that estimates of teacher effects are little affected by the addition of several state-level controls - the average level of education of whites aged 25-55, the state-level white male unemployment rate (among those aged 16 and older), and the mean value of homes in the state. ${ }^{33}$ However, the addition of these covariates leads to greater attenuation in the estimated coefficients of the pupil-teacher ratio. We conclude that the effects of teacher wages are reasonably robust to other controls, whereas the pupil-teacher effects are more sensitive, and are likely overstated in the simplest models.

To get a sense of the magnitudes implied by the estimates in Table 2, recall that the state effects from equation (7), which form the dependent variable in the second stage model, are scaled in years of education. Teacher salaries are scaled in hundreds of dollars per year. Thus a coefficient of 0.15 on annual teacher salary - as is approximately the case in families with parental education of 5-8 grades - implies that a $\$ 500$ increase in average teacher salaries is associated with a 0.75 year increase in completed education. This is a relatively large effect, and implies that moving from a low school quality state like Alabama to a high school quality state like California would lead to an extra two years of education for the children of parents who have 5-8 years of schooling. Assuming a 7\% return to each year of education, this would yield about $15 \%$ higher earnings per year of work, as well as other potential benefits. ${ }^{34}$

One concern with these models is that the Tobit functional form is incorrect. To test the robustness of our conclusions, we re-estimated our first stage models using a probit specification, treating education beyond high school as a single top category. We then used the estimated state effects from these models as dependent variables in our second stage models. The results are summarized in Appendix Table B8. The estimated effects of PT and $W$ are qualitatively very similar to the effects in Table 2 , though all the coefficients are re-scaled by a factor of roughly $0.1 .^{35}$ Thus the estimates imply that a $\$ 500$ increase in average teacher salaries is associated with a roughly six to eight percentage point increase in the probability of achieving at least 9th grade for children whose parents have eight years of schooling.

\footnotetext{
${ }^{33}$ See Appendix Tables B6 and B7 for the full set of estimated coefficients.

${ }^{34} \mathrm{As}$ for the coefficients on the pupil-teacher ratio, the largest effect in the multiple regression models (with covariates) is approximately -0.10 , for sons of very poorly educated parents. This too is quite a large effect; a 5-pupil reduction in the pupil-teacher ratio is associated with a 0.5 year increase in completed education.

${ }^{35}$ The correlation of the estimated effects of teacher wages on the state effects from ordered probit models for white males (in Appendix Table B8) with the corresponding effects of teacher wages on the state effects from first stage Tobit models in Appendix Table B4 is 0.95 .
} 
In the extant literature a common way of characterizing the parent-child education link is with a regression of the child's education $E_{i}$ on the parent's education $P_{i} .{ }^{36}$ The models summarized in Tables 2 and 3 suggest that higher school quality affects the slope of this relationship, since increased quality has a differential affect on the schooling attainment of children with more and less-educated parents. To illustrate this directly, we estimate separate Tobit models relating desired child education to parental education for states with high, medium, and low levels of average teacher wages, including dummies for parental education and the same controls included in our main first-stage models. Panel A of Figure 9 shows the coefficients of the parental education dummies in these three models. In states with relatively high teacher wages, an increase in parental education from $P_{i}=2$ to $P_{i}=12$, leads to about a 3.5 year gain in child education, i.e., the slope of the parentchild gradient is approximately 0.35 . In states with low teacher wages, on the other hand, the corresponding slope is approximately 0.75. (We discuss Panel B of Figure 9 below.)

\subsection{School Quality and Education Choices-Black Families}

We proceed with an analogous exercise for black families located in the South. In comparison to white parents, relatively few black parents have more than elementary education, so our top education bin is now for parental education $>8$ grades.

Results for black daughters and sons are presented in Table $3{ }^{37}$ As with white families, we observe the expected negative relationship between the pupil-teacher ratio and educational attainment and positive relationship between the teacher wage and education. However, for black families the relationship between school quality and education does not vary substantially according to parental education.

There are two complementary explanations for this finding. First, few black students in the South attended college in the late 1930s. Thus the discontinuity in marginal costs for $E>12$ was largely irrelevant, leading to an expected empirical relationship closer to equation (6). Second, in our discussion above we posited that within-state sorting may have flattened the relationship between average school quality and the expected quality of schooling children of highly-educated parents. Black families in the South may have been an exception. Disenfranchisement meant that African Americans had little control over the quality of their schools, weakening the sorting effect. These observations suggest an empirical strategy in which we simply pool all parental education groups in the same first-stage Tobit model. We do so, and give the results in the final rows of Panel A and Panel B in Table 3.

Although the models in Table 3 are estimated on only 18 observations, they point to relatively precisely estimated effects of local school quality on the educational attainment

\footnotetext{
${ }^{36}$ The coefficient on parental education ranges from 0.14 to 0.45 in eight papers cited by Mulligan (1999).

${ }^{37}$ Interested readers can find estimated coefficients for the Tobit first stage in Table B9. Unweighted variants of regression (3) from Table 3 are in Table B10. Estimates of the covariate coefficients are in Tables B11 and B12.
} 
of black sons and daughters, with similar effects for the two gender groups. The estimated effects are comparable in magnitude to the effects we obtained for white children with parents in the middle of the white parent's education distribution (5-8 years of schooling); in various specification for black students, the average teacher wage effect is approximately $0.10-0.20$. Thus a $\$ 500$ increase in teacher salary is associated with a 0.5 to 1 year increase in complete schooling. Taking such estimates at face value, the $\$ 2000$ per year gap in teacher salary gap between Georgia and the District of Columbia would be associated with a two to four year gap in completed schooling for black children.

As with white families, we estimated a probit variant of our model, in which the object of interest is 9th grade attainment. Results are reported in Appendix Table B13. Inferences using this approach correspond closely to those in our main analysis (Table 3 ).

Further insights are offered in Panel B of Figure 9, where we show the relationship between the educational attainment of black children and their parent's education, following the same steps we used to construct Panel A of this figure for white children. We show the estimated relationship separately for the Deep South states, which had very low school quality metrics for black students; the Peripheral Southern states, where observable school quality measures were higher, and more similar for blacks and whites; and states outside of the South, where most black students attended non-segregated schools. For families outside the South the relationship is quite similar to the profile for white families in high-teacherwage states shown in panel A, and suggests a remarkable degree of upward mobility in human capital for blacks. The profiles in the South - especially the Deep South - are much lower and show far less upward mobility. To appreciate just how unfavorable the estimated outcomes are for African American children in the Deep South, it is important to realize that about one-half of black parents in these states had 4 grades or less of schooling. For these families, predicted child schooling is only about 6 years - a very modest gain when compared to the gains of 4 or more years for the children of white parents with comparable levels of schooling.

\subsection{Interpretation of State-Level Analysis: the Role of Minimum Teacher Salary Standards}

Our analysis of the relationship between parental and child schooling takes advantage of the near-population data in the 1940 Census: our first stage models are estimated using data for millions of families. But our inferences about the mediating role of school quality depend on state-level variation, giving us only 49 observations for white children and 18 for black children. While the relationships between the schooling attainment and school quality are suggestive of a causal link, there are concerns with this interpretation. One is that the use of state-level school quality measures leads to biases (Hanushek, Rivkin and Taylor, 1996). Another is that we cannot fully control for other local factors that vary across states. The limited set of covariates included in our richest models in Table 2, for example, may not adequately control for differences in labor market opportunities that 
induced children to acquire more (or less) education and are correlated with school quality measures.

To push further, in the next section we study the quality of schooling at the county level, focusing on adjacent counties that lie along the borders of Southern states. The idea is that these neighboring counties likely share similar economic and social conditions, while being subject to substantially different state-level policies. To set the stage for this cross-border design, and to provide additional clarity to our state-level regressions, it is worth considering the origins of the variation we observe in state schooling policies.

We have already noted that during the first few decades of the 20th century, many states implemented public schooling reform - a process leading to greater equalization and standardization within states. As of 1940 most school spending was still at the local level (approximately 68\%, according to Bensen and O'Halloran, 1987), but in many states key local decisions were unmistakably shaped by state-level policies. For instance, in 1940 a total of 23 states set a floor on teacher salaries, including a number of states in the South, where the minimum salary schedules were usually lower for black teachers than their white counterparts. These provisions were typically part of broader legislation through which states provided supplementary funding for local schools. In exchange, counties were required to adhere to the minimum salary scale, which most counties were doing by 1940 . We provide a brief summary of the history of minimum salaries regulations in Appendix A, and provide empirical evidence for the importance of minimum wage regulation in pushing up the lower tail of wages for both black and white teachers. ${ }^{38}$

Figures in Appendix A provide visual evidence of the importance of minimum salary policies in driving statewide teacher salaries. In Figures A4 and A5 we plot the distribution of earnings of full-time public school teachers (from the 1940 Census) for each state with a mandated minimum, again separately by race, along with a line representing the minimum salary. When looking at these figures it is helpful to note that earnings are generally thought to be noisily measured in the 1940 Census - a fact that will lead to apparent noncompliance with the law. ${ }^{39}$ Those figures show strong visual evidence that minimum wage laws were pushing up the lower tail of wages for black teachers in states like Alabama, Delaware, Georgia, and Mississippi, and doing the same for white teachers in states like Alabama, Kentucky, Missouri, and North Carolina.

With all this in mind, consider the simple bivariate regressions shown in Table 4 . In the first column is an OLS regression of the state dummies from regression (7) on the state teacher salaries, just as in the second column of Tables 2 and 3, but for states with minimum teacher-salary regulations. Results are quite similar to those found with the full sample. We implement a 2SLS procedure using the state's minimum teacher salary as an

\footnotetext{
${ }^{38}$ National Educational Association (1940) provides a useful contemporary discussion of the laws.

${ }^{39}$ Miller and Paley (1958) conducted a reliability analysis of reported incomes in the 1950 Census using a large sample of Census households matched to corresponding Federal tax records. They found substantial measurement error in the Census. For example, among households who reported $\$ 2500-2999$ income in tax filings, $12.6 \%$ report income of $\$ 1000-1499$ to the Census.
} 
instrument. The first stage fits remarkably well. ${ }^{40}$ The 2SLS estimates are quite similar to their OLS counterparts.

In Table 5 we repeat this analysis, but now include both the state pupil-teacher ratio and state teacher salary variables. For white students, a group for which $n=23$, results are little changed from the bivariate 2SLS results of Table 4. Given the small sample of black students $(n=10)$, it is unsurprising that we make no headway with 2SLS when we include both school quality measures; we do not report 2SLS results because of a failure at the first stage (low $F$ statistics).

In broad terms our analyses demonstrate robust state-level associations between teacher salaries and educational attainment, and the 2SLS estimates suggest a key role for statelevel policies in shaping these relationships. Estimated teacher salary effects are largest for black families and for white families with poorly educated parents. This is striking because during the era we study neither Southern black families nor poorly educated white families had much in the way of political control over state educational policy.

\section{Comparisons at the County Level: A Cross-Border Design}

In our final set of analyses we evaluate the schooling choices of children from families in adjacent counties that lie along the borders of the Southern states. Figure 10 shows the borders in question, highlighting the counties on each side. Relative to the statewide comparisons in Tables $2-5$, these border county comparisons have two key advantages. First, the matched counties along each border have similar socioeconomic conditions, including local demand factors that may have influenced the schooling decisions of children. Second, the number of border counties is relatively large, enabling us to expand the list of controls included in our models.

Table 6 provides an overview of the differences in teacher wages in the states included in our border sample, with four columns of data for black teachers and four for whites. The first two columns for each race represent mean wages of teachers in the 1940 Census for the border counties and for the state as a whole. ${ }^{41}$ The third column shows the average salary for the state in the Card-Krueger data, collected from administrative reports. Finally, the fourth column shows the minimum wage applying to teachers in the state, or in states with no minimum, the 10th percentile wage for teachers, estimated over all teachers in the state. We give the 10th percentile as a benchmark, indicating the approximate highest minimum salary that would leave the extant salary structure unchanged (bearing in mind that many especially low earnings reports are due to measurement error).

\footnotetext{
${ }^{40}$ If we instead regress the $\log$ of state teacher-salary average on the $\log$ of the state teacher minimum salary, the coefficient is 0.58 for whites and 0.64 for blacks. These results imply that a $10 \%$ increase in the minimum salary generated an increase in average salaries of around $6 \%$.

${ }^{41}$ We classify individuals as "teachers" if their 1940 and 1950 occupation codes are "teacher" and they are over the age of 14 with at least fifth grade education and are employed at the Census date in the "educational services" industry (according to the 1950 Occupational classification).
} 
Although the Census data and administrative data likely contain substantial measurement errors, at the state level the two series are highly correlated. When we regress the Census average on the administrative average we obtain a coefficient of 0.69 (s.e. 0.04) and $R^{2}=0.97$ for whites, and a coefficient of 0.71 (s.e. 0.04 ) and $R^{2}=0.89$ for blacks. At the county level, we collected administrative data (where available) on average teacher salaries for our border counties. ${ }^{42}$ Figure 11 shows a high correlation (0.83) between these administrative salaries and mean teacher salaries estimated from the 1940 Census. Because there are some states with no county-level administrative data, we proceed in this section using teacher wages as calculated using Census data.

We notice that between-state differences in wages were particularly large for black teachers. Using Census data we find that annual teacher earnings ranged from $\$ 295$ in Mississippi (a state with a minimum salary for black teachers of $\$ 80$ ) to $\$ 1223$ in Delaware (where the minimum was $\$ 1000$ ). Also, we confirm that there were often large gaps between the minimum wages for white and black teachers. For example, the minimum wage for black teachers was $75 \%$ of the minimum for white teachers in Alabama, $63 \%$ in Georgia, $58 \%$ in Maryland, $77 \%$ in North Carolina, and $74 \%$ in Virginia. In contrast, in several Peripheral states the minimum teacher wages were the same across race (Delaware, Kentucky, Oklahoma, Tennessee, and West Virginia).

\subsection{Identifying and Characterizing Border County Pairs}

We use the county adjacency file published by the Census Bureau, ${ }^{43}$ to identify contiguous counties along the borders between Southern states. ${ }^{44}$ To avoid comparing counties with widely different economic conditions, we eliminate all pairs with more than a one-year absolute difference in the mean education of white residents. We also exclude counties with fewer than five black residents between 16 and 18 years of age, and those with no resident black teachers. These restrictions narrow our data set to 208 county pairs along 28 distinct border segments. We conduct a parallel analysis for white families with poorlyeducated parents, yielding 270 border county pairs along 32 distinct border segments.

Some basic summary statistics for the border segments are presented in Table $7 .{ }^{45} \mathrm{We}$ show average levels of adult education on each side of the border segment as well as the average proportion of adults living on farms or in urban areas and average incomes. In each case the first state listed has the higher minimum teacher salary or 10th percentile of teacher wages.

\footnotetext{
${ }^{42}$ We have data on border counties in Alabama, Delaware, Florida, Georgia, Louisiana, Maryland, Missouri, North Carolina, South Carolina, Tennessee, Texas, and Virginia. Administrative data not available at the county level (or not available by race) for other states.

${ }^{43}$ U.S. Census Bureau, County Adjacency File (2010).

${ }^{44}$ Some counties on one side of a border can be paired with two counties on the other side.

${ }^{45}$ To streamline this table, we present only border segments for which there are at least 100 black $16-18$ year olds on each side of the border, though we do not exclude less-populated borders in our analysis.
} 
Consider the first border segment in the Panel A of Table 7, which includes counties along the Alabama (AL)-Florida (FL) border. This segment has 4 counties in AL and 5 in FL. In terms of demographic characteristics, we note close similarities in the two sets of counties, e.g., in mean annual incomes for whites (\$619 in AL vs. $\$ 642$ in FL) and for blacks ( $\$ 310$ in AL vs. $\$ 330$ in FL). We also show our baseline measure of upward mobility - the fraction of children aged 16-18 with at least 9th grade education among those whose parents have 5-8 years of schooling - for white and black families on each side of the border. For white families upward mobility is not much different in the AL counties (0.44) and FL counties (0.47), but for black families upward mobility is much lower in AL (0.17) than FL (0.31). The border segments in Panel A are between Deep South and Peripheral South states. In seven out of eight segments the state with the lower black teacher minimum salary (or 10th percentile) has lower upward mobility for black students, and the state with the lower minimum salary (or 10th percentile) is generally the Deep South state.

Panel B of Table 7 reports statistics for other well-populated border segments used in our analysis. Again, in most cases the state with the lower minimum teacher salary (or 10th percentile) for black teachers has lower average upward mobility among black students.

\subsection{Econometric Approach}

We proceed with an analysis of the impact of teacher compensation policies on educational attainment for families in the border counties. We focus on teacher salaries for three reasons. First, as noted in the discussion of Tables 2 and 3, the measured effect of teacher salaries across states appears to be relatively robust to the inclusion of other measures of school quality and other potential controls. Second, one might be concerned that differences in enrollment choices of black children lead to (inversely correlated) changes in the number of pupils per teacher, creating an endogeneity bias in the measured effect of the pupil teacher ratio. A third key reason is that we can use differences in state-wide teacher salary laws as an instrument for the difference in teacher wages.

\section{Model Specification}

We have two approaches for measuring the effects of school quality on educational choices and upward mobility, both of which parallel our state-level analyses.

With our first approach, we begin with a Tobit model, estimated for black sons age 14-18 and black daughters age 14-16 who live with their parent(s) in a Southern state. The models are similar to the specifications in Table 3, but pool parental education groups and include unrestricted county dummies, as well as controls for the age and gender of the child, whether the family lives on a farm or urban area, whether the family is headed by a single mother or a single father, whether at least one parent was born in a different state, 
and single-year indicators for the highest level of parental schooling. ${ }^{46}$

In the second stage we then form the difference $\Delta y_{p}$ in the estimated dummies for the two counties in matched pair $p$ and fit the following model:

$$
\Delta y_{p}=\pi_{0}+\Delta W_{p} \pi_{W}+\Delta X_{p} \pi_{X}+\epsilon_{p},
$$

where $\Delta W_{p}$ is the with-pair difference in average teacher wages for border pair $p$, and $\Delta X_{p}$ is a vector of within-pair differences in a set of controls, including

- the differences in the fractions of black families living on a farm or in urban areas,

- the differences in mean parental earnings and parental education of black families,

- the difference in mean education of white adults, and

- the difference in the county-average number of Rosenwald teachers per black student in the 1931 birth cohort (from Aaronson, et al., 2017).

We estimate equation (9) both by OLS and by instrumental variables, using the withinpair difference in state-wide minimum teacher salaries as an instrument for $\Delta W_{p}$. Standard errors are clustered at the border segment level. ${ }^{47}$

Our second approach focuses directly on the probability of attaining at least 9th grade. We again use a two-step approach. We begin with a linear probability model for bordercounty families with chidren aged 16-18: the dependent variable is 9th grade attainment, and the explanatory variables include our family-level characteristics and the county dummy variable. Then we proceed by estimating equation (9), now setting $\Delta y_{p}$ to be the within-pair difference in county dummies from our 9th grade attainment regression.

\section{Teacher Salaries: Sources}

As we have mentioned, in our analyses we use the county-level average public school teacher earnings as calculated in the Census. Since our design looks at adjacent counties, we do not normalize wages by local economic conditions. ${ }^{48}$

\footnotetext{
${ }^{46}$ Since we are evaluating counties in bordering states, we might be concerned that there is some crossborder migration which contaminates our evaluation. Thus we also tried including a dummy variable indicating that a parent was born in the neighboring state. This specification choice made virtually no difference to estimated coefficients reported below.

${ }^{47}$ There are 28 such border segments, so we are close to the edge of respectability with regard to the number of clusters we have for our regression analysis.

${ }^{48}$ Nonetheless, in work not reported here, we also formed "adjusted teacher earnings" by pooling "teachers" (identified as described above) with better-educated "non-teachers" (people age 18-64 with at least 9th grade education) and fit a model with individual controls, a set of county dummies, and a parallel set of interactions of the county dummies with a teacher indicator. The latter represent county-specific teacher wage premiums relative to other better-educated workers in the county. Results using these adjusted wages were extremely similar to results reported below.
} 
State-level averages of the county-specific teacher wage premiums are interesting. See Figure 12. In all states white teachers in the Southern border counties were paid less than non-teachers (controlling for their age, education and gender), with considerable variation in the extent to this disadvantage. Black teachers, however, earned more than comparable non-teachers in some states, including four of the five states in which the minimum teacher salary was the same for black and white teachers (Delaware, Oklahoma, Tennessee, and West Virginia).

\subsection{Results}

Panel A of Table 8 shows estimates of equation (9). We report OLS estimates in the first column, the estimated first stage and reduced form effects in the second and third columns, and then the 2SLS estimate, along with the F-statistic for the first stage model. We have 208 county pairs lying along 28 distinct border segments. Standard errors are clustered at the border segment level.

Row 1 reports our baseline specification. The dependent and independent variables in this specification are comparable to the ones for our state-level models reported in the second column of the bottom rows in Panels A and B Table 3. OLS estimates in those models suggest that a $\$ 100$ increase in teacher salaries is associated with an increase in schooling attainment of approximately 0.21-0.22 years; the corresponding estimate from the border county analysis is slightly higher, 0.28 years.

Our 2SLS procedure is predicated on the assumption that state minimum wages had a strong effect on teacher salaries in the border counties. This is confirmed in Appendix Figures A2 and A3, which plot average teacher salaries for the border counties against the state minimums (for the set of states with a minimum teacher wage).

To implement the 2SLS procedure on our entire sample of border counties, we need to define a "proxy minimum wage" for states with no law. We proceed by using the 10th percentile of teacher wages. This corresponds to the assumption that in the absence of any law (and any measurement error), teacher wages would be at least as high as the observed 10th percentile of wages in the state. As shown in the second column of Table 8 the first stage estimate under this assumption is 0.8 , and is relatively precisely estimated, while the reduced form estimate is 0.27 , and is also precisely estimated. The resulting 2SLS estimate of 0.33 is not too different than the OLS estimate, as would be expected if the unobserved determinants of the within-county-pair difference in black children's desired educational attainment were orthogonal to the corresponding within-pair difference in black teacher wages, conditional on the controls. ${ }^{49}$

A potential objection to this procedure is that our use of the 10th percentile as a proxy

\footnotetext{
${ }^{49}$ We have re-estimated the OLS model with alternative subsets of the control variables and found that none of the added controls has a large effect on the estimated teacher wage coefficient. Altonji, Taber, and Todd (2005) and Oster (2017) suggest that this invariance can be taken as evidence that other unobserved determinants of educational attainment are unlikely to lead to substantially different estimates.
} 
minimum wage is inappropriate. To check this concern, we constructed an average of the county effects for counties on each side of the 10 border segments for which we have a minimum wage on both sides. We then formed 10 cross-border differences, and estimated a simple OLS model relating these to the cross border difference in the minimum wage. ${ }^{50}$ The estimate from this procedure is 0.23 (s.e. 0.11 ), which is very similar to the reduced form estimate across all border-pairs reported in column 3 of Table 8.

In row 2 of Table 8 we provide estimates for the case in which we limit the first-stage Tobit model to families living in the rural areas of each border county. We conduct this analysis because rural schools were plausibly poorer than urban schools, and more likely to have salaries shifted by state minimum teacher salary policies. In fact we see little change from our baseline specification.

Panel B of Table 8 presents estimates intended to examine the relationship depicted in Figure 5. That figure shows a strong correlation across states between average teacher wages and 9th grade attainment among 16-18 year old black children whose parents had 5-8 grades of education. Here we examine this relationship in our border counties, but to build sample sizes within counties, we use all black families (not just those with parental education of 5-8 grades, as is the case in Figure 5). In so doing we note from Table 7 that black adult education was very low in our border counties, so 9th grade attainment represents substantial "upward mobility" in most families. The effect of teacher salary on 9th grade attainment is positive, as expected, but these results have relatively low statistical significance. ${ }^{51}$ Still, taken at face value our 2SLS estimates are quite large. A $\$ 500$ increase in teacher salary is estimated to increase 9 th grade attainment by 7 to 9 percentage points.

A possible concern about the analysis at the county level is that our sample period (1940) coincides with the latter stages of the Great Migration of African Americans from the South. ${ }^{52}$ Some black families likely migrated out of the South because of poor educational prospects, and such migration was plausibly largest in counties with poor schools. If so, this could complicate the interpretation of our results, since parents remaining behind in counties with poor schools would have been negatively selected in terms of parental aspirations for their children, i.e., had disproportionately low values of the altruism factor $\theta$ in the model represented by equation (1).

We evaluate this concern by constructing a simple measure of net out-migration for black families in our border counties - the ratio of black 14-18 year olds in 1940 relative to 4-8 year olds in 1930 - and look for a relationship between out-migration and black teacher

\footnotetext{
${ }^{50}$ We proceed this way, rather than by fitting a model at the county-pair level, because with only 10 border segments we cannot cluster the standard errors at the segment level.

${ }^{51}$ In South Carolina, high school began with grade 8 (not grade 9 ) during the period we study. In our regression analyses we tried substituting "8th grade attainment" for "9th grade attainment" in that state, and found that results are little changed. The same is true for our analysis of white children below.

${ }^{52}$ See Boustan (2016) for a recent economic history of the Great Migration, and an overview of previous work on the topic. Black, et al. (2015) and Aaronson, et al. (2017) study selection into migration during the Great Migration.
} 
wages. Panel A of Figure 13 shows that there was no relationship between our measure of out-migration and teacher earnings. ${ }^{53}$ We conclude that selective out-migration is probably not seriously biasing our estimates. (Panel B of Figure 13 shows that the same observation holds true for white families. This is relevant for the analysis below.)

In summary, our analysis shows that policies that increased teacher salaries substantially improved educational attainment among black children in the South in 1940. We believe additional research will be useful to help fully develop our understanding of the mechanisms whereby these policies affected educational outcomes. One important possibility is that the higher salaries for black teachers in states with high minimum salaries led to a better-educated teacher workforce. Panel A of Figure 14 provides evidence consistent with this hypothesis; among our border counties, those with higher teacher earnings generally had better-educated teachers. Panel B shows a similar pattern for white teachers in our border counties. ${ }^{54}$

\section{Additional Results-White Families}

The primary focus of our cross-border design is black families. This focus makes sense in our context because of the very large differences in state policies as they pertained to black students in the South. Nonetheless, as a final exercise we repeat our border county analysis using data for white sons and daughters. Table 9 presents a replication of the specifications in Tables 8 for white families, with one key modification. In our analysis of black children we include all families, regardless of parental education, which is sensible given that estimated effects are found to be similar across parental education breakdowns for black families (see Table 4). For white children, in contrast, the estimated effects of school quality in our cross state models are much larger for families with poorly educated parents, so we estimate our cross-border models for families with parental education 0-4 and 5-8. As with black families we estimate models for the county pairs in general (our "baseline") and also for a subset of families living in rural areas.

Our OLS estimated teacher salary effects are positive (and statistically significant), but are somewhat smaller than those estimated at the state level (Table 2). Consistent with the pattern in Table 2, we find that the effects of higher teacher wages are larger for children of parents with only $0-4$ years of schooling versus those with 5-8 years of schooling. Turning to the 2SLS estimates, for families with poorly-educated parents, we note two things. First, the first stage effect of minimum teacher salaries on white teacher average salaries $(0.48)$ is substantially lower than the corresponding first stage effect for black teachers (0.80 from row 1 of Table 8$)$. Second, for whites the 2SLS point estimate

\footnotetext{
${ }^{53}$ See Appendix Table B14 for a regression analysis showing that the relationship between the two variables is actually negative, though far from statistically significant.

${ }^{54}$ In viewing these graphs it is useful to note that the number of black teachers per county was typically much lower than the number of white teachers. This partially explains the race-specific differences in the number of counties in which the share of college-educated teachers was exactly 0 or 1 .
} 
is substantially larger than the corresponding OLS estimate, and is closer in magnitude to the OLS and 2SLS estimates for black students. As with our estimates for black families, it appears that any upward biases in the OLS specification caused by endogeneity of local teacher wages may be small, and indeed OLS estimates may be downward biased due to measurement error.

On the basis of the 2SLS estimates, it appears that the impacts of teacher wages in the border counties were only moderately lower for white children of poorly-educated parents than for black children.

With regard to 9th grade attainment, for white families we restrict attention to families with parental education 5-8. Our border analysis is consistent with our state-level analysis for families in the middle of the parental education distribution; higher teacher salaries substantially improve the prospects of children moving up the educational ladder by completing at least grade 9 .

\section{Conclusion}

This paper provides the most comprehensive evaluation to date of the intergenerational transmission of human capital during the "golden age" of upward mobility in the United States. We find systematic variation in upward mobility in education by race and by location. A plausible explanation for observed patterns relates to location-specific differences is the quality of educational opportunities. In a state-level analysis we find that educational outcomes for children in white families with poorly-educated parents are strongly tied to school quality measures, more so than for children in families with well-educated parents. Our state-level analysis similarly finds a strong relationship between upward mobility and school quality metrics for black families. Finally, an investigation of adjacent counties across state borders reinforces this basic message, and increases our confidence in an interpretation that assigns a causal role to school quality.

Our work shows that there were important consequences of inequalities in public schooling in the U.S., especially disparities due to racial segregation in education. In many Southern states, black public school teachers earned less than half of what white teachers earned - a disparity that is all the more striking given that white teachers in the South were relatively poorly paid. In 1940 a substantial majority of black children were educated in the South, and thus the median black child lived in a state in which the cost-of-living adjusted salary of black teachers was only $\$ 649$ (in Virginia), while the corresponding median white student had a teacher with cost-of-living adjusted salary of $\$ 1727$ (in Wisconsin). ${ }^{55}$

\footnotetext{
${ }^{55}$ In calculating these statistics, we assigned state average teacher wages from administrative records for all children aged 6-18 in the state in which the child lived, making adjustments as described in footnote 28. Given that more than half of black children lived in the South, the median teacher salary for black students was in a segregated state, Virginia, which paid lower salaries to black public school teachers than their white public school teachers.
} 
Taking our baseline IV estimate for black children at face value ( 0.33 from row 1 of Table 8), this gap translates to a disadvantage in completed schooling of approximately 3.5 years. Assuming a 7\% return to each year of education, an increase in resources allocated to the median black child (to the median level of white children) would have resulted in $27 \%$ higher earnings per year of work. But this calculation may well understate the disadvantage to black cohorts born in the 1920s because, as Card and Krueger (1992a) show, low schooling quality also reduces the return to schooling. A rough calculation that incorporates their estimate suggests that our counter-factual increase in schooling quality for black students might have increased annual earnings by approximately $35 \% .{ }^{56}$

Of course, in addition to higher earnings, increased education has many other potential benefits, including a longer work life, lower lifetime unemployment, higher status and gains in education for the grandchildren's generation. The low upward mobility in human capital experienced by black children during the first half of the twentieth century was likely an important precursor to the persistence of racial inequality in labor markets over the remainder of the century (Bayer and Charles, forthcoming), and the similarly disadvantageous patterns of income mobility experienced by African Americans in the late 20th century (Chetty et al., 2018).

On a more positive note, in our paper's introduction we reflected on the potential role of rapidly rising levels of human capital during the first half of the twentieth century for general prosperity and declining inequality in the decades following World War II. As an empirical matter, we then document that especially among children in poorly-educated white families, but also for many black families (especially those outside of the South), educational quality appears to be a key factor driving upward mobility in human capital. In general terms our findings thus draws attention to high-quality public education as a viable means of improving equality of opportunities across generations.

\footnotetext{
${ }^{56}$ Card and Krueger (1992a) find that a $10 \%$ increase in teachers' pay is associated with a 0.1 percentage point increase in the return to schooling. So a doubling of teacher pay is associated with a one point increase in the return to schooling. If we evaluate this gap for an individual with eight years of years of schooling, this amounts to differential in annual earnings on the order of $8 \%$.
} 
Table 1: Characteristics of Individuals Aged 14-18, Living with a Parent in 1940

\begin{tabular}{|c|c|c|c|c|c|c|c|c|c|c|c|c|}
\hline \multirow[b]{2}{*}{ Age } & \multicolumn{3}{|c|}{ White Female } & \multicolumn{3}{|c|}{ White Male } & \multicolumn{3}{|c|}{ Black Female } & \multicolumn{3}{|c|}{ Black Male } \\
\hline & Home & Sch. & $\begin{array}{l}\text { Med. } \\
\text { Gr. }\end{array}$ & Home & Sch. & $\begin{array}{c}\text { Med. } \\
\text { Gr. }\end{array}$ & Home & Sch. & $\begin{array}{c}\text { Med. } \\
\text { Gr. }\end{array}$ & Home & Sch. & $\begin{array}{l}\text { Med } \\
\text { Gr. }\end{array}$ \\
\hline 14 & 0.92 & 0.92 & 8 & 0.93 & 0.92 & 7 & 0.82 & 0.88 & 6 & 0.82 & 0.84 & 5 \\
\hline 15 & 0.91 & 0.88 & 9 & 0.92 & 0.87 & 8 & 0.80 & 0.81 & 7 & 0.82 & 0.76 & 6 \\
\hline 16 & 0.88 & 0.80 & 10 & 0.91 & 0.76 & 9 & 0.77 & 0.69 & 7 & 0.81 & 0.60 & 6 \\
\hline 17 & 0.82 & 0.69 & 11 & 0.90 & 0.63 & 10 & 0.70 & 0.53 & 8 & 0.80 & 0.42 & 7 \\
\hline 18 & 0.71 & 0.45 & 11 & 0.87 & 0.42 & 11 & 0.60 & 0.36 & 8 & 0.77 & 0.27 & 7 \\
\hline
\end{tabular}

Note: Authors' calculations, 1940 U.S. Census. "Home" reports the proportion of all children (of the given age) living with at least one parent, "Sch." reports the proportion of children in school among those living with a parent, and "Med. Gr." gives the median grade attained among these same children. 
Table 2: The Relationship between State-Level School Quality Measures and Educational Attainment-White Families

\begin{tabular}{l|cc|cc|cc}
\hline \hline \multicolumn{7}{c}{ Models (1) and (2) } \\
$\begin{array}{l}\text { Parental } \\
\text { Education }\end{array}$ & $\begin{array}{c}\text { Pupil-Teacher } \\
\text { Ratio }\end{array}$ & $\begin{array}{c}\text { Teacher } \\
\text { Salary }\end{array}$ & $\begin{array}{c}\text { Pupil-Teacher } \\
\text { Ratio }\end{array}$ & $\begin{array}{c}\text { Teacher } \\
\text { Salary }\end{array}$ & $\begin{array}{c}\text { Pupil-Teacher } \\
\text { Ratio }\end{array}$ & $\begin{array}{c}\text { Teacher } \\
\text { Salary }\end{array}$ \\
\hline \multicolumn{7}{l}{ A. Daughters } \\
\hline \multirow{2}{*}{$0-4$} & $-0.189^{* * *}$ & $0.307^{* * *}$ & $-0.113^{* * *}$ & $0.273^{* * *}$ & $-0.063^{*}$ & $0.231^{* * *}$ \\
& $(0.039)$ & $(0.030)$ & $(0.034)$ & $(0.029)$ & $(0.033)$ & $(0.059)$ \\
$5-8$ & $-0.117^{* * *}$ & $0.180^{* * *}$ & $-0.084^{* * *}$ & $0.160^{* * *}$ & $-0.036^{*}$ & $0.137^{* * *}$ \\
& $(0.034)$ & $(0.025)$ & $(0.025)$ & $(0.019)$ & $(0.021)$ & $(0.031)$ \\
$9-12$ & $-0.050^{* * *}$ & $0.071^{* * *}$ & $-0.041^{* * *}$ & $0.066^{* * *}$ & -0.018 & $0.047^{* *}$ \\
& $(0.017)$ & $(0.014)$ & $(0.014)$ & $(0.012)$ & $(0.013)$ & $(0.017)$ \\
$>12$ & -0.007 & 0.018 & -0.005 & 0.018 & 0.002 & 0.004 \\
& $(0.016)$ & $(0.014)$ & $(0.015)$ & $(0.013)$ & $(0.014)$ & $(0.020)$ \\
& & & & & \\
\hline
\end{tabular}

B. Sons

\begin{tabular}{l|cc|cc|cc}
\hline \multirow{3}{*}{$0-4$} & $-0.232^{* * *}$ & $0.303^{* * *}$ & $-0.155^{* * *}$ & $0.254^{* * *}$ & $-0.107^{* * *}$ & $0.259^{* * *}$ \\
& $(0.033)$ & $(0.034)$ & $(0.027)$ & $(0.032)$ & $(0.030)$ & $(0.057)$ \\
$5-8$ & $-0.152^{* * *}$ & $0.190^{* * *}$ & $-0.116^{* * *}$ & $0.162^{* * *}$ & $-0.068^{* * *}$ & $0.169^{* * *}$ \\
& $(0.026)$ & $(0.027)$ & $(0.016)$ & $(0.023)$ & $(0.016)$ & $(0.031)$ \\
$9-12$ & $-0.060^{* * *}$ & $0.087^{* * *}$ & $-0.050^{* * *}$ & $0.080^{* * *}$ & $-0.019^{* *}$ & $0.082^{* * *}$ \\
& $(0.014)$ & $(0.016)$ & $(0.010)$ & $(0.014)$ & $(0.009)$ & $(0.014)$ \\
$>12$ & 0.006 & $0.020^{* *}$ & 0.008 & $0.021^{* *}$ & $0.020^{* *}$ & 0.015 \\
& $(0.010)$ & $(0.009)$ & $(0.010)$ & $(0.009)$ & $(0.009)$ & $(0.015)$ \\
\hline \hline
\end{tabular}

Note: Authors' calculations, 1940 U.S. Census. Dependent variable is the state fixed effect from equation (7), and reflects years of child schooling. (1) and (2) are bivariate regressions; (3) are multiple regression. For regression (3) we have two versions, the second of which adds the following state-level covariates: education (white adults), income (whites), and housing values. $n=49$. Significance: ${ }^{* * *} p<0.01,{ }^{* *} p<0.05 ;{ }^{*} p<0.10$. 
Table 3: The Relationship between State-Level School Quality Measures and Educational Attainment-Black Families

\begin{tabular}{l|cc|cc|cc}
\hline \hline \multicolumn{7}{c}{ Model (1) and (2) } \\
$\begin{array}{l}\text { Parental } \\
\text { Education }\end{array}$ & $\begin{array}{c}\text { Pupil-Teacher } \\
\text { Ratio }\end{array}$ & $\begin{array}{c}\text { Teacher } \\
\text { Salary }\end{array}$ & $\begin{array}{c}\text { Pupil-Teacher } \\
\text { Ratio }\end{array}$ & $\begin{array}{c}\text { Teacher } \\
\text { Salary }\end{array}$ & $\begin{array}{c}\text { Pupil-Teacher } \\
\text { Ratio }\end{array}$ & $\begin{array}{c}\text { Teacher } \\
\text { Salary }\end{array}$ \\
\hline \multicolumn{7}{l}{ A. Daughters } \\
\hline \multirow{2}{*}{$0-4$} & $-0.131^{* * *}$ & $0.211^{* * *}$ & $-0.072^{* * *}$ & $0.121^{* * *}$ & $-0.068^{* *}$ & $0.186^{* *}$ \\
& $(0.021)$ & $(0.037)$ & $(0.028)$ & $(0.031)$ & $(0.028)$ & $(0.070)$ \\
$5-8$ & $-0.107^{* * *}$ & $0.208^{* * *}$ & $-0.072^{* * *}$ & $0.068^{*}$ & $-0.067^{*}$ & $0.112^{*}$ \\
& $(0.017)$ & $(0.031)$ & $(0.027)$ & $(0.036)$ & $(0.032)$ & $(0.057)$ \\
$>8$ & $-0.104^{* * *}$ & $0.129^{* * *}$ & $-0.082^{* *}$ & 0.040 & $-0.076^{*}$ & 0.061 \\
& $(0.016)$ & $(0.028)$ & $(0.027)$ & $(0.027)$ & $(0.036)$ & $(0.067)$ \\
All & $-0.145^{* * *}$ & $0.211^{* * *}$ & $-0.091^{* *}$ & $0.105^{* *}$ & $-0.085^{*}$ & $0.181^{*}$ \\
& $(0.023)$ & $(0.037)$ & $(0.036)$ & $(0.042)$ & $(0.039)$ & $(0.084)$ \\
& & & & & & \\
\hline
\end{tabular}

B. Sons

\begin{tabular}{l|cc|cc|cc}
\hline & & & & & \\
$0-4$ & $-0.132^{* * *}$ & $0.211^{* * *}$ & $-0.070^{* *}$ & $0.125^{* *}$ & $-0.061^{* *}$ & $0.220^{* *}$ \\
& $(0.022)$ & $(0.038)$ & $(0.029)$ & $(0.040)$ & $(0.024)$ & $(0.080)$ \\
$5-8$ & $-0.116^{* * *}$ & $0.168^{* * *}$ & $-0.072^{* *}$ & $0.084^{* *}$ & $-0.056^{* *}$ & $0.179^{* *}$ \\
& $(0.019)$ & $(0.038)$ & $(0.026)$ & $(0.027)$ & $(0.024)$ & $(0.069)$ \\
$>8$ & $-0.116^{* * *}$ & $0.151^{* * *}$ & $-0.078^{* *}$ & $0.067^{*}$ & -0.066 & 0.126 \\
& $(0.018)$ & $(0.031)$ & $(0.029)$ & $(0.035)$ & $(0.042)$ & $(0.087)$ \\
All & $-0.150^{* * *}$ & $0.223^{* * *}$ & $-0.086^{* *}$ & $0.122^{* *}$ & $-0.071^{*}$ & $0.234^{* *}$ \\
& $(0.026)$ & $(0.042)$ & $(0.036)$ & $(0.045)$ & $(0.036)$ & $(0.096)$ \\
\hline \hline
\end{tabular}

Note: Authors' calculations, 1940 U.S. Census. Dependent variable is the state fixed effect from equation (7), and reflects years of child schooling. (1) and (2) are bivariate regressions; (3) are multiple regression. For regression (3) we have two versions, the second of which adds the following state-level covariates: education (white adults), income (whites), and housing values. $n=18$. Significance: ${ }^{* * *} p<0.01,{ }^{* *} p<0.05 ;{ }^{*} p<0.10$. 
Table 4: The Relationship between Teacher Salaries and Educational Attainment: Bivariate 2SLS Analyses (with Minimum Teacher Salary as Instrument)

\begin{tabular}{|c|c|c|c|c|c|c|}
\hline $\begin{array}{l}\text { Parental } \\
\text { Education }\end{array}$ & OLS & $\begin{array}{l}\text { First } \\
\text { Stage }\end{array}$ & $\begin{array}{c}\text { Reduced } \\
\text { Form }\end{array}$ & 2SLS & F-Stat & $n$ \\
\hline \multicolumn{7}{|c|}{ A. White Daughters } \\
\hline Grades $0-4$ & $\begin{array}{c}0.300^{* * *} \\
(0.036)\end{array}$ & $\begin{array}{c}1.365^{* * *} \\
(0.129)\end{array}$ & $\begin{array}{c}0.401^{* * *} \\
(0.076)\end{array}$ & $\begin{array}{c}0.293^{* * *} \\
(0.040)\end{array}$ & 111.7 & 23 \\
\hline Grades 5-8 & $\begin{array}{c}0.196^{* * *} \\
(0.032)\end{array}$ & $\begin{array}{c}1.365^{* * *} \\
(0.136)\end{array}$ & $\begin{array}{c}0.273^{* * *} \\
(0.061)\end{array}$ & $\begin{array}{c}0.200^{* * *} \\
(0.033)\end{array}$ & 100.4 & 23 \\
\hline Grades $9-12$ & $\begin{array}{c}0.089^{* * *} \\
(0.018)\end{array}$ & $\begin{array}{c}1.324^{* * *} \\
(0.140)\end{array}$ & $\begin{array}{c}0.135^{* * *} \\
(0.030)\end{array}$ & $\begin{array}{c}0.102^{* * *} \\
(0.021)\end{array}$ & 88.8 & 23 \\
\hline$>12$ Grades & $\begin{array}{c}0.031^{* *} \\
(0.019)\end{array}$ & $\begin{array}{c}1.312^{* * *} \\
(0.140)\end{array}$ & $\begin{array}{c}0.047^{* * *} \\
(0.024)\end{array}$ & $\begin{array}{c}0.035^{* * *} \\
(0.016)\end{array}$ & 87.5 & 23 \\
\hline \multicolumn{7}{|c|}{ B. White Sons } \\
\hline Grades $0-4$ & $\begin{array}{c}0.287^{* * *} \\
(0.036)\end{array}$ & $\begin{array}{c}1.367^{* * *} \\
(0.125)\end{array}$ & $\begin{array}{c}0.394^{* * *} \\
(0.072)\end{array}$ & $\begin{array}{c}0.288^{* * *} \\
(0.040)\end{array}$ & 118.7 & 23 \\
\hline Grades 5-8 & $\begin{array}{c}0.192^{* * *} \\
(0.030)\end{array}$ & $\begin{array}{c}1.345^{* * *} \\
(0.136)\end{array}$ & $\begin{array}{c}0.282^{* * *} \\
(0.058)\end{array}$ & $\begin{array}{c}0.209^{* * *} * \\
(0.033)\end{array}$ & 96.6 & 23 \\
\hline Grades $9-12$ & $\begin{array}{c}0.093^{* * *} \\
(0.019)\end{array}$ & $\begin{array}{c}1.286^{* * *} \\
(0.146)\end{array}$ & $\begin{array}{c}0.146^{* * *} \\
(0.031)\end{array}$ & $\begin{array}{c}0.114^{* * *} \\
(0.021)\end{array}$ & 77.2 & 23 \\
\hline$>12$ Grades & $\begin{array}{c}0.029 * * \\
(0.012)\end{array}$ & $\begin{array}{c}1.277^{* * *} \\
(0.144)\end{array}$ & $\begin{array}{c}0.043^{* * *} \\
(0.021)\end{array}$ & $\begin{array}{c}0.033^{* * *} \\
(0.016)\end{array}$ & 78.0 & 23 \\
\hline
\end{tabular}

C. Black Daughters

\begin{tabular}{ccccccc}
\hline 0-4 Grades & $0.220^{* *}$ & $1.329^{* * *}$ & $0.336^{* * *}$ & $0.253^{* * *}$ & 32.2 & 10 \\
& $(0.065)$ & $(0.234)$ & $(0.098)$ & $(0.068)$ & & \\
$5-8$ Grades & $0.170^{* *}$ & $1.342^{* * *}$ & $0.298^{* * *}$ & $0.222^{* * *}$ & 33.3 & 10 \\
& $(0.072)$ & $(0.232)$ & $(0.072)$ & $(0.061)$ & & \\
$>8$ Grades & $0.179^{* *}$ & $1.359^{* * *}$ & $0.307^{* * *}$ & $0.226^{* * *}$ & 35.5 & 10 \\
& $(0.081)$ & $(0.228)$ & $(0.070)$ & $(0.058)$ & & \\
\hline
\end{tabular}

D. Black Sons

\begin{tabular}{lcccccc}
\hline Grades 0-4 & $0.249^{* * *}$ & $1.328^{* * *}$ & $0.372^{* * *}$ & $0.282^{* * *}$ & 28.9 & 10 \\
& $(0.070)$ & $(0.238)$ & $(0.094)$ & $(0.064)$ & & \\
Grades 5-8 & $0.211^{* * *}$ & $1.328^{* * *}$ & $0.338^{* * *}$ & $0.255^{* * *}$ & 30.8 & 10 \\
& $(0.075)$ & $(0.238)$ & $(0.086)$ & $(0.054)$ & & \\
$>8$ Grades & $0.192^{*}$ & $1.328^{* * *}$ & $0.354^{* * *}$ & $0.262^{* * *}$ & 35.9 & 10 \\
& $(0.081)$ & $(0.238)$ & $(0.080)$ & $(0.067)$ & & \\
\hline \hline
\end{tabular}

Note: Robust standard errors in parentheses. Significance: ${ }^{* * *} p<0.01,{ }^{* *} p<0.05,{ }^{*} p<$ 0.10 . 
Table 5: The Relationship between Teacher Salaries and Educational Attainment: Multivariate 2SLS Analyses (with Minimum Teacher Salary as Instrument)

\begin{tabular}{|c|c|c|c|c|c|c|}
\hline \multirow{2}{*}{$\begin{array}{l}\text { Parental } \\
\text { Education }\end{array}$} & \multicolumn{2}{|r|}{ OLS } & \multicolumn{2}{|r|}{$2 \mathrm{SLS}$} & \multirow[b]{2}{*}{ F-Stat } & \multirow[b]{2}{*}{$n$} \\
\hline & PT Ratio & Teacher Salary & PT Ratio & Teacher Salary & & \\
\hline \multicolumn{7}{|c|}{ A. White Daughters } \\
\hline Grades $0-4$ & $\begin{array}{c}-0.101^{*} \\
(0.054)\end{array}$ & $\begin{array}{c}0.265^{* * *} \\
(0.034)\end{array}$ & $\begin{array}{c}-0.094^{*} \\
(.052)\end{array}$ & $\begin{array}{c}0.282^{* * * *} \\
(0.037)\end{array}$ & 111.9 & 23 \\
\hline Grades 5-8 & $\begin{array}{l}-0.067 \\
(0.039)\end{array}$ & $\begin{array}{c}0.176^{* * *} \\
(0.025)\end{array}$ & $\begin{array}{l}-0.060 \\
(0.039)\end{array}$ & $\begin{array}{c}0.196^{* * *} \\
(0.029)\end{array}$ & 109.2 & 23 \\
\hline Grades 9-12 & $\begin{array}{l}-0.030 \\
(0.021)\end{array}$ & $\begin{array}{c}0.082^{* * *} \\
(0.015)\end{array}$ & $\begin{array}{l}-0.024 \\
(0.023)\end{array}$ & $\begin{array}{c}0.101^{* * *} * \\
(0.017)\end{array}$ & 103.8 & 23 \\
\hline$>12$ Grades & $\begin{array}{c}-0.010 \\
(0.023) \\
\end{array}$ & $\begin{array}{c}0.029 * \\
(0.015) \\
\end{array}$ & $\begin{array}{l}-0.008 \\
(0.022) \\
\end{array}$ & $\begin{array}{c}0.035^{* *} \\
(0.016) \\
\end{array}$ & 105.7 & 23 \\
\hline \multicolumn{7}{|c|}{ B. White Sons } \\
\hline Grades $0-4$ & $\begin{array}{c}-0.131^{* *} \\
(0.046)\end{array}$ & $\begin{array}{c}0.237^{* * * *} \\
(0.039)\end{array}$ & $\begin{array}{c}-0.116^{* *} \\
(.047)\end{array}$ & $\begin{array}{c}0.267^{* * *} \\
(0.037)\end{array}$ & 110.1 & 23 \\
\hline Grades 5-8 & $\begin{array}{c}-0.099^{* * *} \\
(0.026)\end{array}$ & $\begin{array}{c}0.161^{* * *} \\
(0.028)\end{array}$ & $\begin{array}{c}-0.084^{* * *} \\
(0.031)\end{array}$ & $\begin{array}{c}0.209^{* * *} * \\
(0.026)\end{array}$ & 102.8 & 23 \\
\hline Grades 9-12 & $\begin{array}{c}-0.041^{* * *} \\
(0.014)\end{array}$ & $\begin{array}{c}0.083^{* * *} \\
(0.018)\end{array}$ & $\begin{array}{c}-0.031^{*} \\
(0.018)\end{array}$ & $\begin{array}{c}0.113^{* * *} \\
(0.018)\end{array}$ & 91.2 & 23 \\
\hline$>12$ Grades & $\begin{array}{c}0.006 \\
(0.013)\end{array}$ & $\begin{array}{c}0.030^{* *} \\
(0.011)\end{array}$ & $\begin{array}{c}0.007 \\
(0.012)\end{array}$ & $\begin{array}{c}0.033^{* *} \\
(0.016)\end{array}$ & 97.2 & 23 \\
\hline \multicolumn{7}{|c|}{ C. Black Daughters } \\
\hline Grades $0-4$ & $\begin{array}{l}-0.064 \\
(0.048)\end{array}$ & $\begin{array}{c}0.139 \\
(0.087)\end{array}$ & - & - & 3.9 & 10 \\
\hline Grades 5-8 & $\begin{array}{l}-0.083 \\
(0.055)\end{array}$ & $\begin{array}{c}0.051 \\
(0.107)\end{array}$ & - & - & 3.5 & 10 \\
\hline$>8$ Grades & $\begin{array}{c}-0.100^{* *} \\
(0.039)\end{array}$ & $\begin{array}{c}0.021 \\
(0.053) \\
\end{array}$ & - & - & 3.1 & 10 \\
\hline \multicolumn{7}{|c|}{ D. Black Sons } \\
\hline Grades $0-4$ & $\begin{array}{l}-0.064 \\
(0.053)\end{array}$ & $\begin{array}{c}0.161 \\
(0.110)\end{array}$ & - & - & 3.4 & 10 \\
\hline Grades 5-8 & $\begin{array}{l}-0.076 \\
(0.049)\end{array}$ & $\begin{array}{c}0.103 \\
(0.111)\end{array}$ & - & - & 3.2 & 10 \\
\hline$>8$ Grades & $\begin{array}{c}-0.118^{* *} \\
(0.043)\end{array}$ & $\begin{array}{c}0.011 \\
(0.097)\end{array}$ & - & - & 3.1 & 10 \\
\hline
\end{tabular}

Note: Robust standard errors in parentheses. Results not reported for 2SLS when first-stage $F<10$.

Significance: ${ }^{* *} p<0.01,{ }^{* *} p<0.05,{ }^{*} p<0.10$. 
Table 6: Teacher Wages and State Minimum Wages in Southern States

\begin{tabular}{l|cccc|cccc}
\hline \hline & \multicolumn{3}{c}{ Black Teachers } \\
\hline & Census Earnings: & Admin. & Minimum/ & Census Earnings: & Admin. & Minimum/ \\
& Border & State & Salary & 10th per. & Bd \\
Border & State & Salary & 10th per. \\
\hline \multirow{2}{*}{ Alabama } & 412 & 457 & 412 & 262.5 & 784 & 864 & 878 & 350 \\
Arkansas & 374 & 416 & 375 & $210^{\dagger}$ & 678 & 644 & 636 & $320^{\dagger}$ \\
Delaware & 1003 & 1223 & 1500 & 1000 & 1189 & 1388 & 1715 & 1000 \\
Florida & 489 & 548 & 585 & $360^{\dagger}$ & 849 & 1023 & 1148 & $640^{\dagger}$ \\
Georgia & 458 & 438 & 404 & 175 & 831 & 879 & 924 & 280 \\
Kentucky & 628 & 835 & 522 & 525 & 737 & 902 & 853 & 525 \\
Louisiana & 413 & 522 & 509 & $245^{\dagger}$ & 947 & 1063 & 1197 & $670^{\dagger}$ \\
Maryland & 776 & 1185 & 1446 & 585 & 1208 & 1471 & 1689 & 1000 \\
Mississippi & 280 & 295 & 232 & 80 & 751 & 769 & 776 & $392^{\dagger}$ \\
Missouri & 551 & 1130 & 1153 & $450^{\dagger}$ & 831 & 997 & 1153 & $530^{\dagger}$ \\
N. Carolina & 687 & 670 & 737 & 504 & 911 & 968 & 1027 & 656 \\
Oklahoma & 704 & 787 & 993 & 585 & 847 & 940 & 1016 & 585 \\
S. Carolina & 438 & 464 & 371 & $260^{\dagger}$ & 885 & 923 & 953 & $657^{\dagger}$ \\
Tennessee & 676 & 676 & 580 & 320 & 859 & 873 & 909 & 320 \\
Texas & 567 & 584 & 705 & $330^{\dagger}$ & 967 & 1035 & 1138 & $640^{\dagger}$ \\
Virginia & 547 & 635 & 605 & $400^{\dagger}$ & 806 & 992 & 987 & $540^{\dagger}$ \\
W. Virginia & 982 & 1048 & 1170 & 585 & 1024 & 1056 & 1170 & 585 \\
\hline \hline Note Auta & & & & & & & \\
\hline
\end{tabular}

Note: Authors' analysis. "Census earnings" are from the 1940 Census (with averages given for border counties only and for the state); state average are also reported from administrative sources; and minimum statutory salaries, for states with minimum mandated teacher salaries are described in Appendix A. ${ }^{\dagger}$ These states have no statutory minim salary. Instead we give the 10th percentile of the race-specific statewide earnings among public school teachers working at least 16 weeks the previous year. 
Table 7: Comparisons of Cross-Border Counties, State with the Lower Minimum Black Teacher Salary (or 10th Percentile) Listed First

\begin{tabular}{|c|c|c|c|c|c|c|c|c|c|c|}
\hline \multirow[t]{2}{*}{$\begin{array}{l}\text { State } \\
\text { Border }\end{array}$} & \multicolumn{2}{|c|}{$\begin{array}{c}\text { Education } \\
\text { of Adults }\end{array}$} & \multirow[t]{2}{*}{ Farm } & \multirow[t]{2}{*}{ Urban } & \multicolumn{2}{|c|}{$\begin{array}{c}\text { Mean } \\
\text { Income }\end{array}$} & \multicolumn{2}{|c|}{$\begin{array}{l}\text { Upward } \\
\text { Mobility }\end{array}$} & \multirow[t]{2}{*}{$\begin{array}{l}\text { Coun- } \\
\text { ties }\end{array}$} & \multirow[t]{2}{*}{$\begin{array}{c}\text { Blacks } \\
16-18 \\
\end{array}$} \\
\hline & White & Black & & & White & Black & White & Black & & \\
\hline \multicolumn{11}{|c|}{ A. Borders between a Deep South State and a Peripheral South State } \\
\hline Alabama & 7.68 & 4.63 & 0.55 & 0.13 & 619 & 310 & 0.44 & 0.17 & 4 & 439 \\
\hline Florida & 7.44 & 4.82 & 0.45 & 0.12 & 642 & 330 & 0.47 & 0.31 & 5 & 249 \\
\hline AL-FL Gap & 0.24 & -0.19 & 0.09 & 0.01 & -23 & -20 & -0.03 & -0.14 & & \\
\hline Alabama & 7.57 & 4.34 & 0.68 & 0.17 & 635 & 257 & 0.37 & 0.19 & 2 & 546 \\
\hline Tennessee & 7.77 & 5.31 & 0.72 & 0.12 & 688 & 351 & 0.40 & 0.21 & 3 & 271 \\
\hline AL-TN Gap & -0.20 & -0.97 & -0.04 & 0.06 & -53 & -94 & -0.03 & -0.01 & & \\
\hline Arkansas & 8.72 & 5.08 & 0.63 & 0.14 & 930 & 332 & 0.51 & 0.22 & 4 & 970 \\
\hline Louisiana & 8.71 & 4.42 & 0.73 & 0.10 & 1004 & 355 & 0.62 & 0.22 & 5 & 830 \\
\hline AR-LA Gap & 0.01 & 0.65 & -0.10 & 0.04 & -74 & -23 & -0.11 & -0.00 & & \\
\hline Georgia & 8.10 & 4.15 & 0.51 & 0.14 & 796 & 319 & 0.49 & 0.21 & 8 & 508 \\
\hline Florida & 8.09 & 4.15 & 0.58 & 0.13 & 773 & 323 & 0.49 & 0.20 & 6 & 431 \\
\hline GA-FL Gap & 0.01 & 0.00 & -0.07 & 0.01 & 23 & -4 & 0.00 & 0.01 & & \\
\hline Louisiana & 8.43 & 4.47 & 0.50 & 0.23 & 971 & 404 & 0.61 & 0.23 & 6 & 1096 \\
\hline Texas & 8.36 & 5.51 & 0.63 & 0.16 & 812 & 348 & 0.59 & 0.32 & 6 & 685 \\
\hline LA-TX Gap & 0.07 & -1.04 & -0.13 & 0.07 & 159 & 56 & 0.02 & -0.07 & & \\
\hline Mississippi & 8.58 & 4.14 & 0.88 & 0.00 & 1007 & 264 & 0.38 & 0.05 & 3 & 1810 \\
\hline Arkansas & 8.05 & 4.72 & 0.77 & 0.10 & 870 & 300 & 0.38 & 0.15 & 4 & 1241 \\
\hline MS-AR Gap & 0.53 & -0.58 & 0.11 & -0.10 & 137 & -35 & 0.05 & -0.10 & & \\
\hline Mississippi & 8.25 & 5.06 & 0.81 & 0.06 & 480 & 230 & 0.43 & 0.11 & 5 & 466 \\
\hline Tennessee & 8.32 & 5.46 & 0.65 & 0.15 & 769 & 301 & 0.46 & 0.26 & 5 & 2031 \\
\hline MS-TN Gap & -0.07 & -0.40 & 0.17 & -0.09 & -290 & -72 & -0.03 & -0.15 & & \\
\hline S. Carolina & 7.77 & 4.64 & 0.57 & 0.14 & 887 & 384 & 0.46 & 0.24 & 9 & 1240 \\
\hline N. Carolina & 7.84 & 5.12 & 0.61 & 0.13 & 872 & 405 & 0.54 & 0.33 & 12 & 749 \\
\hline SC-NC Gap & -0.06 & -0.48 & -0.04 & 0.01 & 15 & -21 & -0.08 & -0.09 & & \\
\hline
\end{tabular}

Note: Table continues on the next page. 
Table 7: Comparisons of Cross-Border Counties, State with the Lower Minimum Black Teacher Salary (or 10th Percentile) Listed First - Table Continued

\begin{tabular}{|c|c|c|c|c|c|c|c|c|c|c|}
\hline \multirow[t]{2}{*}{$\begin{array}{l}\text { State } \\
\text { Border }\end{array}$} & \multicolumn{2}{|c|}{$\begin{array}{l}\text { Education } \\
\text { of Adults }\end{array}$} & \multirow[t]{2}{*}{ Farm } & \multirow[t]{2}{*}{ Urban } & \multicolumn{2}{|c|}{$\begin{array}{c}\text { Mean } \\
\text { Income }\end{array}$} & \multicolumn{2}{|c|}{$\begin{array}{l}\text { Upward } \\
\text { Mobility }\end{array}$} & \multirow[t]{2}{*}{$\begin{array}{c}\text { Coun- } \\
\text { ties }\end{array}$} & \multirow[t]{2}{*}{$\begin{array}{c}\text { Blacks } \\
16-18 \\
\end{array}$} \\
\hline & White & Black & & & White & Black & White & Black & & \\
\hline \multicolumn{11}{|c|}{ B. Borders Not between a Deep South State and a Peripheral South State } \\
\hline Arkansas & 7.73 & 6.06 & 0.62 & 0.09 & 545 & 373 & 0.42 & 0.28 & 4 & 141 \\
\hline Oklahoma & 7.14 & 5.57 & 0.55 & 0.03 & 509 & 280 & 0.43 & 0.23 & 2 & 326 \\
\hline AR-OK Gap & 0.58 & 0.49 & 0.07 & 0.05 & 36 & 93 & 0.00 & 0.05 & & \\
\hline Arkansas & 8.53 & 5.36 & 0.54 & 0.29 & 835 & 354 & 0.49 & 0.21 & 1 & 608 \\
\hline Texas & 8.85 & 6.12 & 0.62 & 0.14 & 833 & 332 & 0.55 & 0.34 & 2 & 924 \\
\hline AR-TX Gap & -0.32 & -0.76 & -0.08 & 0.15 & 2 & 22 & -0.06 & -0.13 & & \\
\hline Georgia & 7.78 & 4.56 & 0.57 & 0.21 & 792 & 351 & 0.47 & 0.21 & 13 & 453 \\
\hline Alabama & 7.54 & 4.50 & 0.69 & 0.12 & 778 & 295 & 0.40 & 0.17 & 9 & 593 \\
\hline GA-AL Gap & 0.24 & 0.06 & -0.12 & 0.09 & 14 & 56 & 0.07 & 0.04 & & \\
\hline Georgia & 8.37 & 4.52 & 0.60 & 0.21 & 865 & 322 & 0.50 & 0.20 & 11 & 816 \\
\hline S. Carolina & 8.61 & 4.30 & 0.64 & 0.07 & 902 & 299 & 0.55 & 0.18 & 9 & 978 \\
\hline GA-SC Gap & -0.25 & 0.22 & -0.04 & 0.15 & -37 & 22 & -0.05 & 0.02 & & \\
\hline Maryland & 8.09 & 5.67 & 0.40 & 0.16 & 857 & 455 & 0.60 & 0.51 & 4 & 333 \\
\hline Delaware & 8.90 & 5.66 & 0.48 & 0.15 & 1078 & 472 & 0.57 & 0.42 & 2 & 443 \\
\hline MD-DE Gap & -0.81 & 0.01 & -0.08 & 0.01 & -221 & -17 & 0.03 & 0.09 & & \\
\hline Mississippi & 8.61 & 5.10 & 0.65 & 0.11 & 627 & 293 & 0.51 & 0.18 & 8 & 548 \\
\hline Alabama & 7.92 & 4.99 & 0.57 & 0.16 & 693 & 360 & 0.41 & 0.23 & 6 & 794 \\
\hline MS-AL Gap & 0.69 & 0.11 & 0.09 & -0.05 & -65 & -67 & 0.10 & -0.05 & & \\
\hline Mississippi & 9.14 & 4.74 & 0.74 & 0.12 & 804 & 307 & 0.53 & 0.13 & 9 & 638 \\
\hline Louisiana & 8.92 & 3.94 & 0.72 & 0.12 & 941 & 291 & 0.58 & 0.15 & 8 & 572 \\
\hline MS-LA Gap & 0.22 & 0.80 & 0.02 & 0.00 & -137 & 17 & -0.05 & -0.02 & & \\
\hline Tennessee & 7.31 & 5.40 & 0.68 & 0.11 & 619 & 366 & 0.37 & 0.23 & 11 & 193 \\
\hline Kentucky & 7.42 & 5.68 & 0.66 & 0.11 & 568 & 300 & 0.37 & 0.24 & 15 & 134 \\
\hline TN-KY Gap & -0.11 & -0.27 & 0.02 & -0.01 & 51 & 66 & 0.00 & -0.01 & & \\
\hline Tennessee & 6.94 & 4.12 & 0.63 & 0.00 & 406 & 236 & 0.25 & 0.02 & 1 & 171 \\
\hline Missouri & 6.96 & 4.94 & 0.70 & 0.00 & 528 & 281 & 0.35 & 0.18 & 1 & 415 \\
\hline TN-MO Gap & -0.02 & -0.83 & -0.07 & 0.00 & -122 & -46 & -0.10 & -0.15 & & \\
\hline Virginia & 8.17 & 4.81 & 0.54 & 0.01 & 981 & 476 & 0.58 & 0.26 & 7 & 346 \\
\hline Maryland & 8.16 & 5.31 & 0.41 & 0.22 & 973 & 402 & 0.59 & 0.49 & 4 & 419 \\
\hline VA-MD Gap & 0.01 & -0.51 & 0.14 & -0.21 & 8 & 73 & -0.00 & -0.23 & & \\
\hline Virginia & 7.47 & 4.54 & 0.75 & 0.04 & 856 & 383 & 0.46 & 0.21 & 10 & 779 \\
\hline N. Carolina & 8.05 & 5.11 & 0.69 & 0.07 & 938 & 409 & 0.58 & 0.28 & 11 & 745 \\
\hline VA-NC Gap & -0.59 & -0.57 & 0.05 & -0.03 & -87 & -26 & -0.12 & -0.06 & & \\
\hline
\end{tabular}

Note: Authors' analysis, 1940 U.S. Census. Summary statistics are displayed for border county pairs for which the difference in the average educational attainment of whites aged $25-55$ is less than one year. We list cases with at least 100 black 16-18 year olds on each side of the border. "Upward mobility" is the fraction of 16-18 year olds attaining 9th grade in families with parental education 5-8. 37 
Table 8: Effect of Teacher Salaries on Educational Attainment among Black Children, Border County Analysis

\begin{tabular}{lccccccc}
\hline \hline & First & Reduced & & & & & \\
& OLS & Stage & Form & 2SLS & F-Stat & $n$ & $n_{c}$ \\
\hline
\end{tabular}

\section{A. Effects on Years of Schooling}

\begin{tabular}{lccccccc}
\hline 1. Baseline & $0.285^{* * *}$ & $0.800^{* * *}$ & $0.265^{* * *}$ & $0.331^{* * *}$ & 66.8 & 207 & 28 \\
& $(0.057)$ & $(0.097)$ & $(0.061)$ & $(0.064)$ & & & \\
2. Rural Areas & $0.327^{* * *}$ & $0.814^{* * *}$ & $0.295^{* * *}$ & $0.362^{* * *}$ & 65.9 & 206 & 28 \\
& $(0.074)$ & $(0.100)$ & $(0.076)$ & $(0.080)$ & & & \\
\hline
\end{tabular}

B. Effects on 9th Grade Attainment

\begin{tabular}{lccccccc}
\hline 1. Baseline & $0.012^{* *}$ & $0.845^{* * *}$ & 0.012 & $0.014^{*}$ & 69.0 & 208 & 28 \\
& $(0.005)$ & $(0.102)$ & $(0.008)$ & $(0.009)$ & & & \\
2. Rural Areas & 0.010 & $0.860^{* * *}$ & $0.016^{*}$ & $0.018^{* *}$ & 66.4 & 207 & 28 \\
& $(0.007)$ & $(0.105)$ & $(0.008)$ & $(0.009)$ & & &
\end{tabular}

Note: Author's analysis, 1940 Census and state administrative records. The sample is restricted to county border pairs for which the difference in the education of whites is less than one year, there are at least five black individuals aged 16-18 in each county, and at least one black teacher in each county in the 1940 Census. Our instrument is the mandated minimum salary (or the 10th percentile of earnings for states with no minimum salary). Teacher salaries are measured from the Census. Controls include differences between counties in high schools, Rosenwald Fund exposure, fraction urban, fraction living on farm, average black parental income and education, and average education of whites. $n$ gives the number of border pairs; $n_{c}$ is the number of borders. Standard errors (in parentheses) are clustered at the border level; ${ }^{* * *} p<0.01$, ${ }^{* *} p<0.05,{ }^{*} p<0.10$. 
Table 9: Effect of Teacher Salaries on Years of Education among White Children, Border County Analysis

\begin{tabular}{lccccccc}
\hline \hline & First & Reduced & & & & & \\
& OLS & Stage & Form & 2SLS & F-Stat & $n$ & $n_{c}$ \\
\hline
\end{tabular}

A. Effects on Years of Schooling (Parental Education 0-4 Grades)

\begin{tabular}{|c|c|c|c|c|c|c|c|}
\hline 1. Baseline & $\begin{array}{c}0.149 * * \\
(0.059)\end{array}$ & $\begin{array}{c}0.477^{* * *} \\
(0.085)\end{array}$ & $\begin{array}{c}0.114^{* *} \\
(0.053)\end{array}$ & $\begin{array}{c}0.238^{* *} \\
(0.110)\end{array}$ & 31.4 & 269 & 32 \\
\hline 2. Rural Areas & $\begin{array}{c}0.138^{* * *} * \\
(0.059)\end{array}$ & $\begin{array}{c}0.483^{* * *} \\
(0.085)\end{array}$ & $\begin{array}{c}0.111^{* *} \\
(0.053)\end{array}$ & $\begin{array}{c}0.231^{* *} \\
(0.103)\end{array}$ & 32.3 & 269 & 32 \\
\hline
\end{tabular}

B. Effects on Years of Schooling (Parental Education 5-8 Grades)

\begin{tabular}{lccccccc}
\hline 1. Baseline & $0.098^{* * *}$ & $0.483^{* * *}$ & 0.054 & 0.112 & 30.1 & 269 & 32 \\
& $(0.033)$ & $(0.088)$ & $(0.050)$ & $(0.095)$ & & & \\
2. Rural Areas & $0.102^{* * *}$ & $0.488^{* * *}$ & 0.060 & 0.123 & 30.8 & 269 & 32 \\
& $(0.035)$ & $(0.087)$ & $(0.050)$ & $(0.092)$ & & & \\
\hline
\end{tabular}

C. Effects on 9th Grade Attainment (Parental Education 5-8 Grades)

\begin{tabular}{lccccccc}
\hline \multirow{2}{*}{ 1. Baseline } & $0.009^{* *}$ & $0.477^{* * *}$ & $0.012^{* *}$ & $0.027^{* *}$ & 29.1 & 270 & 32 \\
& $(0.004)$ & $(0.088)$ & $(0.005)$ & $(0.010)$ & & & \\
2. Rural Areas & $0.009^{*}$ & $0.486^{* * *}$ & $0.014^{* * *}$ & $0.029^{* * *}$ & 31.2 & 269 & 32 \\
& $(0.005)$ & $(0.087)$ & $(0.005)$ & $(0.010)$ & & &
\end{tabular}

Note: Author's analysis, 1940 Census. The sample is restricted to county border pairs for which the difference in the education of whites is less than one year. Our instrument is the mandated minimum salary (or the 10th percentile of earnings for states with no minimum salary). Teacher salaries are measured from the Census. Controls include differences between counties in fraction urban, fraction living on farm, average parental income of whites, and average education of whites. $n$ gives the number of border pairs; $n_{c}$ is the number of borders. Standard errors (in parentheses) are clustered at the border level; ${ }^{* * *} p<0.01,{ }^{* *} p<0.05$, $* p<0.10$. 
Figure 1: Relationship between Parent and Child Education, Children Aged 16-18 in 1940, by Race

Panel A. Differences among Black and White Children by Gender

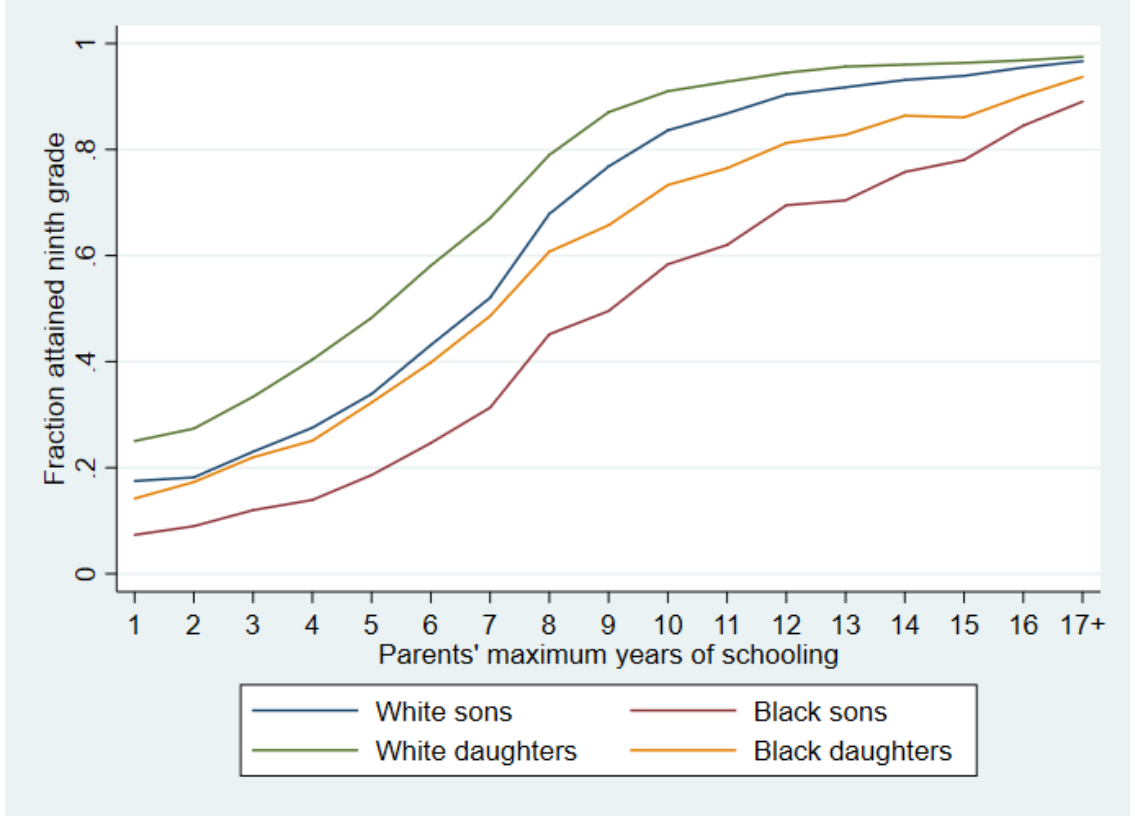


Panel B. Regional Differences for White Daughters

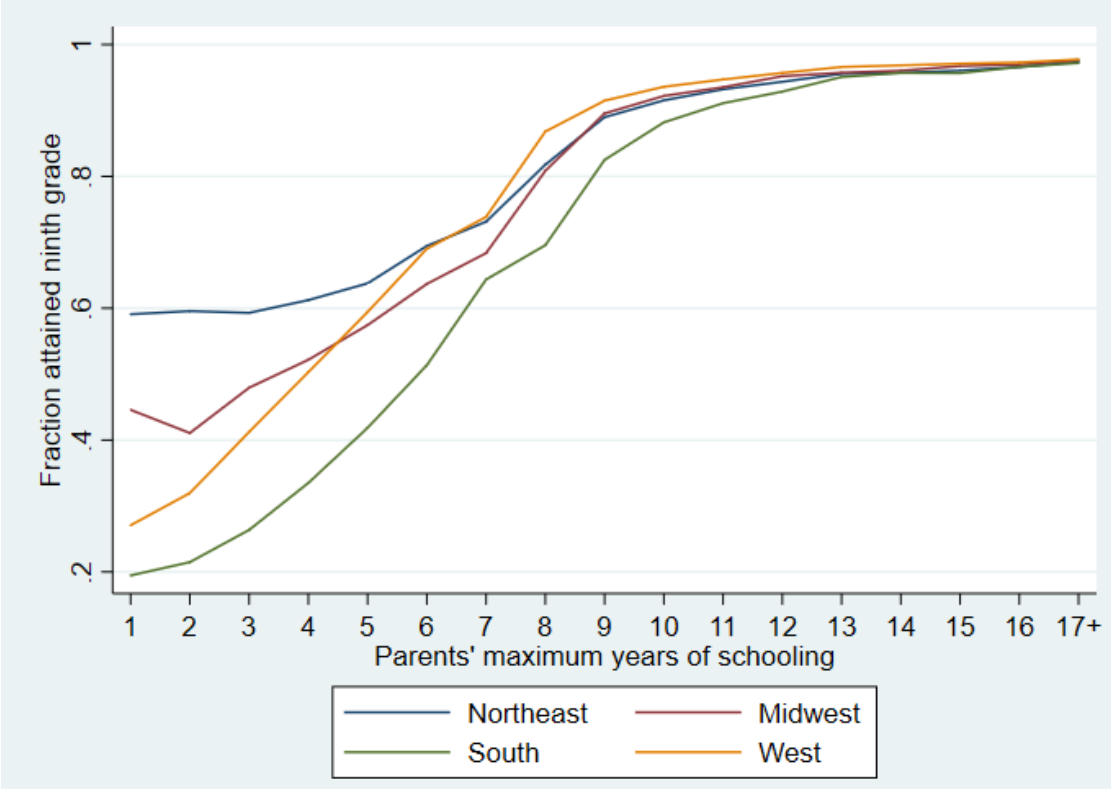

Panel C. Regional Differences for White Sons

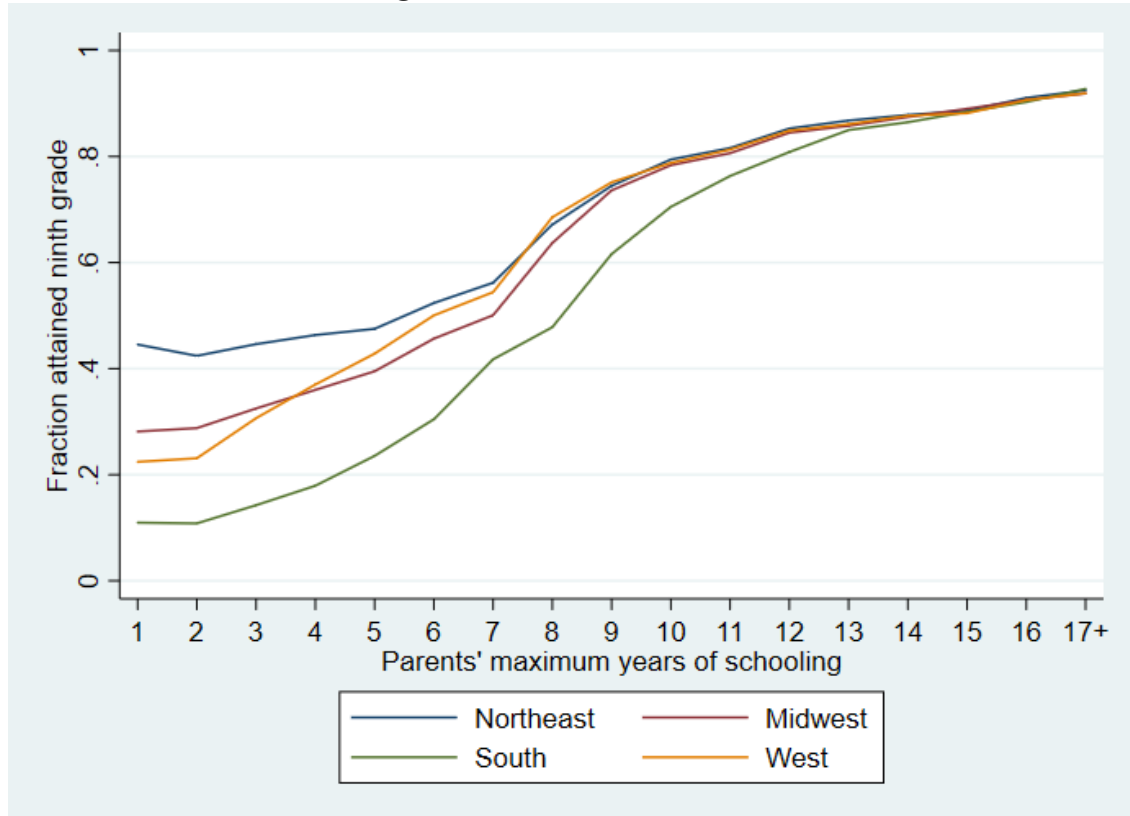


Panel D. Racial Differences in the South for Daughters

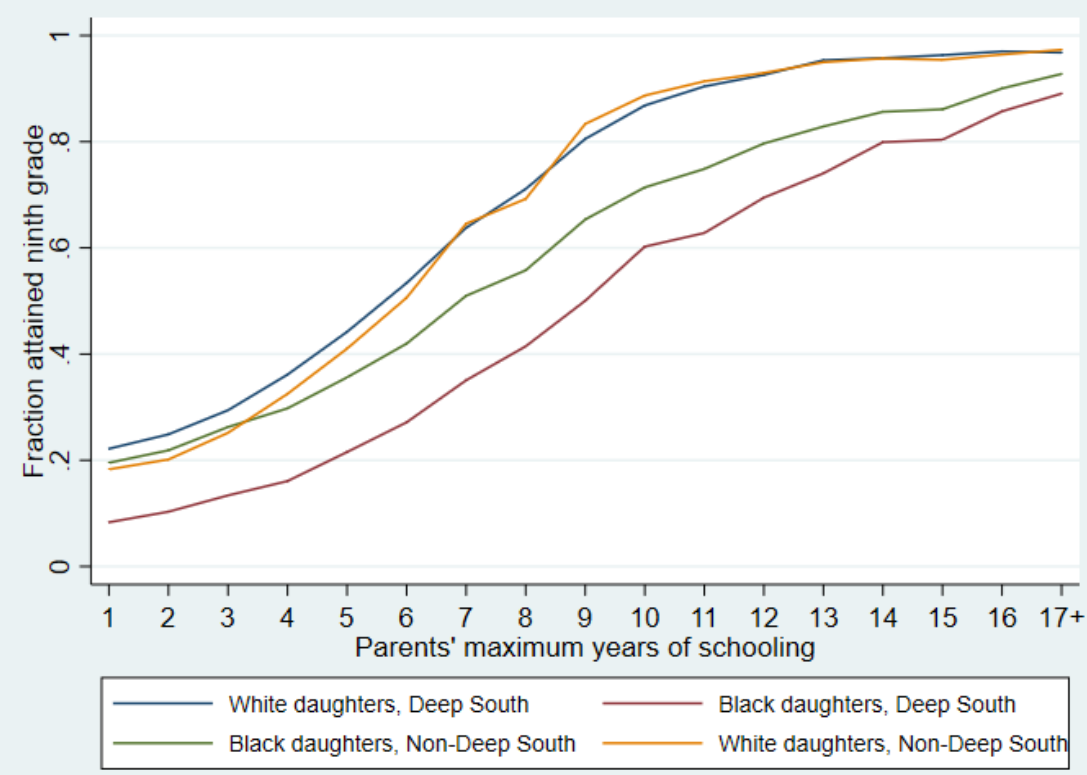

Panel E. Racial Differences in the South for Sons

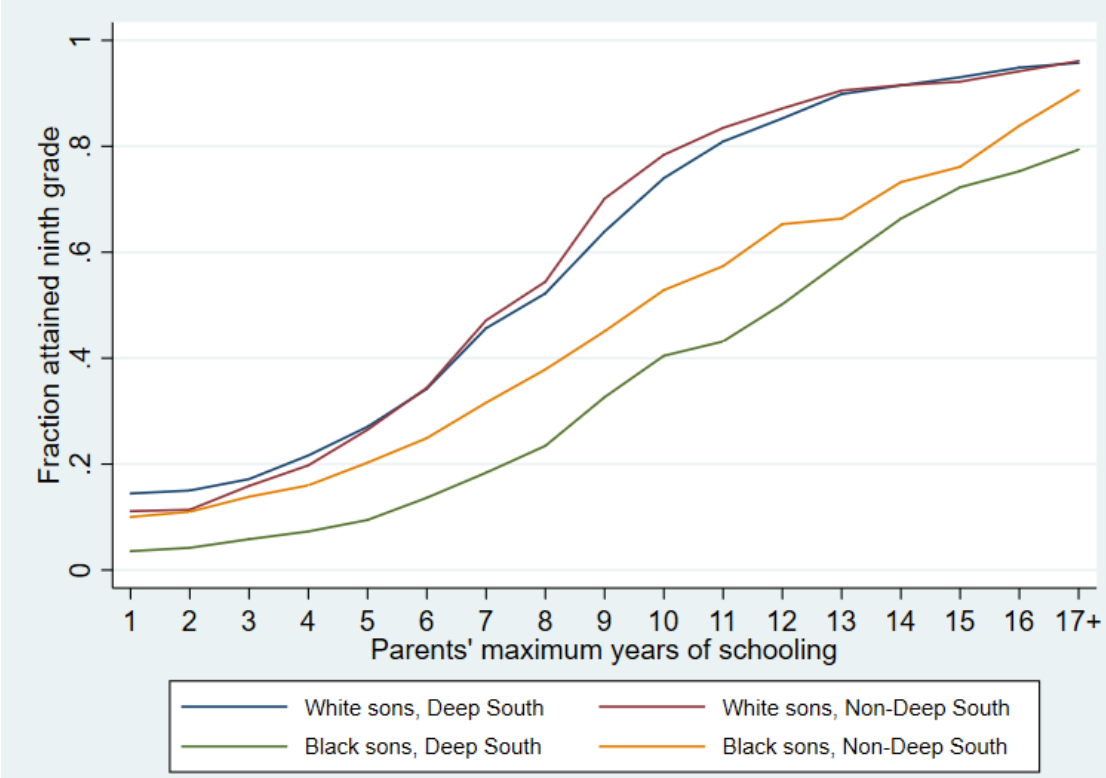


Panel F. Differences among Immigrant and Native-Born Families

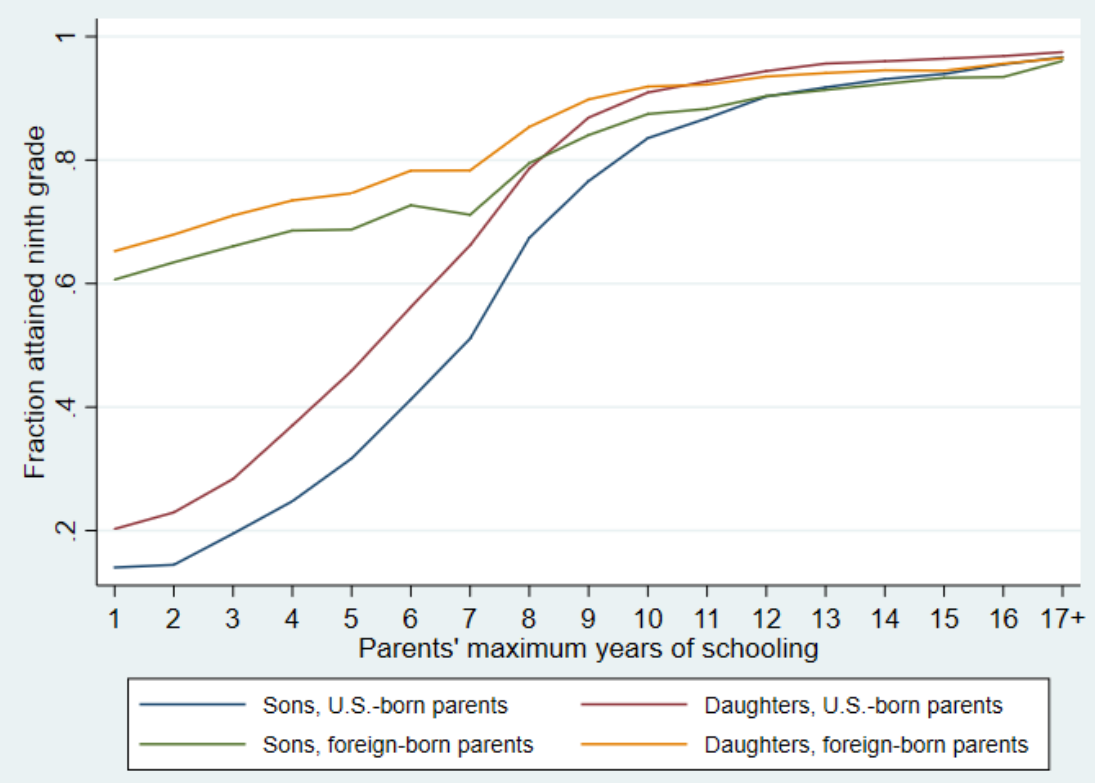

Panel G. Differences among Immigrants by Region

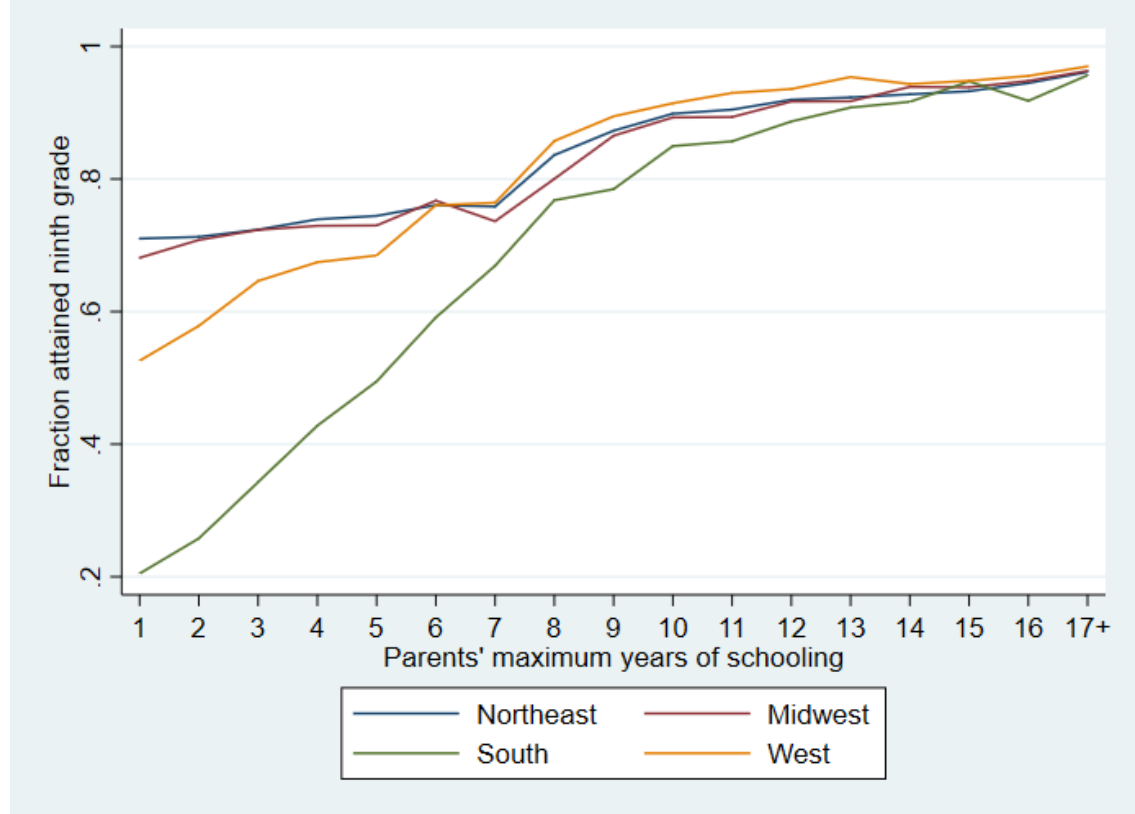


Figure 2: Upward Mobility for Children Aged 16-18 in 1940, by Region

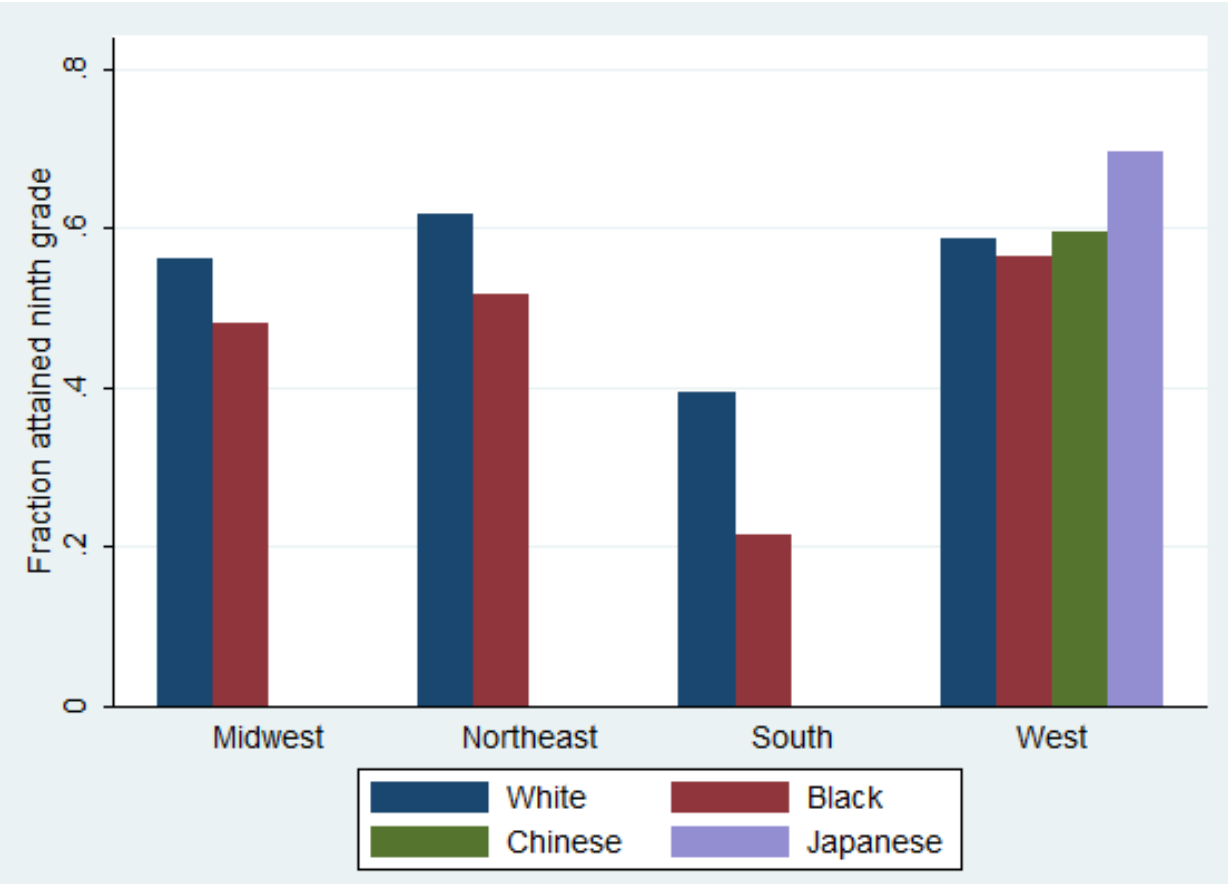


Figure 3: Proportion with 9+ Grades of Education, Children Aged 16-18 whose Parents Have 5-8 Years of Education

Panel A. Upward Mobility for White Daughters by State

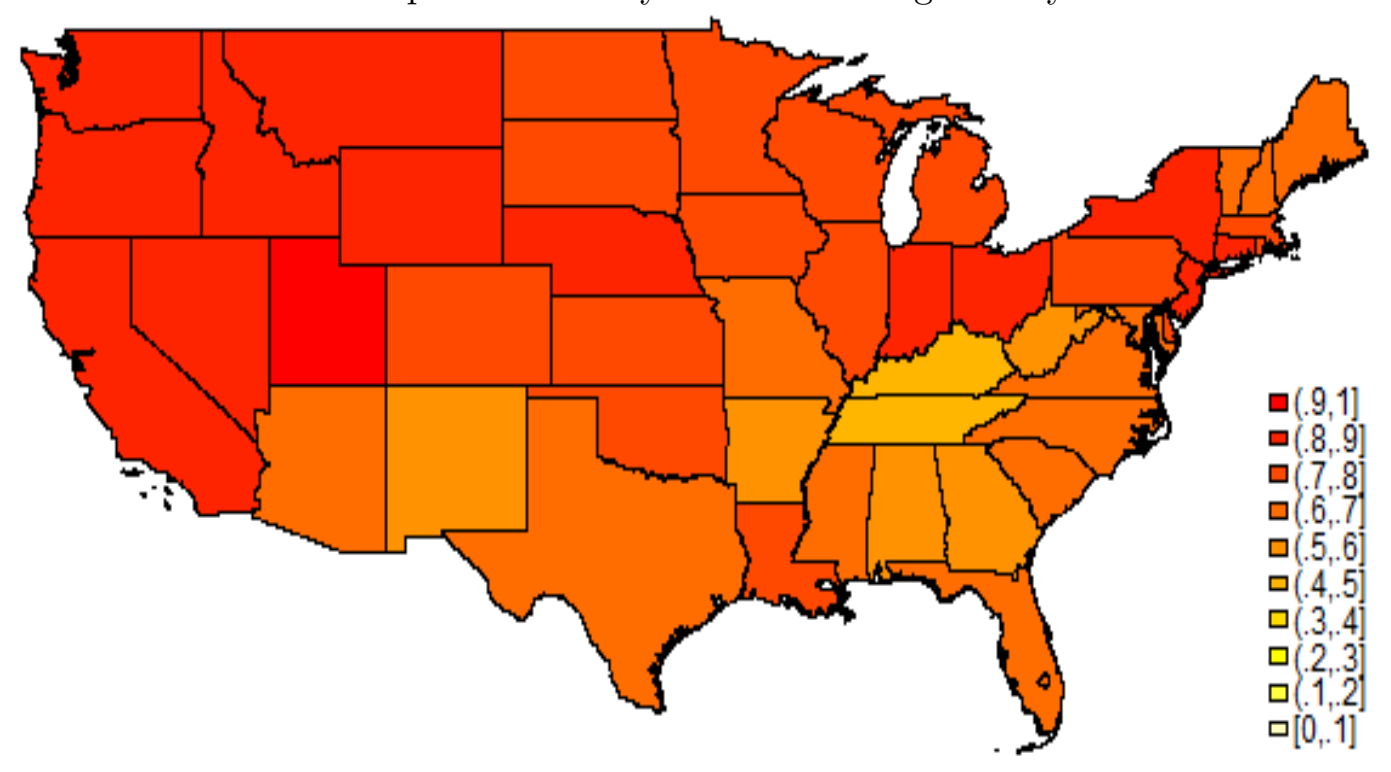

Panel B. Upward Mobility for White Sons by State

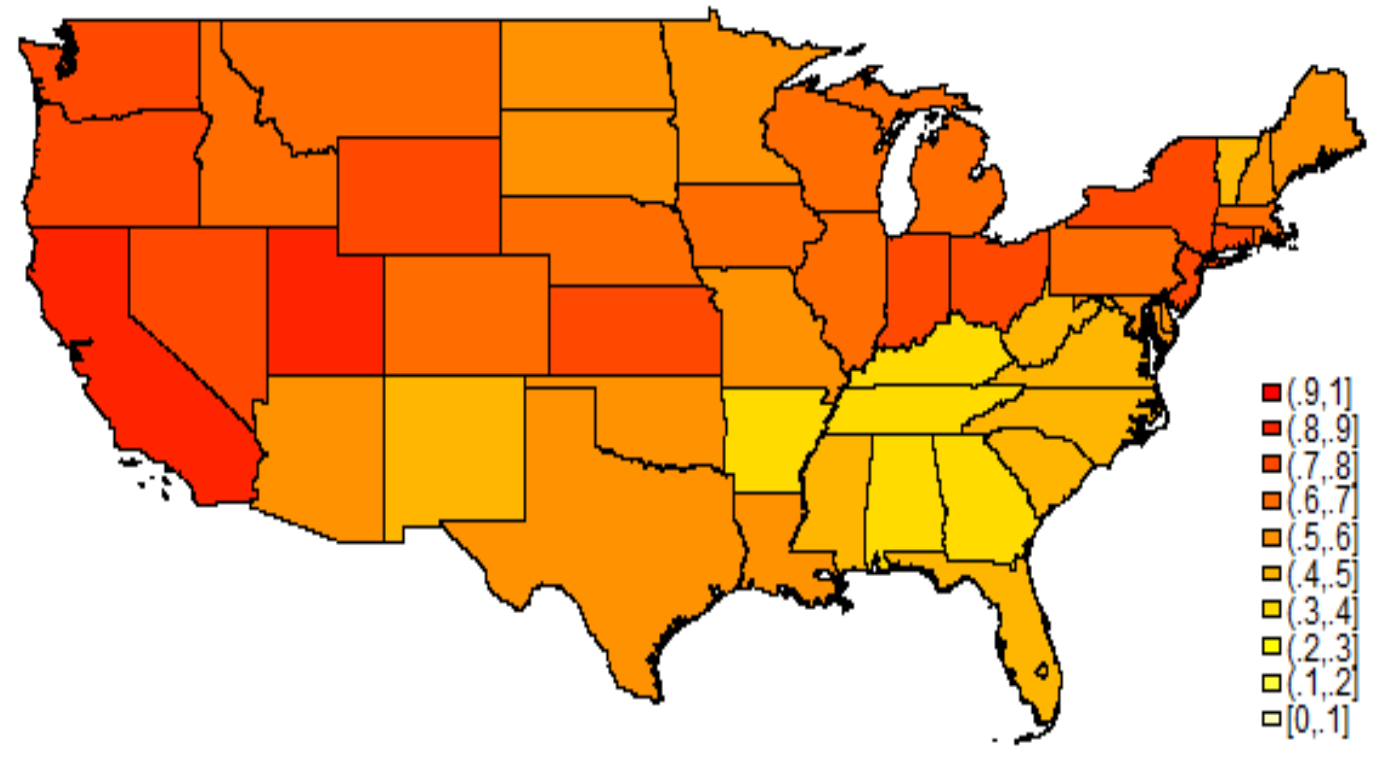


Panel C. Upward Mobility for Black Daughters by State

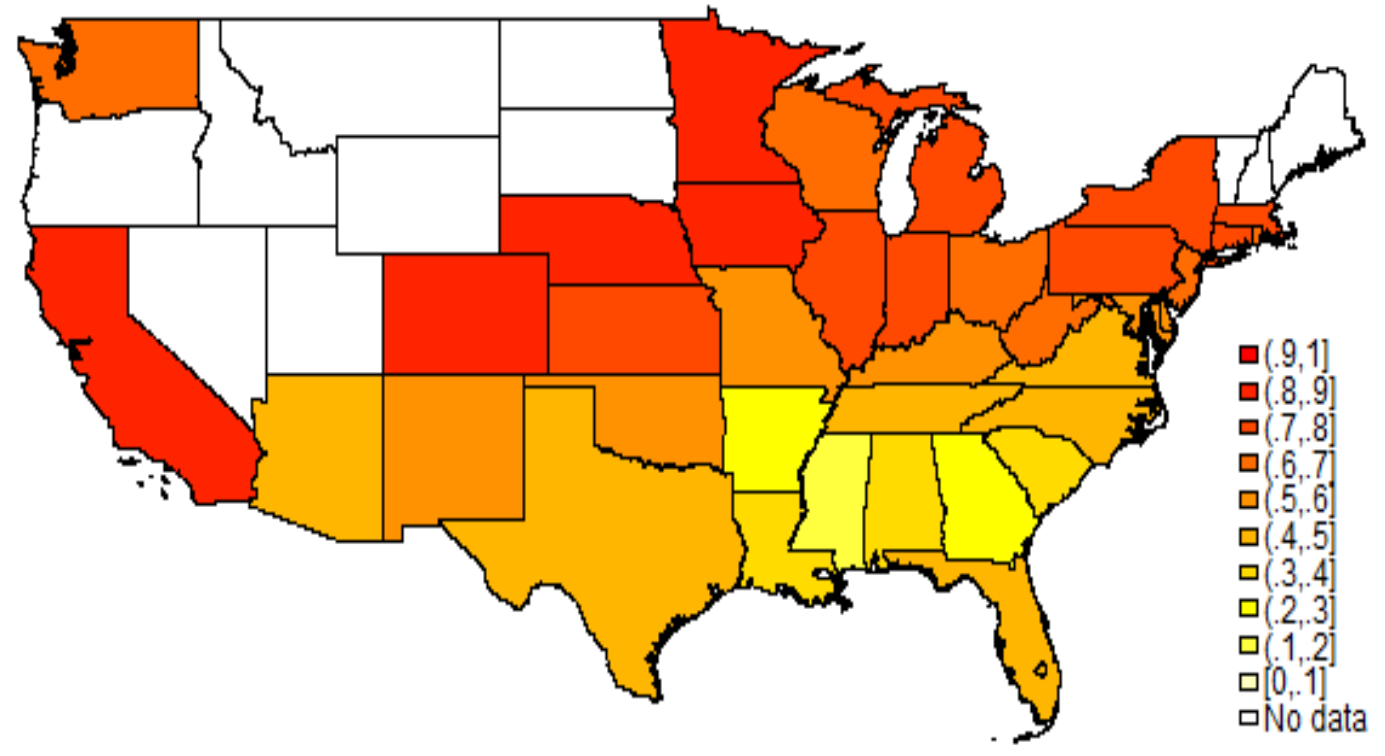

Panel D. Upward Mobility for Black Sons by States

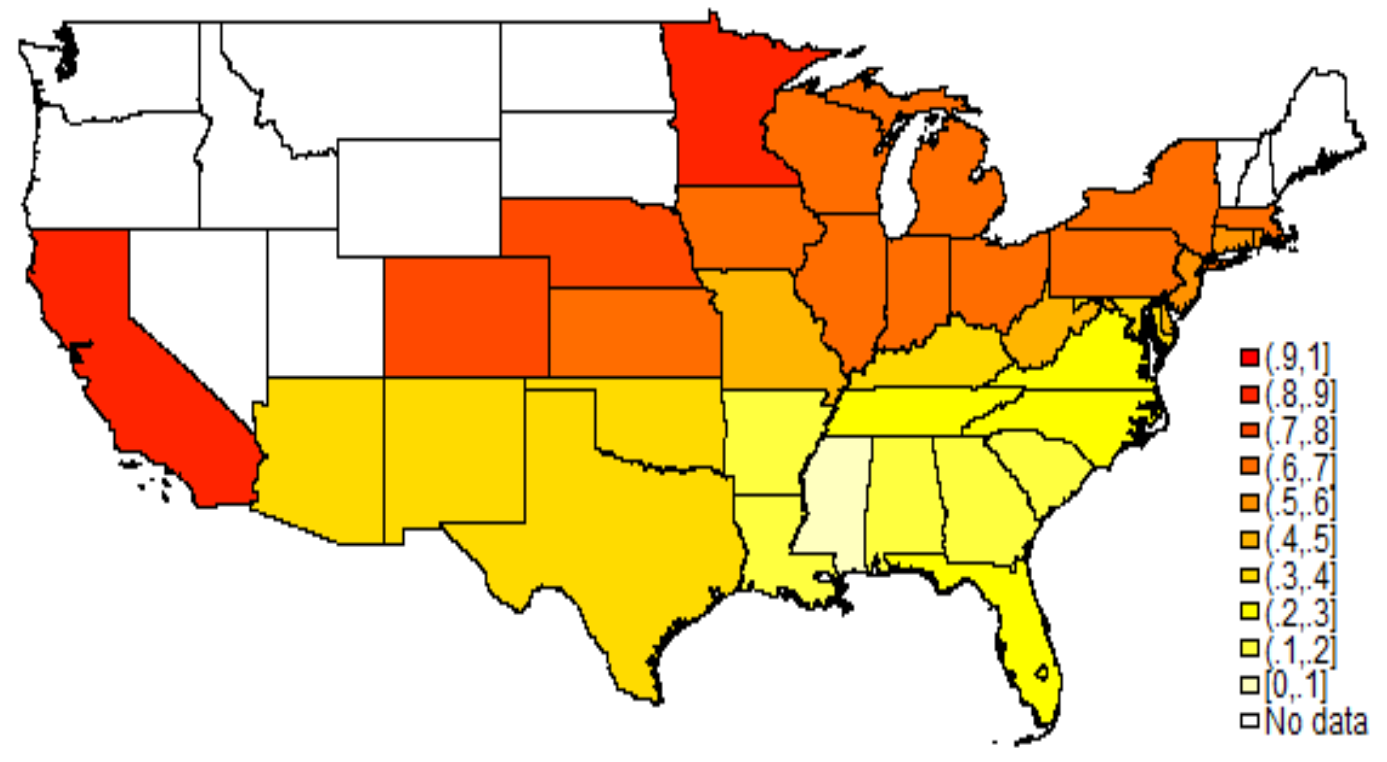


Figure 4: The Geography of Upward Mobility at the County Level

A. Upward Mobility in Education, 1922-26 Birth Cohorts

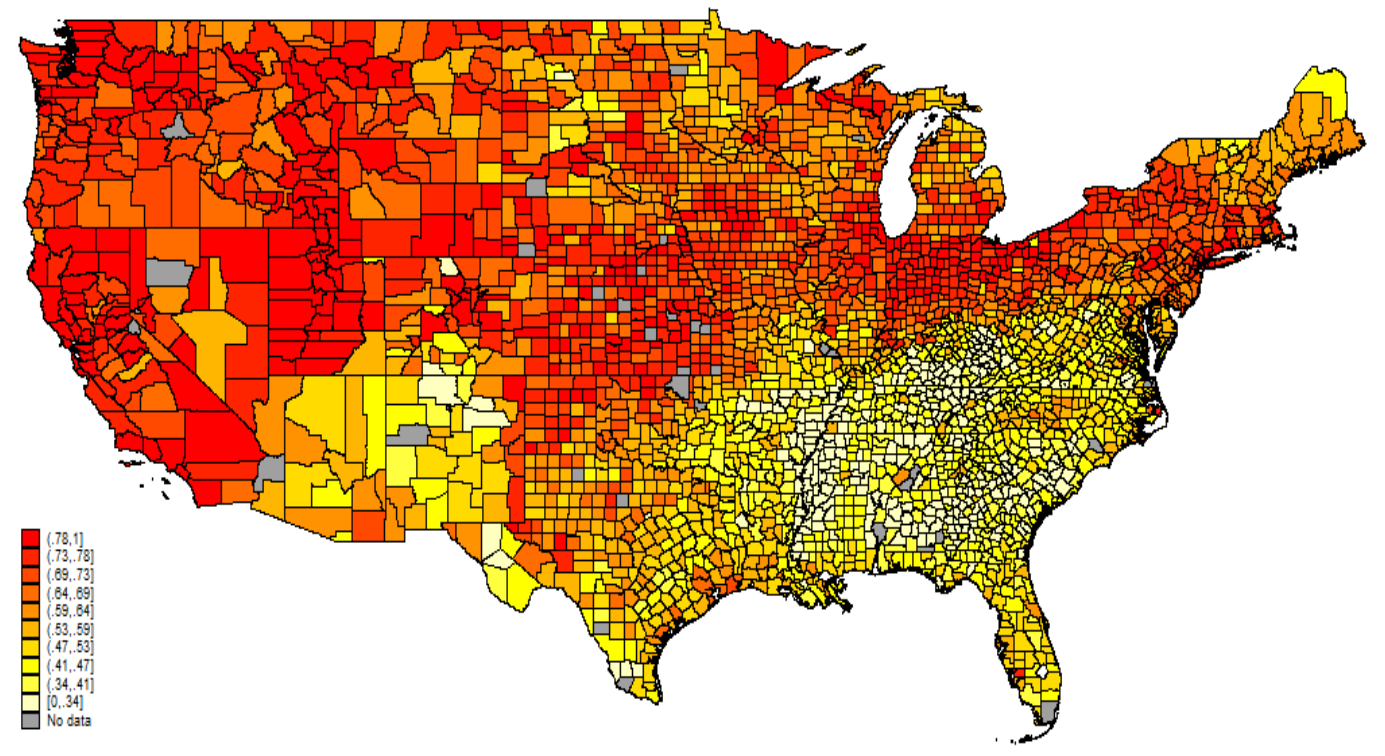

B. Upward Mobility in Income, 1980-93 Birth Cohorts (Chetty et al., 2014a)

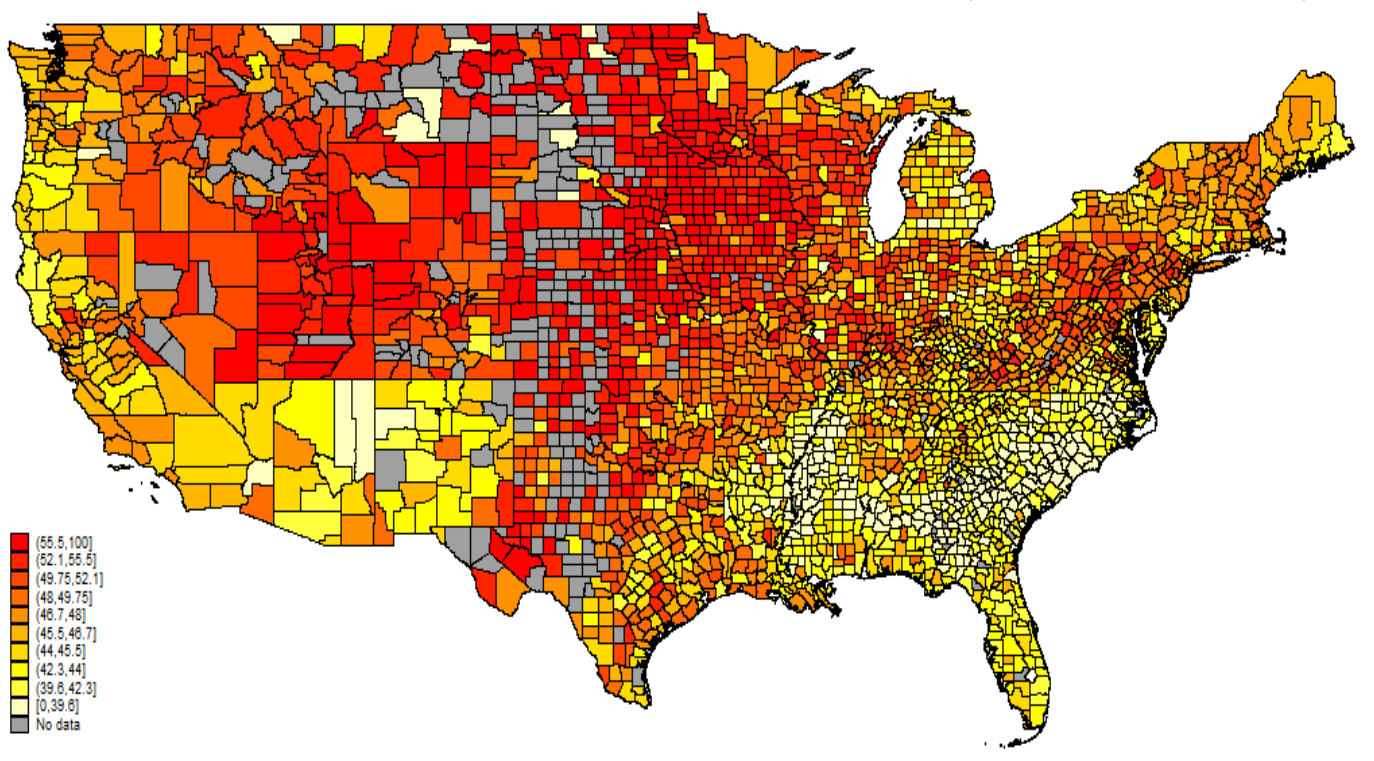


C. Upward Mobility in Education, 1922-26 Birth Cohorts, Black Families

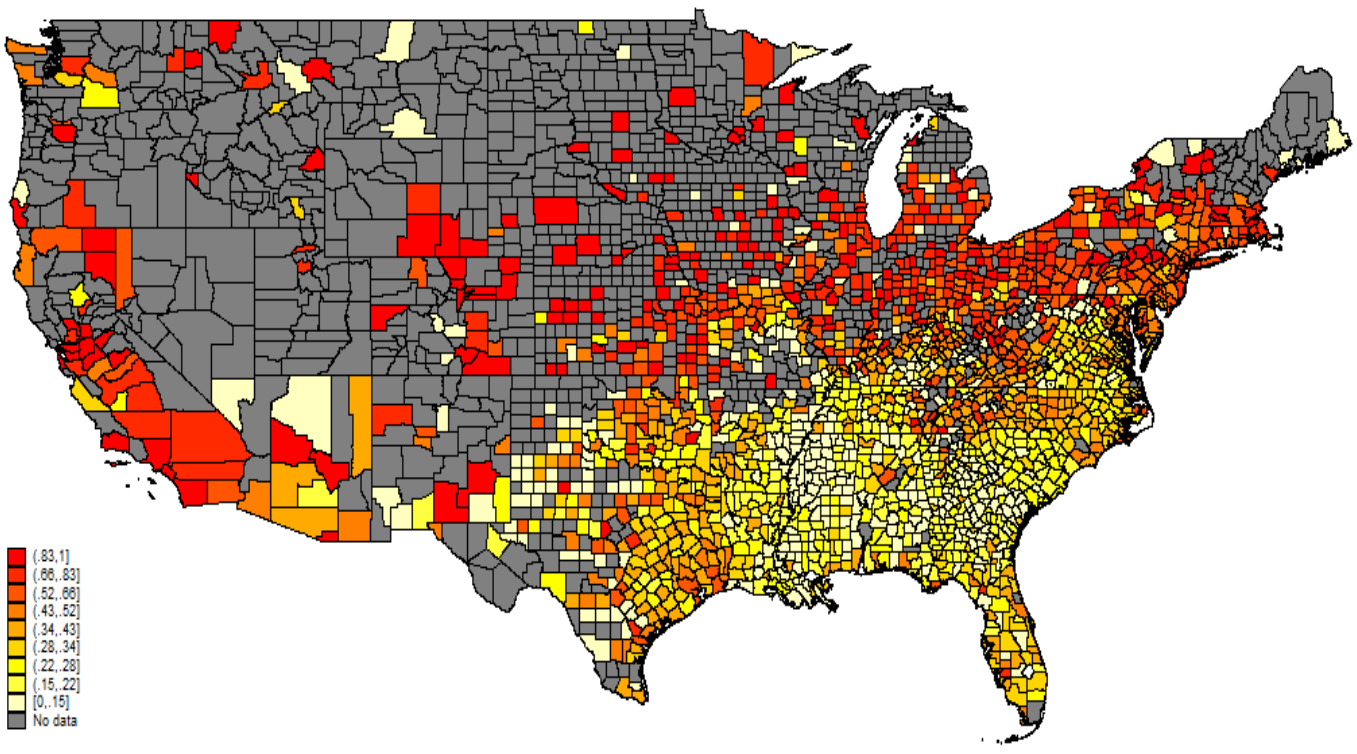

D. Upward Mobility in Education, 1922-26 Birth Cohorts, White Families

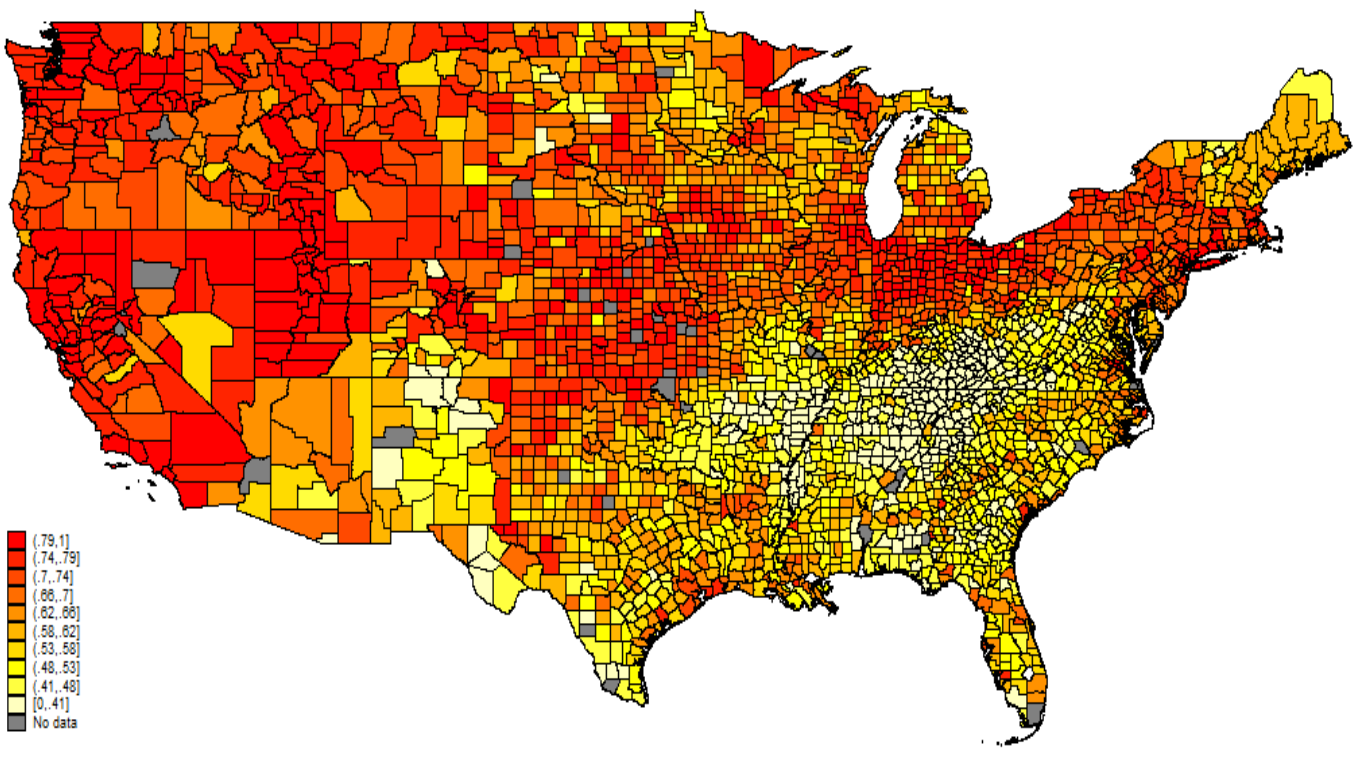


Figure 5: Relationship between Upward Mobility in Education and School Quality Measures

Panel A. White Daughters
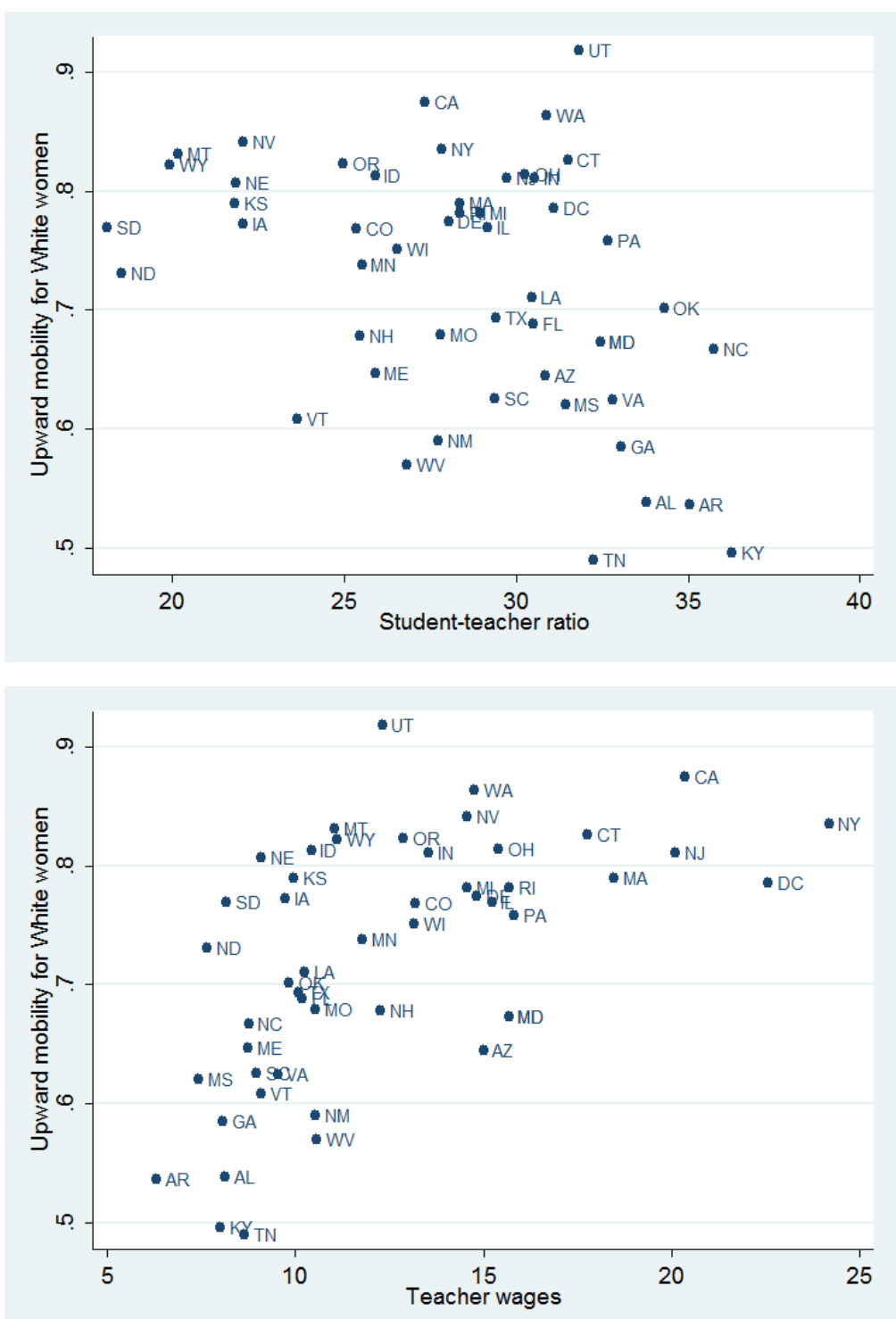
Panel B. White Sons
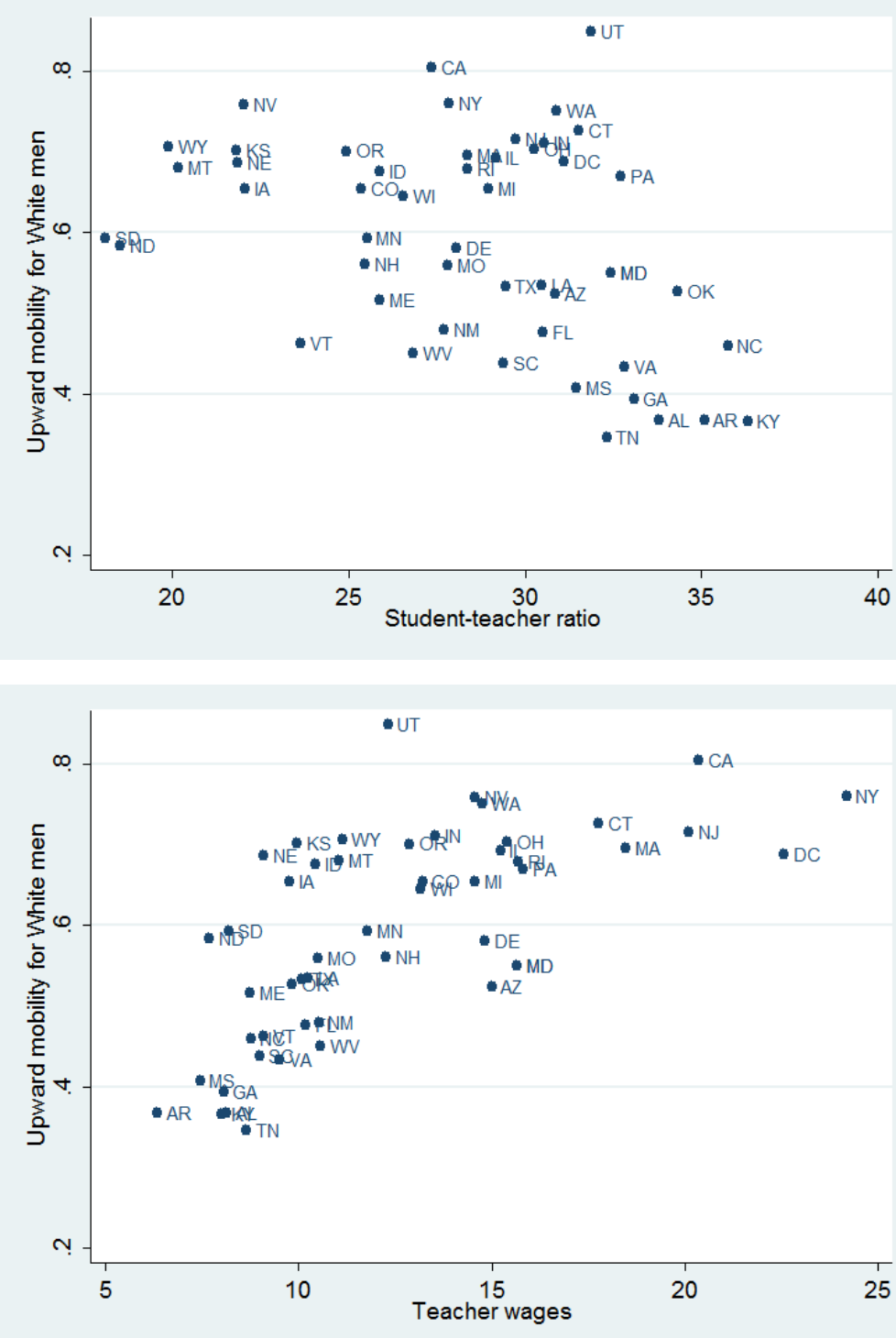
Panel C. Black Daughters in Southern States
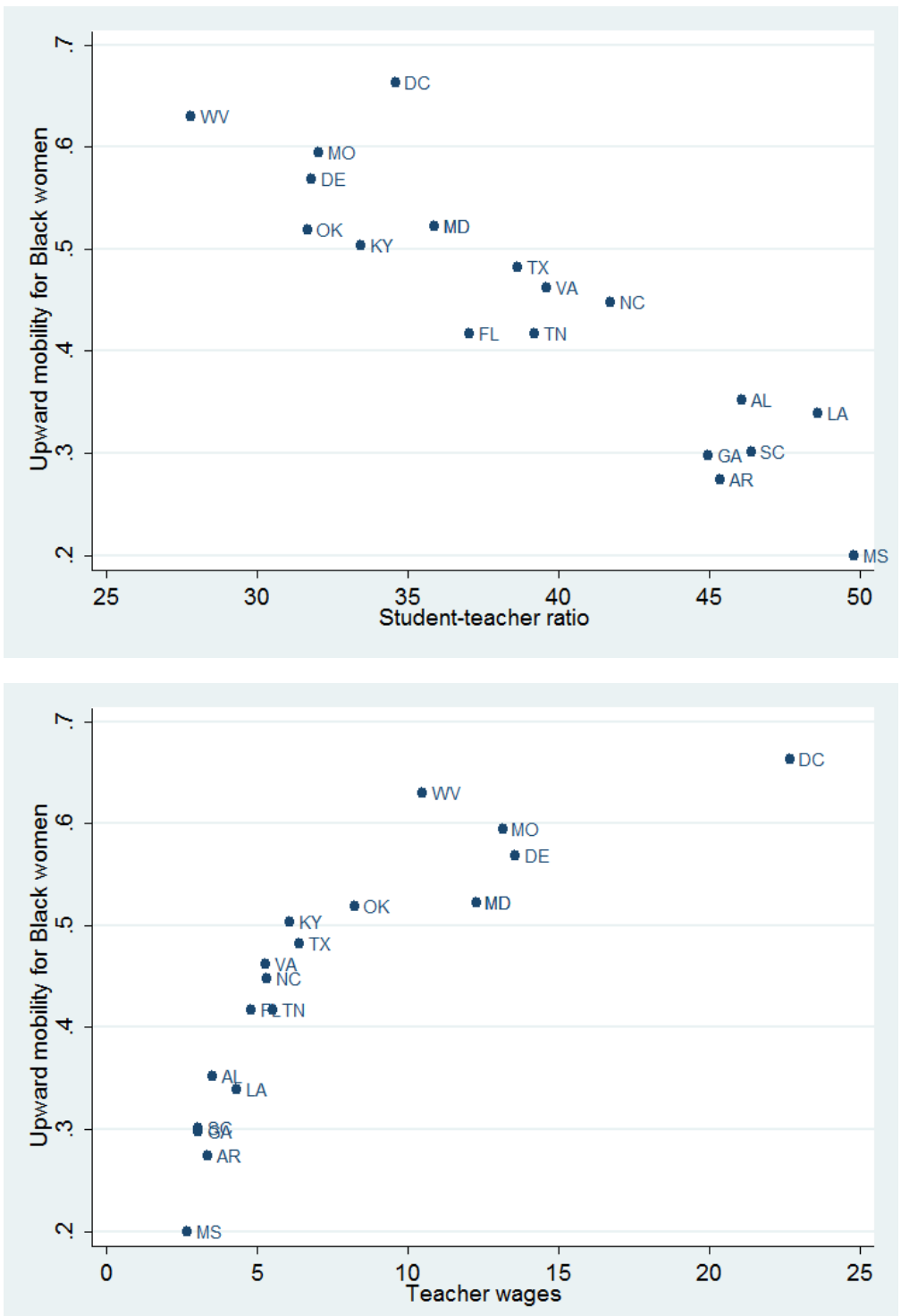
Panel D. Black Sons in Southern States
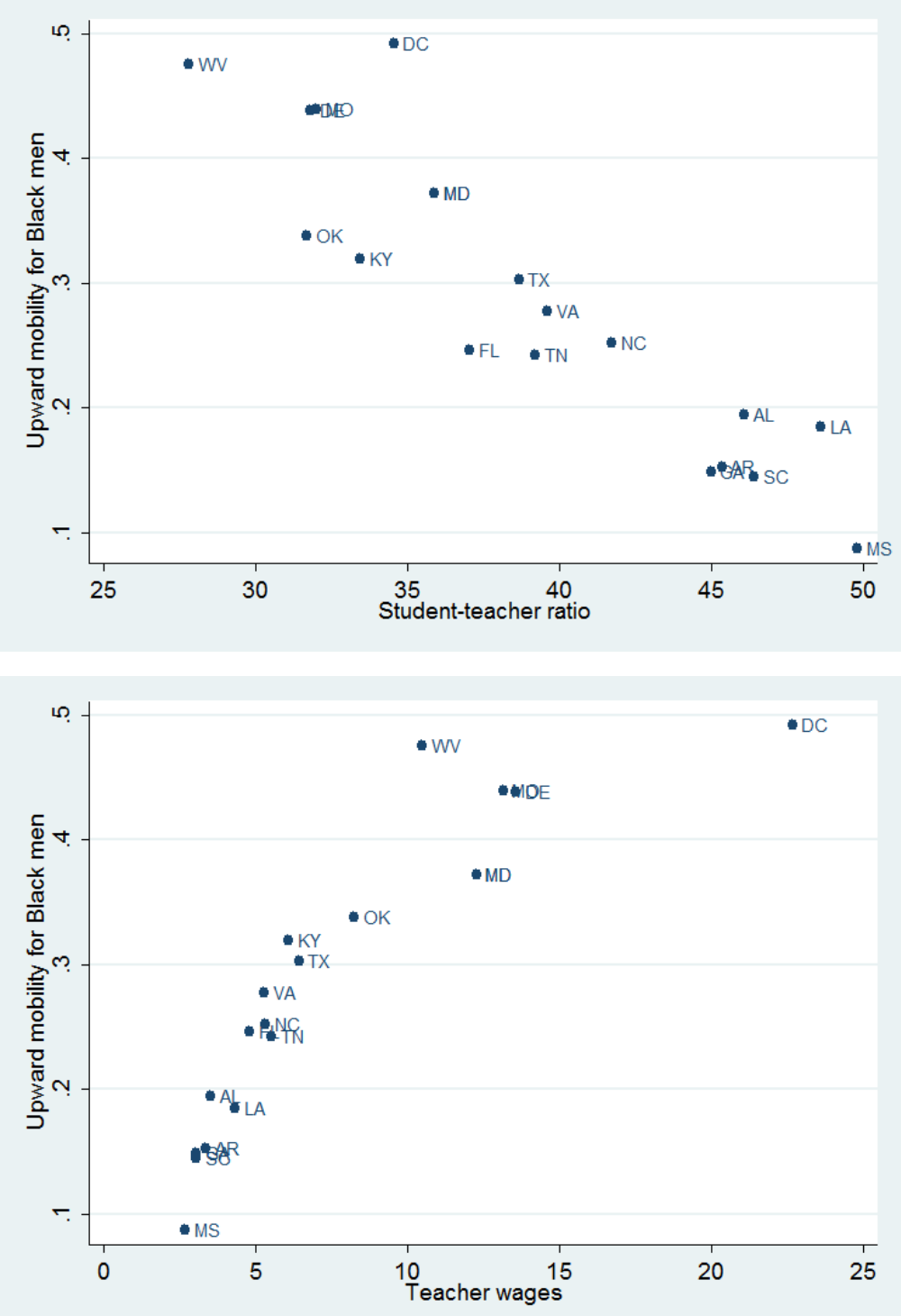
Figure 6: Educational Choice as School Quality Increases-MR $(E)$ Shifts Upward

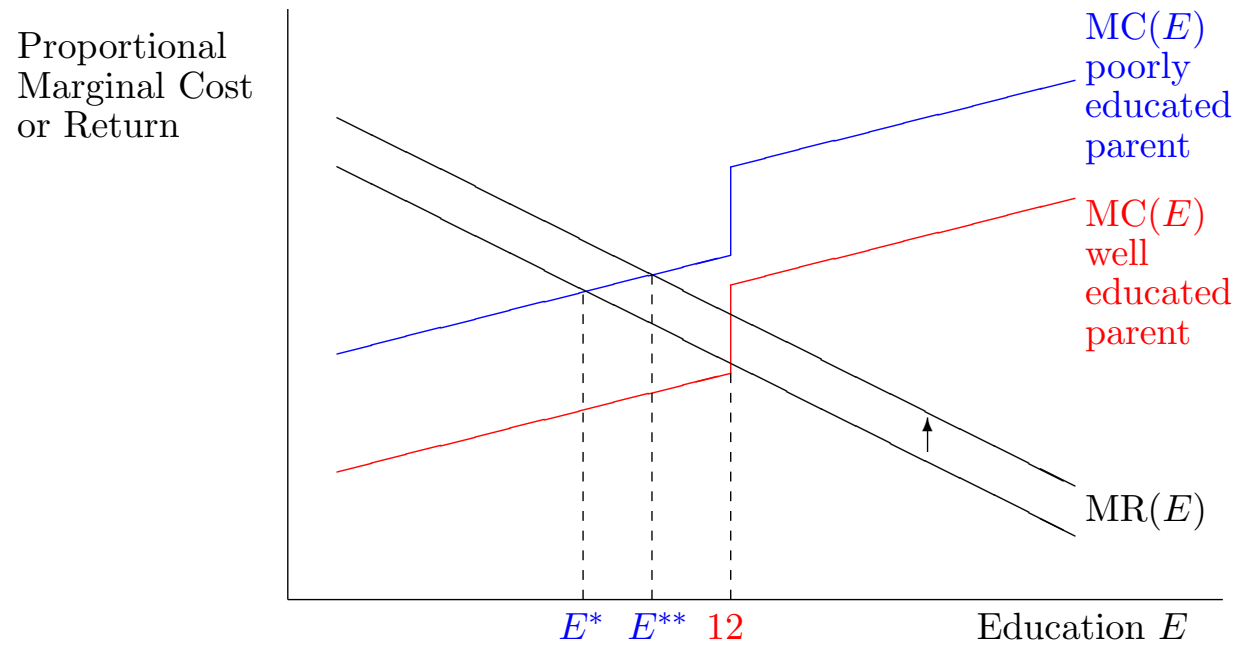


Figure 7: Proportion of Individuals Aged 5 to 20 Living with a Parent and Enrolled in School

Panel A. White Daughters

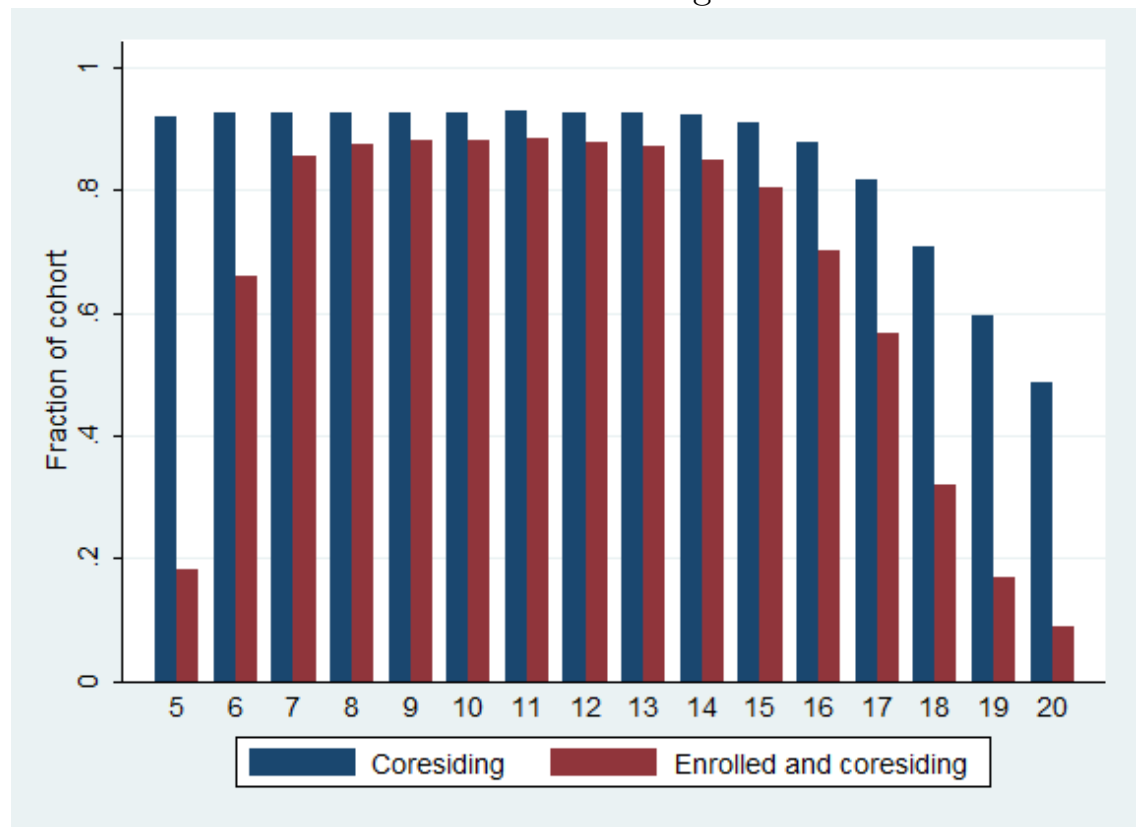

Panel B. White Sons

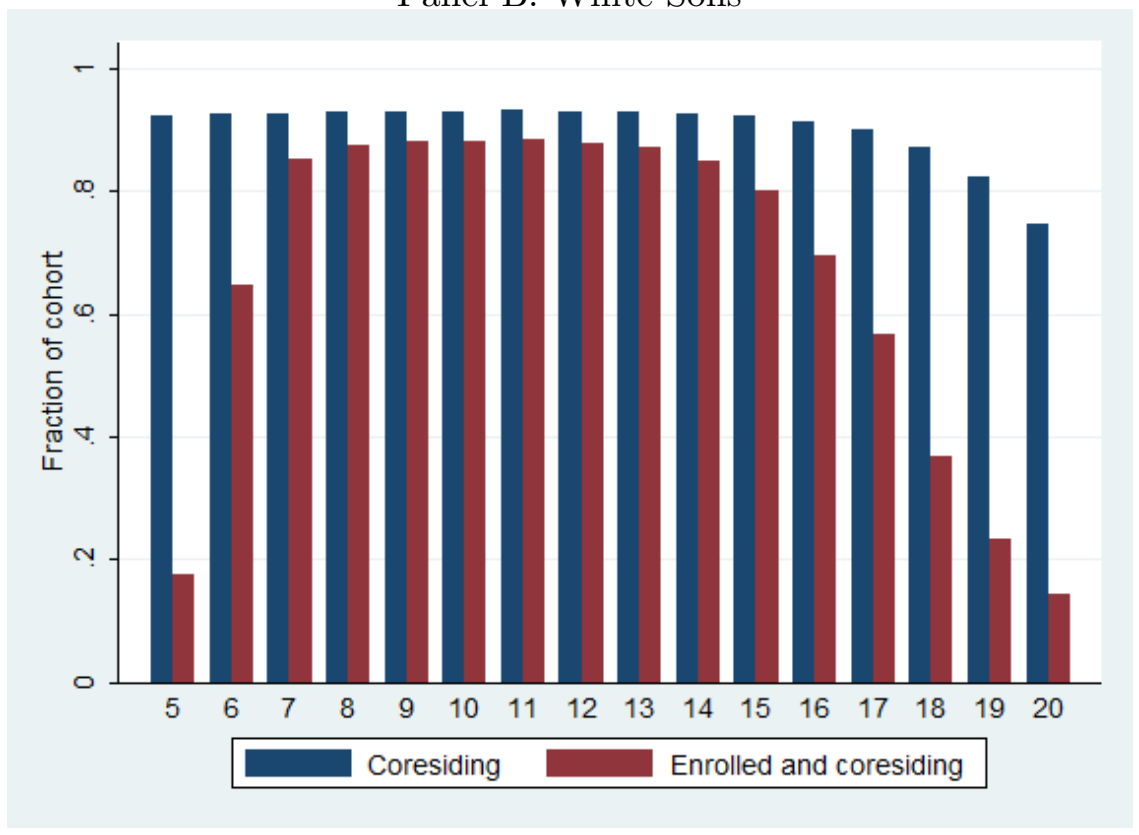


Panel C. Black Daughters

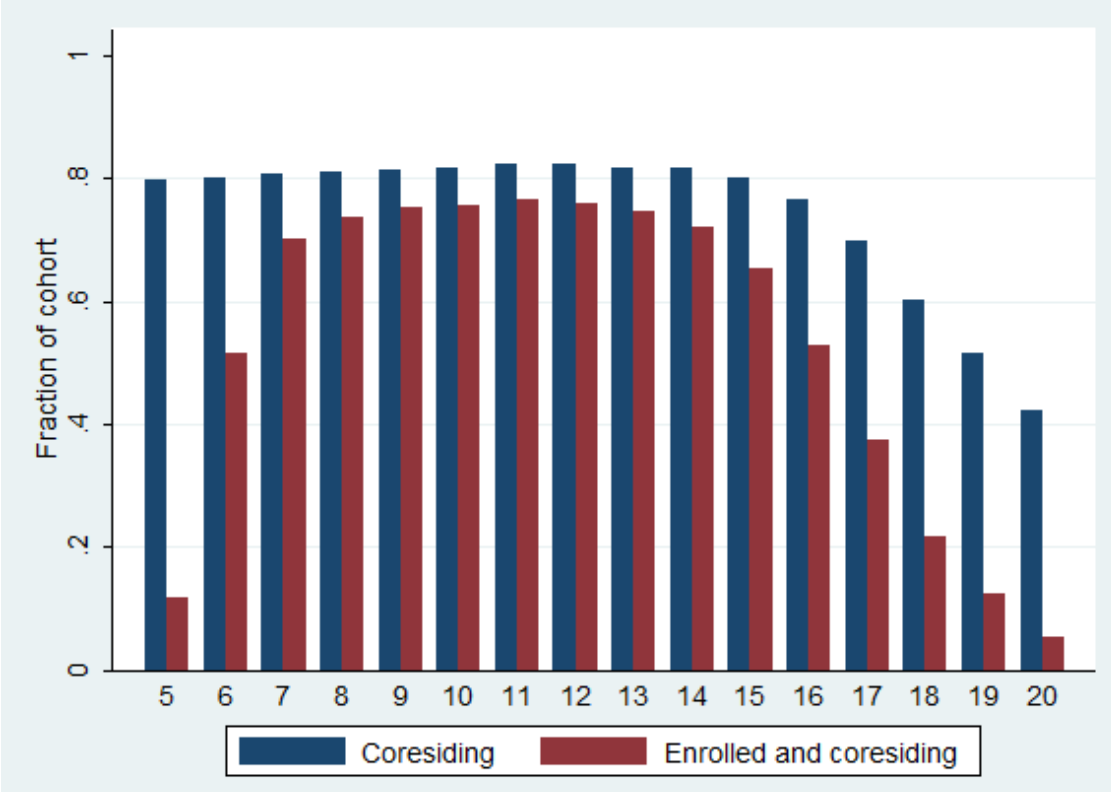

Panel D. Black Sons

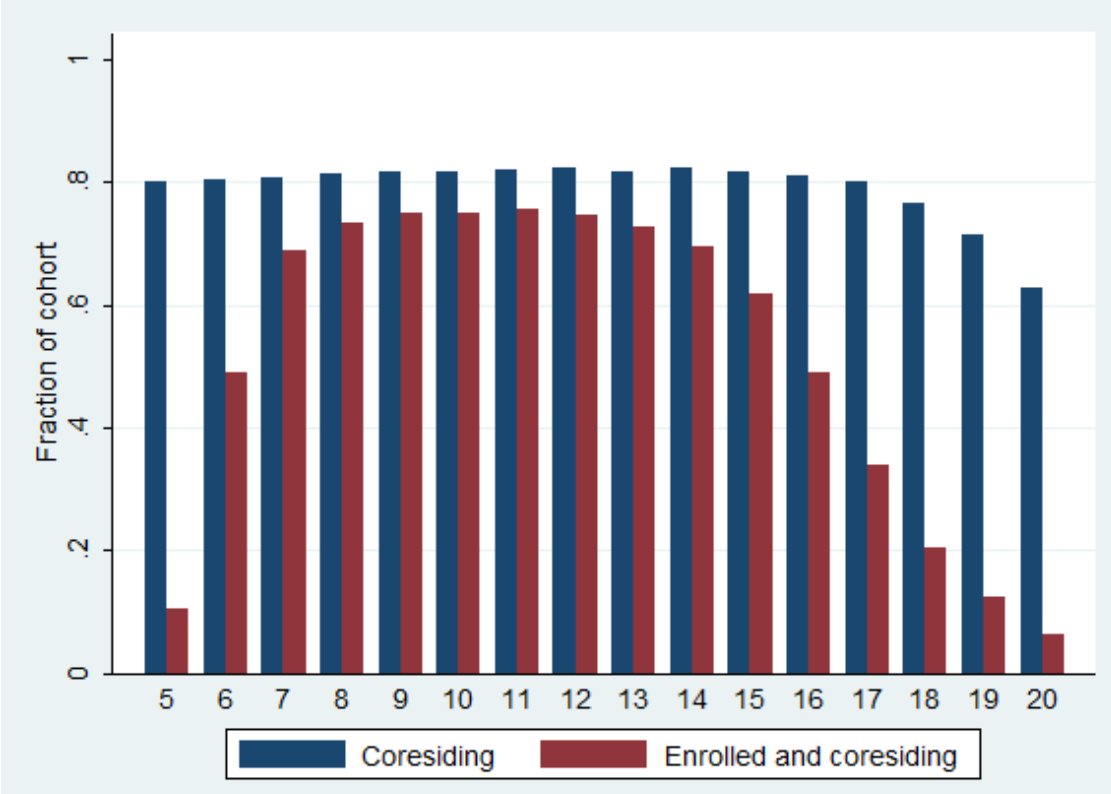


Figure 8: Observations about Teacher Wages in 1940 (Whites Only)
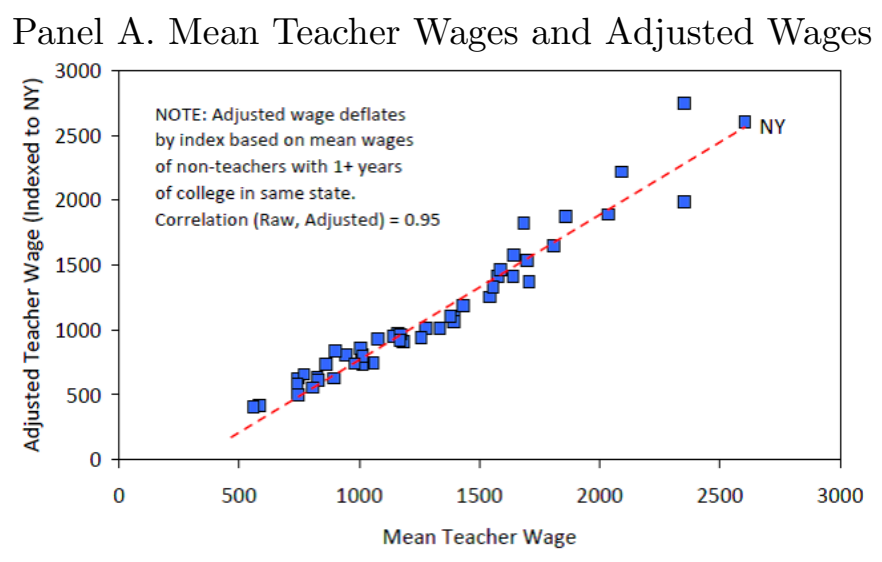

Panel B. Mean Teacher Wages (1940 Administrative Records) and the Fraction of Teachers with a College Degree (1940 Census)

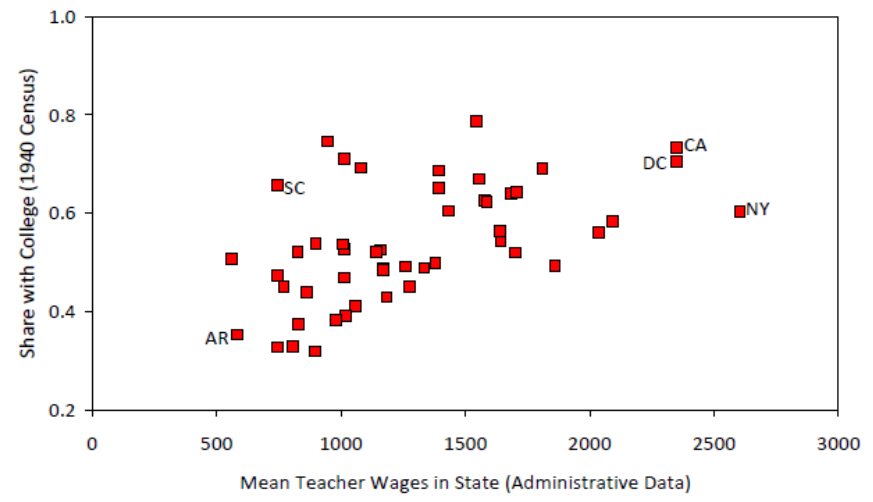

Panel C. Teacher and Non-Teacher Annual Earnings in the 1940 Census, with One or More Years of College

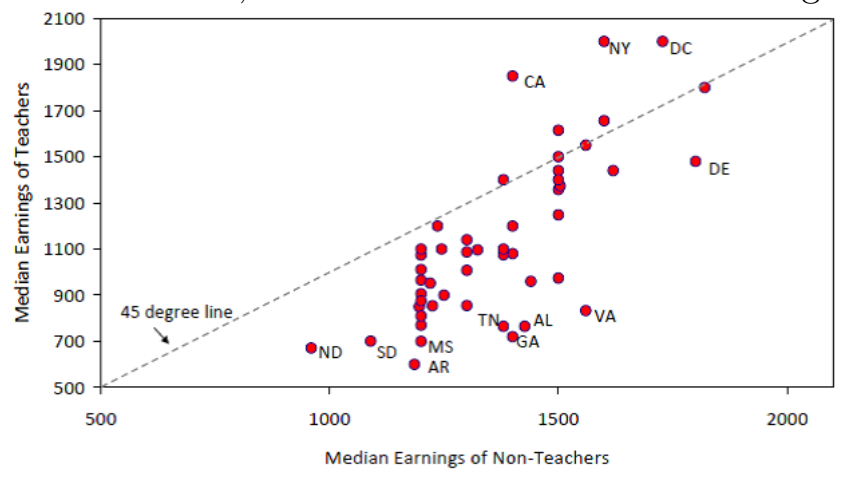


Figure 9: Relationship between Predicted Child Education and Parental Education

Panel A. White Families

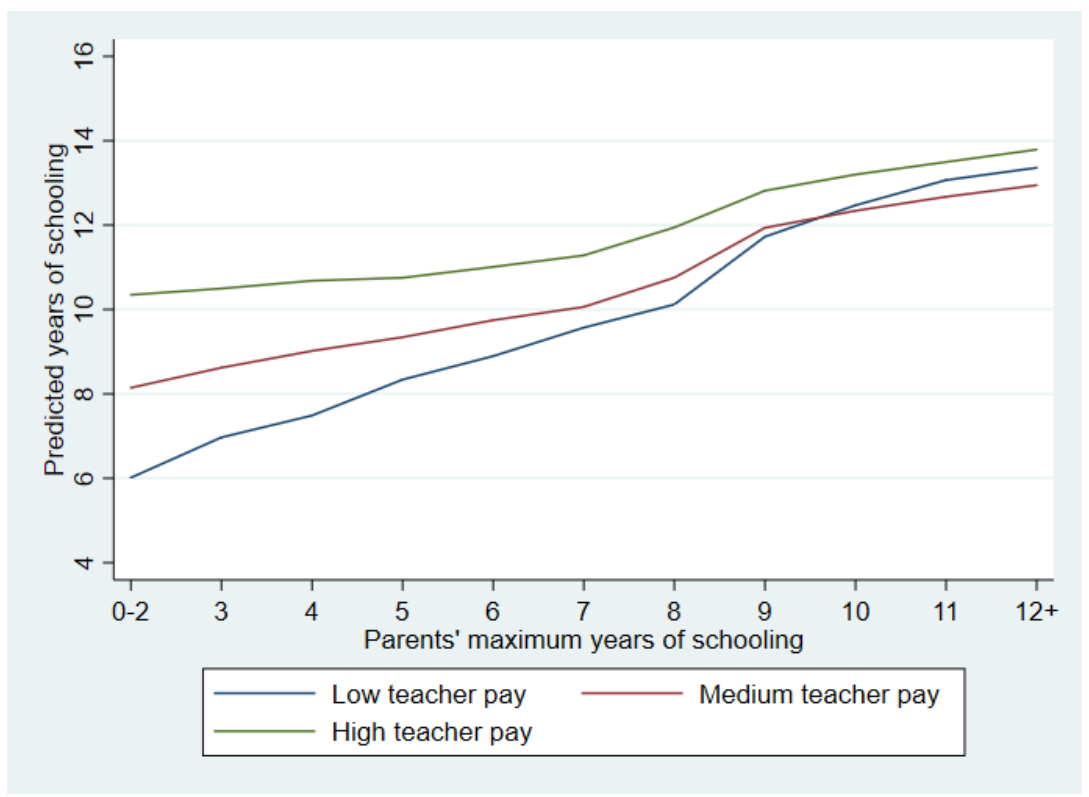

Panel B. Black Families

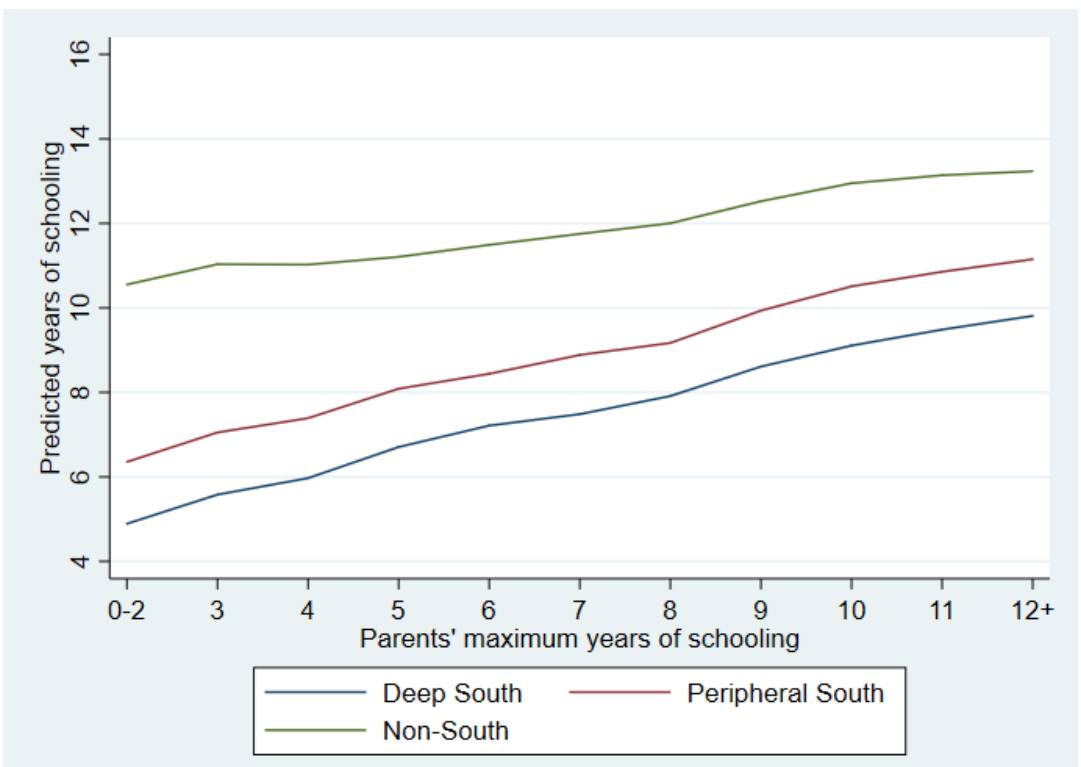


Figure 10: Border Counties Used in the County-Level Analysis

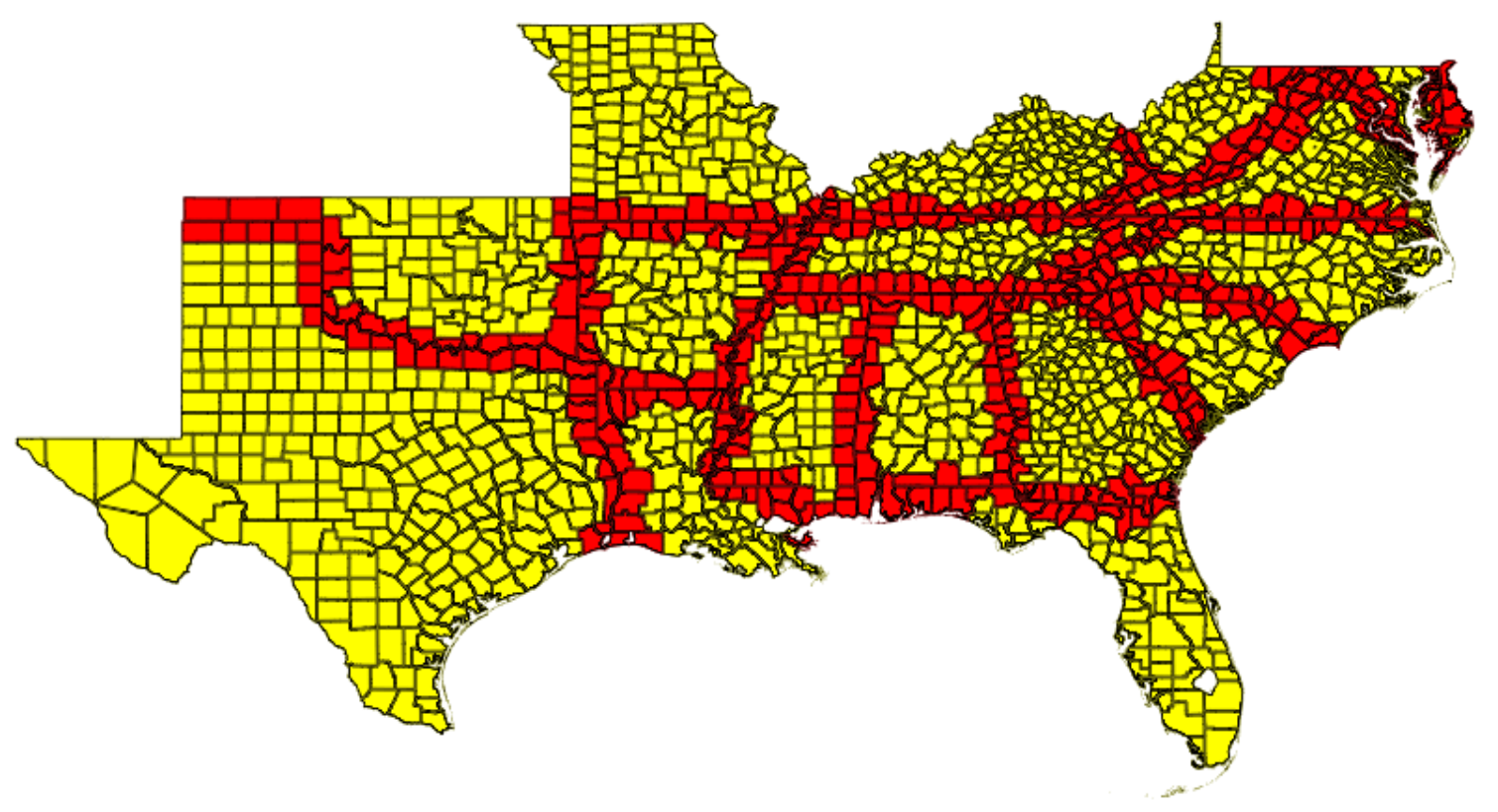


Figure 11: County-Level Teacher Salaries in Border Counties, Deep South and Peripheral South - Census Data and Administrative Records

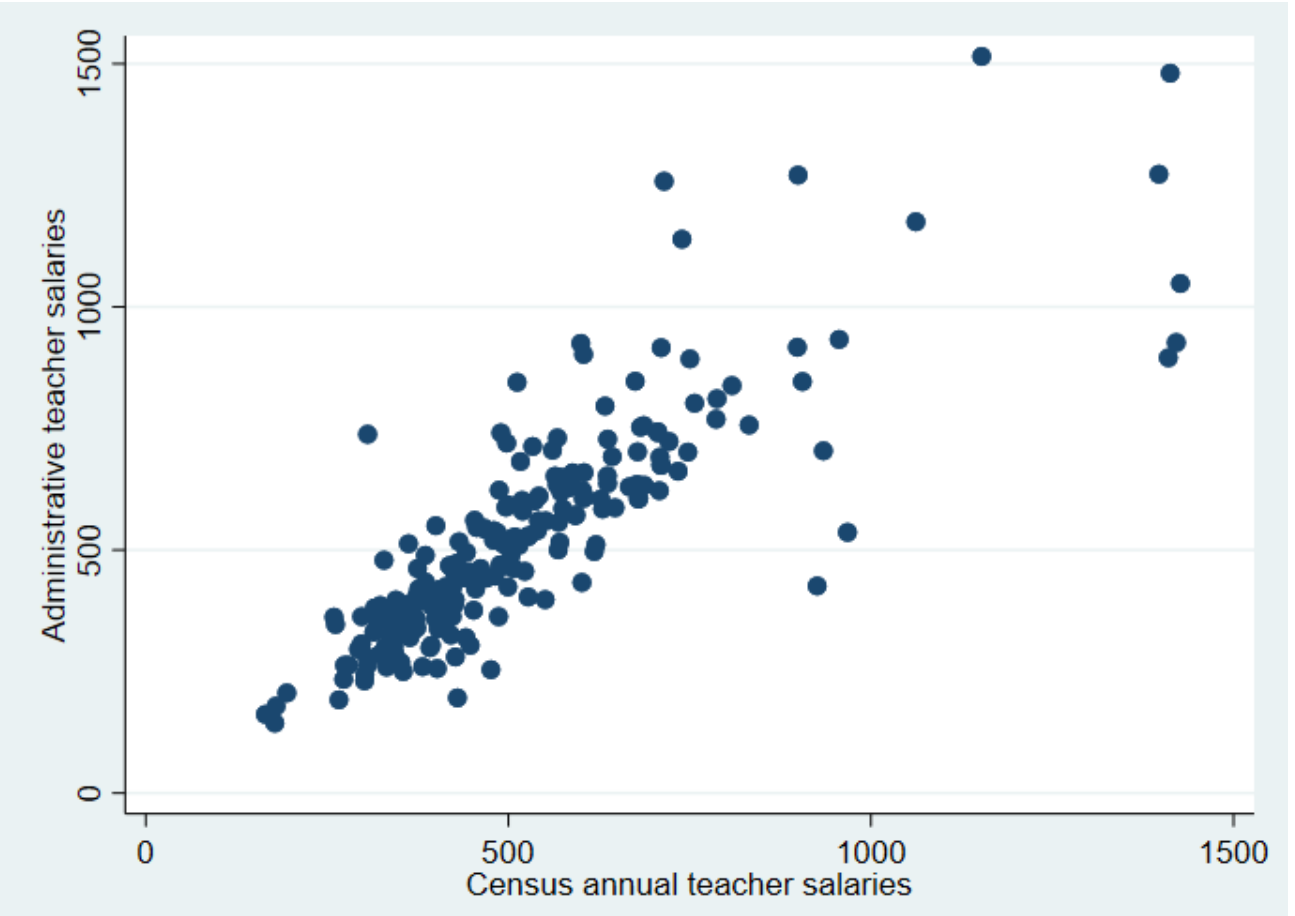

Note: Border counties in Alabama, Delaware, Florida, Georgia, Louisiana, Maryland, Missouri, North Carolina, South Carolina, Tennessee, Texas, and Virginia. 
Figure 12: Earnings of Teachers Relative of Non-Teachers with Similar Education, Border Counties

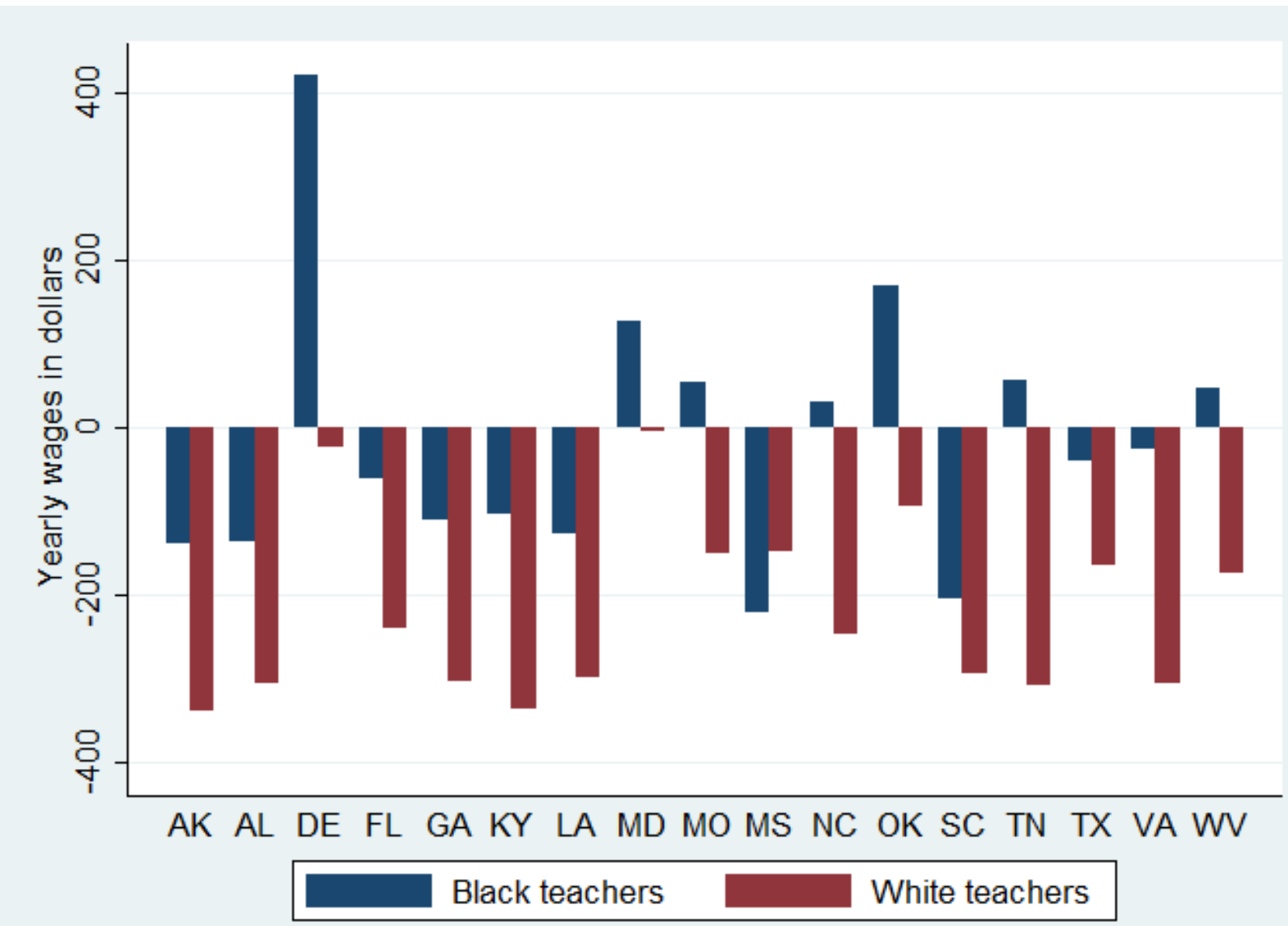


Figure 13: Relationship between County Child-Cohort Population Changes 1930-1940 and Teacher Earnings

Panel A. Black Children

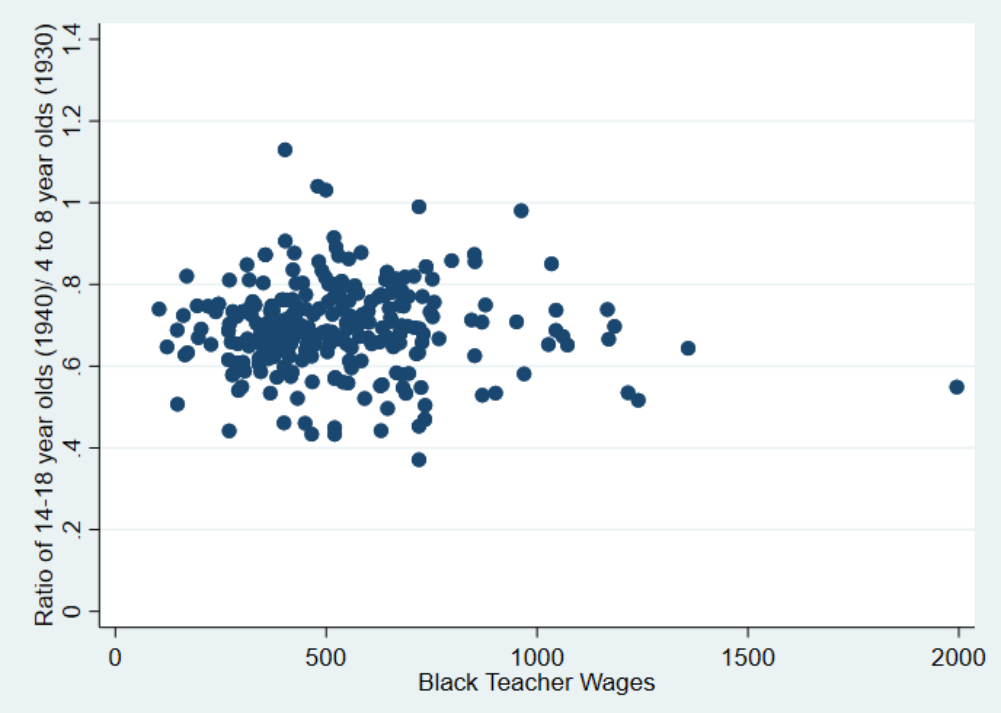

Panel B. White Children

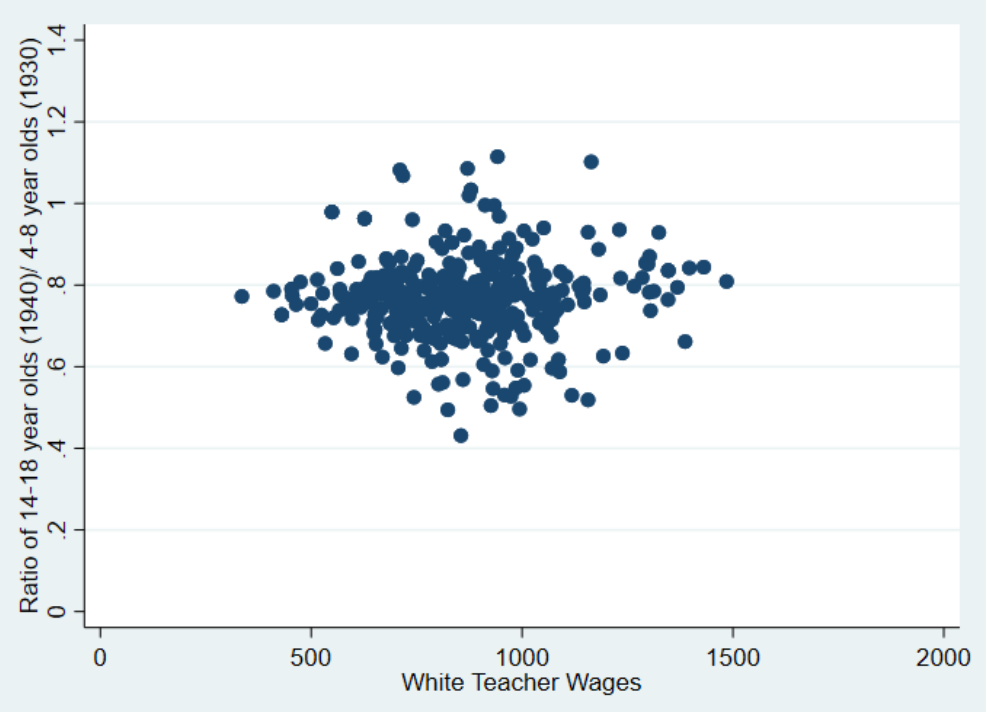

Note: Data from the 1930 and 1940 U.S. Census. Teacher earnings are from the 1940 Census. The sample is restricted to counties included in the border analysis, with more than 20 children aged $14-18$ in 1940. 
Figure 14: Relationship between Teacher Earnings and Teacher Education in Southern Border Counties

Panel A. Black Teachers

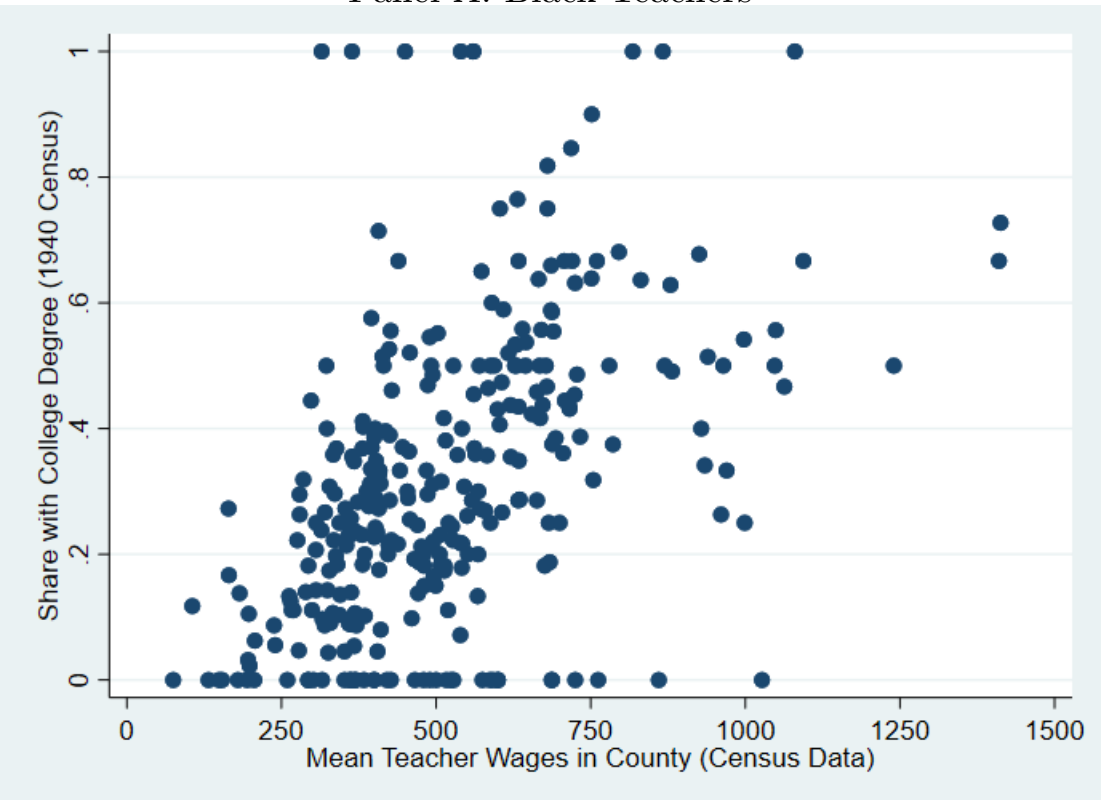

Panel B. White Teachers

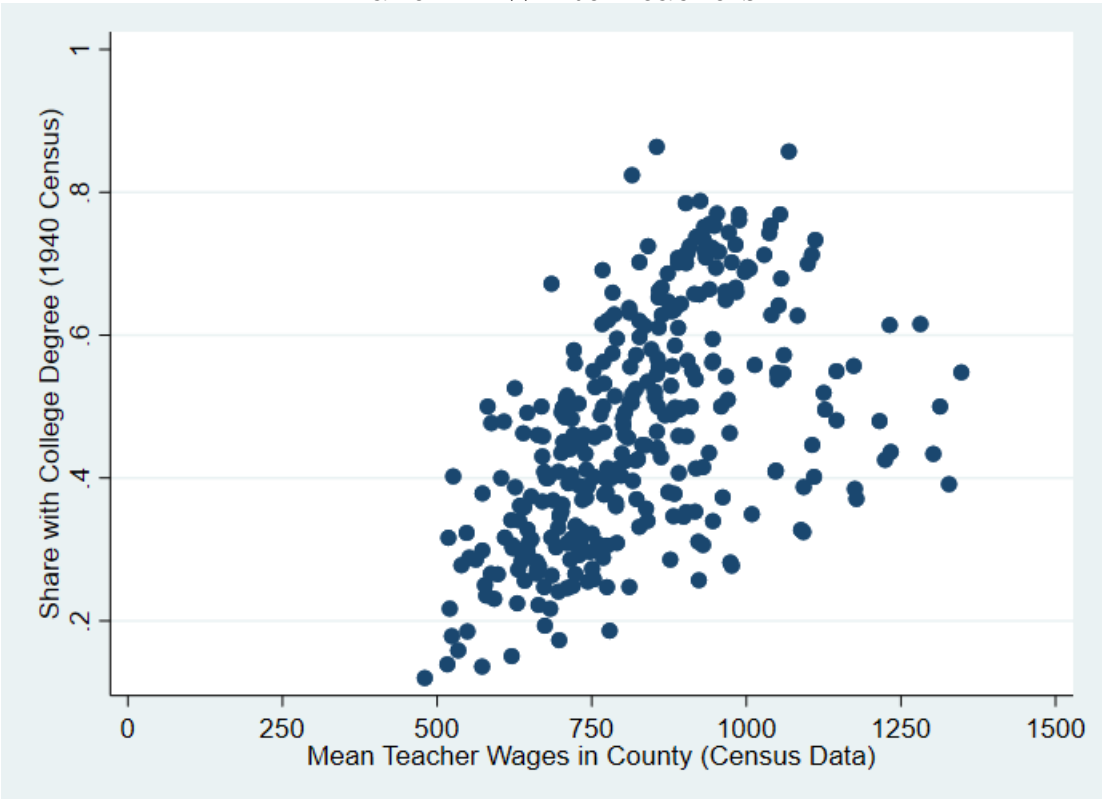




\section{References}

Aakvik, Arild, Kjell Gunnar Salvanes, and Bhashkar Mazumder. 2010. "Measuring Heterogeneity in the Returns to Education Using an Education Reform," European Economic Review, 54(4): 483-500.

Aaronson, Daniel, and Bhashkar Mazumder. 2011. "The Impact of Rosenwald Schools on Black Achievement," Journal of Political Economy, 119(5): 821-888.

Aaronson, Daniel, Bhashkar Mazumder, Seth G. Sanders and Evan J. Taylor. 2017. "Estimating the Effect of School Quality on Mortality in the Presence of Migration: Evidence from the Jim Crow South," Working Paper.

Abbott, Edith. 1908. "A Study of the Early History of Child Labor in America," American Journal of Sociology, 14(1): 15-37.

Altonji, Joseph G., Todd E. Elder, and Christopher R. Taber. 2005. "Selection on Observed and Unobserved Variables: Assessing the Effectiveness of Catholic Schools," Journal of Political Economy, 113(1): 151-184.

Bayer, Patrick and Kerwin K. Charles. forthcoming. "Divergent Paths: A New Perspective on Earnings Differences Between Black and White Men Since 1940," Quarterly Journal of Economics.

Becker, Gary S., and Nigel Tomes. 1979. "An Equilibrium Theory of the Distribution of Income and Intergenerational Mobility," Journal of Political Economy, 87(6): 11531189.

Becker, Gary S., and Nigel Tomes. 1986. "Human Capital and the Rise and Fall of Families," Journal of Labor Economics, 4(3), Part 2: S1-S39.

Benson, Charles S., and Kevin O'Halloran. 1987. "The Economic History of School Finance in the United States," Journal of Education Finance, 12(4): 495-515

Bergeron, Paul, Stephen Ash, and Jeanette Keith. 1999. Tennesseans and Their History, University of Tennessee Press.

Black, Dan, Seth G. Sanders, Evan J. Taylor and Lowell J. Taylor. 2015. "The Impact of the Great Migration on Mortality of African Americans: Evidence from the Deep South," American Economic Review, 105(2): 477-503

Black, Sandra E., Paul J. Devereux, and Kjell G. Salvanes. 2005. "Why the Apple Doesn't Fall Far: Understanding Intergenerational Transmission of Human Capital." American Economic Review, 95(1): 437-449.

Black, Sandra E., and Paul J. Devereux. 2011. "Recent Developments in Intergenerational Mobility." in Orley Ashenfelter and David Card (ed.), Handbook of Labor Economics, volume 4. Amsterdam: North-Holland: 1487-1541.

Blau, Peter M., and Otis Dudley Duncan. 1967. The American Occupational Structure. New York: Wiley.

Bond, Horace Mann. 1934. The Education of the Negro in the American Social Order. Octagon Books. 
Boustan, Leah Platt. 2016. Competition in the Promised Land: Black Migrants in Northern Cities and Labor Markets. Princeton University Press.

Card, David. 1995a. "Earnings, Schooling and Ability Revisited," in Solomon Polachek, ed., Research in Labor Economics, Vol. 14. JAI Press, Greenwich, CT: 23-48.

Card, David. 1995b. "Using Geographic Variation in College Proximity to Estimate the Return to Schooling," in Louis N. Christofides, E. Kenneth Grant, and Robert Swidinsky, eds., Aspects of Labour Market Behaviour: Essays in Honour of John Vanderkamp. University of Toronto Press, Toronto, Canada: 201-222.

Card, David. 1999. "The Causal Effect of Education on Earnings," in Orley Ashenfelter and David Card (ed.), Handbook of Labor Economics, volume 3. Amsterdam: NorthHolland: 1801-1863.

Card, David. 2001. "Estimating the Return to Schooling: Progress on Some Persistent Econometric Problems," Econometrica, 69(5): 1127-1160.

Card, David, John E. DiNardo, and Eugena Estes. 2000. "The More Things Change: Immigrants and the Children of Immigrants in the 1940s, the 1970s, and the 1990s," in George Borjas, editor, Issues in the Economics of Immigration. Chicago: University of Chicago Press for the NBER.

Card, David, and Alan B. Krueger. 1992a. "Does School Quality Matter? Returns to Education and the Characteristics of Public Schools in the United States," Journal of Political Economy, 100(1): 1-40.

Card, David, and Alan B. Krueger. 1992b. "School Quality and Black-White Relative Earnings: A Direct Assessment," Quarterly Journal of Economics, 107(1): 151-200.

Card, David and Alan B. Krueger. 1996. "School Resources and Student Outcomes: An Overview of the Literature and New Evidence from North and South Carolina," Journal of Economic Perspectives, 10(4), 31-50.

Carneiro, Pedro, Italo Garcia, Kjell Salvanes, Emma Tominey. 2015. "Intergenerational Mobility and the Timing of Parental Income," Working Paper.

Carruthers, Celeste and Marianne H. Wanamaker. 2013. "Closing the Gap? The Effect of Private Philanthropy on the Provision of African-American Schooling in the U.S. South," Journal of Public Economics, 101: 53-67.

Clay, Karen, Jeff Lingwall, and Melvin Stephens Jr. 2012. "Do Schooling Laws Matter? Evidence from the Introduction of Compulsory Attendance Laws in the United States," NBER Working Paper No. 18477.

Chetty, Raj, Nathaniel Hendren, Patrick Kline, and Emmanuel Saez. 2014a. "Where is the Land of Opportunity? The Geography of Intergenerational Mobility in the United States," Quarterly Journal of Economics, 129(4): 1553-1623.

Chetty, Raj, Nathaniel Hendren, Patrick Kline, Emmanuel Saez, and Nick Turner. 2014b. "Is the United States Still a Land of Opportunity? Recent Trends in Intergenerational Mobility," American Economic Review Papers and Proceedings, 104(5): 141-147.

Chetty, Raj Chetty and Nathaniel Hendren. 2016a. "The Effects of Neighborhoods 
on Intergenerational Mobility I: Childhood Exposure Effects," NBER Working Paper No. 23,001.

Chetty, Raj Chetty and Nathaniel Hendren. 2016b. "The Impacts of Neighborhoods on Intergenerational Mobility II: County-Level Estimates." NBER Working Paper No. 23,002.

Chetty, Raj, Nathaniel Hendren, Maggie R. Jones, and Sonya R. Porter. 2018. "Race and Economic Opportunity in the United States: An Intergenerational Perspective," NBER Working Paper No. 24,441.

Coen-Pirani, Daniele and Michael Wooley. 2018. "Fiscal Centralization: Theory and Evidence from the Great Depression," American Economic Journal: Economic Policy, 10(2): 39-61.

Coleman, Ada. 1947. "The Salary Equalization Movement," Journal of Negro Education, 16(2): 235-241.

Coleman, James S., et al. 1966. Equality of Educational Opportunity. Washington: Government Printing Office.

Davis, Harwell G., editor. 1927. Alabama School Code. Department of Education, State of Alabama.

Donohue, John, James Heckman, and Petra Todd. 2002. "The Schooling of Southern Blacks: The Roles of Legal Activism and Private Philanthropy, 1910-1960," Quarterly Journal of Economics, 117(1): 225-68.

Dube, Arindrajit, William T. Lester and Michael Reich. 2010. "Minimum Wage Effects across State Borders: Estimates Using Contiguous Counties," Review of Economics and Statistics, 92(4): 945-964

Education, A. D., United States Bicentennial Intern Program in Education Alabama Pilot Project, and Board, S. R. (n. d.). 1975. "History of Education in Alabama."

Eichenlaub, Suzanne C., Stuart E. Tolnay, and J. Trent Alexander. 2010. "Moving Out but Not Up: Economic Outcomes in the Great Migration," American Sociological Review, 75(1): 10125.

Fitzgerald, Stephanie. 2007. The Scopes Trial: The Battle Over Teaching Evolution, Compass Point Books.

Galton, Francis. 1869. Hereditary Genius: An Inquiry into its Laws and Consequences, London: Macmillan.

Goldin, Claudia. 1998. "America's Graduation from High School: The Evolution and Spread of Secondary Schooling in the Twentieth Century," Journal of Economic History, 58(2): 345-374.

Goldin, Claudia. 2001. "The Human-Capital Century and American Leadership: Virtues of the Past," Journal of Economic History, 61(2): 263-292.

Goldin, Claudia, and Lawrence F. Katz. 1998. "The Origins of State-Level Differences in the Public Provision of Higher Education: 1890-1940," American Economic Review, 88(2): 303-308. 
Goldin, Claudia, and Lawrence F. Katz. 1999. "Human Capital and Social Capital: The Rise of Secondary Schooling in America, 1910-1940," Journal of Interdisciplinary History, 29(4): 683-723.

Goldin, Claudia and Lawrence Katz. 2008. The Race between Education and Technology. Cambridge, MA: The Belknap Press of Harvard University Press.

Hanushek, Eric A. 1974. "Efficient Estimators for Regressing Regression Coefficients," The American Statistician, 28(2): 66-67.

Hanushek, Eric A., Steven G. Rivkin, and Lori L. Taylor. 1996. "Aggregation and the Estimated Effects of School Resources," Review of Economics and Statistics, 78(4): 611-27.

Hilger, Nathaniel G. 2017a. "Upward Mobility and Discrimination: the Case of AsianAmericans," Working Paper, Brown University.

Hilger, Nathaniel G. 2017b. "The Great Escape: Intergenerational Mobility in the United States, 1930-2010," Working Paper, Brown University.

Jencks, Christopher. 1972. Inequality: A Reassessment of the Effect of Family and Schooling in America. New York: Basic Books.

Jones, Eugene K. 1928. "Social Work Among Negroes," Annals of the American Academy of Political and Social Science, 130: 287-293.

Knox, Ellis O. 1954. "Racial Integration in the Public Schools of Arizona, Kansas and New Mexico," Journal of Negro Education, 23(3): 290-295.

Kuo, Joyce. 1998. "Excluded, Segregated and Forgotten: A Historical View of the Discrimination of Chinese Americans in Public Schools," Asian American Law Journal, 5(7): 181-212.

Lleras-Muney, Adriana. 2002. "Were Compulsory Education and Child Labor Laws Effective? An Analysis from 1915 to 1939 in the U.S." Journal of Law and Economics, 45(2): 401-435.

Loury, Glenn C. 1981. "Intergenerational Transfers and the Distribution of Earnings," Econometrica, 49(4): 843-867.

Lundborg, Petter, Anton Nillson and Dan-Olof Rooth. 2014. "Parental Education and Offspring Outcomes: Evidence from the Swedish Compulsory School Reform," American Economic Journal: Applied Economics, 6(1): 253-278

Maloney, Thomas N. 1994. "Wage Compression and Wage Inequality between Black and White Males in the United States, 1940-1960," Journal of Economic History, 54 (2): $358-81$.

Margo, Robert A. 1985. Disfranchisement, School Finance, and the Economics of Segregated Schools in the United States South, 1890-1910. New York: Garland Press.

Margo, Robert A. 1986. "Race, Educational Attainment, and the 1940 Census," Journal of Economic History, 46(1): 189-198.

Margo, Robert A. 1990. Race and Schooling in the South, 1880-1950: An Economic History. Chicago: University of Chicago Press. 
Margo, Robert A. 1995. "Explaining Black-White Wage Convergence, 1940-1950," Industrial and Labor Relations Review, 48(3): 470-481.

Mazumder, Bhashkar, 2005. "Fortunate Sons: New Estimates of Intergenerational Mobility in the U.S. using Social Security Earnings Data," Review of Economics and Statistics, 87(2): 235-255.

Meghir, Costas and Martin Palme. 2005. "Educational Reform, Ability and Parental Background," American Economic Review, 95(1): 414-424.

Meghir, Costas, and Pierre-André Chiappori. 2014. "Intrahousehold Inequality," NBER Working Paper No. 20,191.

Meghir, Costas, Mårten Palme, and Emilia Simeonova. 2013. "Education, Cognition and Health: Evidence from a Social Experiment," NBER Working Paper No. 19,002 .

Mincer, Jacob. 1958. "Investment in Human Capital and Personal Income Distribution," Journal of Political Economy, 66(4): 281-302.

Miller, Herman P., and Leon R. Paley. 1958. "Income Reported in the 1950 Census and on Income Tax Returns," in An Appraisal of the 1950 Census Income Data. Princeton University Press.

Mulligan, Casey B. 1999. "Galton versus the Human Capital Approach to Inheritance," Journal of Political Economy, 107(S6): S184-S224.

National Education Association of the United States. 1940. State Minimum-Salary Standards for Teachers, Washington, D.C.

North Carolina, Department of Justice. 1922. Biennial Report of the AttorneyGeneral of the State of North Carolina. Raleigh: Edwards \& Broughton and E. M. Uzzell, State Printers.

Oster, Emily. 2017. "Unobservable Selection and Coefficient Stability: Theory and Evidence," Journal of Business and Economic Statistics, 1-18.

Peterson, Gladys T. 1935. "The Present Status of the Negro Separate School as Defined by Court Decisions." Journal of Negro Education, 4(3): 351-374.

Ruggles, Steven, J. Trent Alexander, Katie Genadek, Ronald Goeken, Matthew B. Schroeder, and Matthew Sobek. 2010. Integrated Public Use Microdata Series: Version 5.0. Machine-Readable Database. Minneapolis: University of Minnesota.

Shiver, Lee A. 1983. "A Historical Review of the Development of Florida's School Finance Plan and the Fiscal Equalization Effects of the Florida Education Finance Program," Ph.D. Dissertation, University of Florida.

Smith, James P., and Finis R. Welch. 1989. "Black Economic Progress after Myrdal," Journal of Economic Literature, 27(2): 519-564.

Snyder, Thomas D. 1993. 120 Years of American Education: A Statistical Portrait. Washington, D.C.: U.S. Department of Education, Office of Educational Research and Improvement, National Center for Education Statistics.

Solon, Gary. 1992. "Intergenerational Income Mobility in the United States," American Economic Review, 82(3): 393-408. 
Solon, Gary. 1999. "Intergenerational Mobility in the Labor Market," in Orley Ashenfelter and David Card (ed.), Handbook of Labor Economics, volume 3, Amsterdam: North-Holland: 1761-1800.

South Carolina, State Department of Education. 1938. Annual Report of the State Superintendent of Education of the State of South Carolina, volume 70-71.

Trow, Martin. 1961. "The Second Transformation of American Secondary Education," International Journal of Comparative Sociology, 2(2): 144-166.

United States Census Bureau. 1975. Historical Statistics of the United States, Colonial Times to 1970. Washington, D.C.

United States Census Bureau. 2010. County Adjacency File. https://www.census.gov /geo/reference/county-adjacency.html

Wallis, John Joseph. 2000. "American Government Finance in the Long Run: 1790 to 1990," Journal of Economic Perspectives, 14(1): 61-82.

Wilson, Charles H. 1947. Education for Negroes in Mississippi since 1910. Boston, MA: Meador.

Wollenberg, Charles. 1974. "Mendez v. Westminster: Race, Nationality and Segregation in California Schools." California Historical Quarterly 53:317-332.

Wollenberg, Charles. 1995. "The Yellow Peril in School," in D. Nakanishi and T. Yamano-Nishida (ed.), The Asian-American Educational Experience: A Source Book for Teacher and Students, New York: Routledge.

Wright, Richard. 1941. 12 Million Black Voices: A Folk History of the Negro in the United States, New York: Viking. 